. 





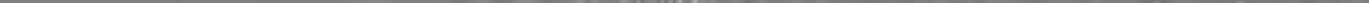





\section{ATHLETIC GAMES IN THE EDUCATION OF WOMEN}

BY

\section{GERTRUDE DUDLEY}

Director of the Women's Department of Physical

Education, University of Chicago

AND

FRANCES A. KELLOR

Author of "Experimental Sociology," "Out of Work"

NEW YORK

\section{HENRY HOLT AND COMPANY}



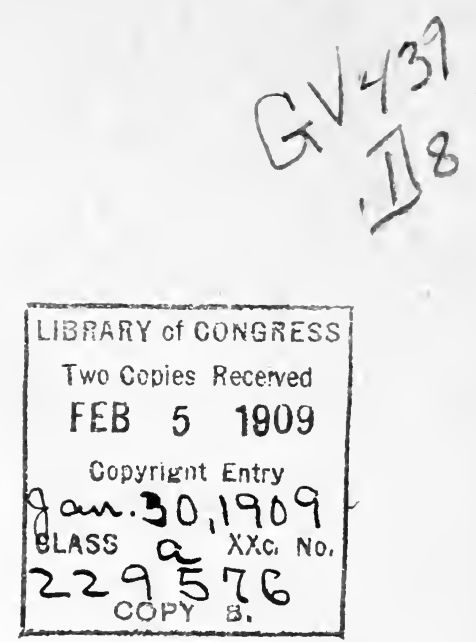

Copyright, 1909,

BY

HENRY HOLT AND COMPANY

Published. February, 1909

THE QUINN \& BODEN CO. PRESS

RAHWAY, N. J. 


\section{W}

\section{TO}

W. G. A.

WHOSE STANDARD AND ACHIEVEMENTS

IN PHYSICAL EDUCATION INSPIRE.

THE BEST EFFORTS IN OTHERS 


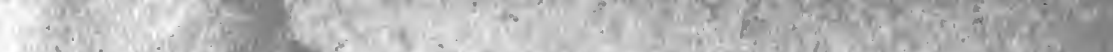

Q

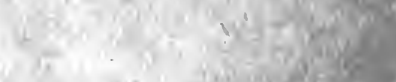

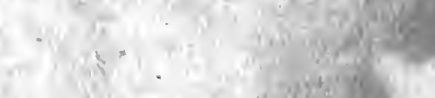

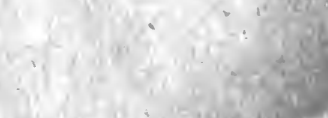
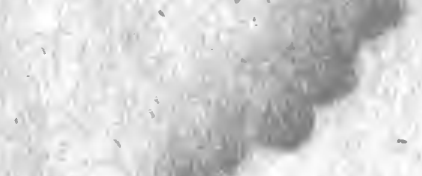

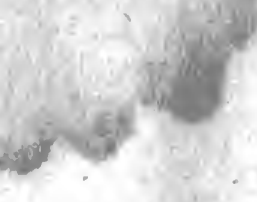

10

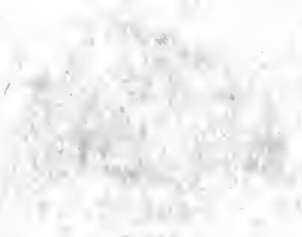

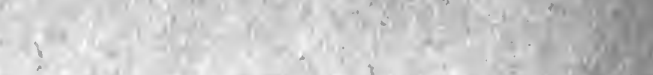

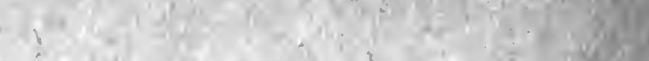

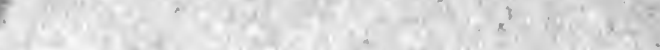

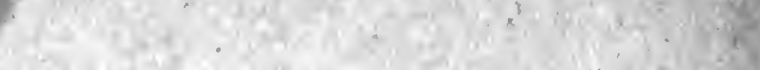

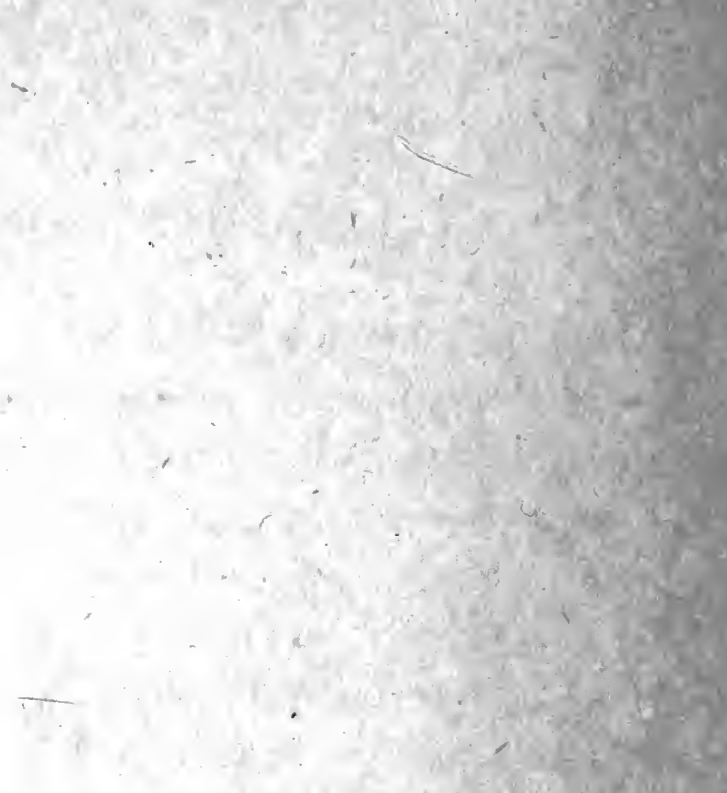

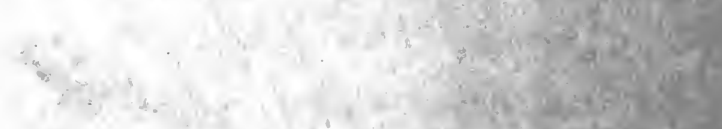

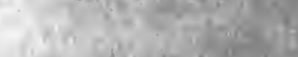

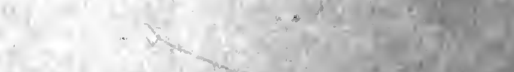
$\frac{6}{2}$$$
\text { . }
$$

\section{.} . 


\section{FOREWORD}

Is offering to the public the results of our investigation, experience and observation, we have purposely set ourselves certain limitations. For a period of ten years we have carefully studied the educational value of organized games and have tested with all classes of girls-in university, high school, private school and social institutions-the theories and suggestions which we have now put into tangible form, in the hope that those interested in social education and group welfare, based on the highest individual efficiency, will find some value in them. Our experiments with many hundreds of students and players have demonstrated repeatedly that athletic games are real factors in education.

We have attempted no study or discussion of gymnastics or sports, for there are many volumes which deal with these subjects. Furthermore, sports are individual, their purpose is primarily recreative and they do not depend upon the co-operation of any other individual. Walking, riding, swimming, golf, bowling, archery and track events are types of such sports. On the other hand, athletic games are social in their nature and may be used for both education and recreation. These games consist of a set of actions performed according to prescribed rules and depend'for their success upon the co-operative action 
of two or more persons. They include the highly organized games of basketball, indoor baseball, hockey, lacrosse, cricket, etc., as well as such minor games as captain-ball, volley-ball, long-ball and drive-ball. We have confined our discussion to more highly organized games, since Mr. Johnson in his excellent work on "Education by Games" includes kindergarten and primary games and brings the discussion up to the point from which we have started. 'Throughout we have maintained the educational point of view which we believe is the only plane upon which athletics for women can be wisely conducted.

It may seem in our emphasis on athletics as a training for citizenship and as a part of general education, that we have neglected their physical value to the individual. While we do not underestimate this value, we believe that it is more generally recognized and that there are so many advocates in its favor that it is unnecessary to emphasize it here.

Although we have restricted this discussion to women, our experience in teaching boys shows the need in this field to be hardly less apparent. Among men the commercial and competitive spirit predominates and there is only a dawning consciousness on the part of comparatively few men instructors of the larger educational worth of athletics. Notwithstanding this, athletics as now used do tend to develop among men, in some measure, a group consciousness as well as admirable personal qualities. This goes far to show that they possess an intrinsic educational value. 
Many instructors who sent us information and suggestions requested that they should not be quoted. Owing to these requests and the rivalry existing among many schools and instructors, we have omitted many of the references. It has not been our purpose to criticise any school or instructor as such, but to present the data in such a way as to make them generally useful, and suggestive to schools, instructors, parents, players and those interested in community. welfare.

We have included a technical discussion of some highly organized games now widely used by women because there are some who would be willing to teach athletics as a part of general education if there were a way to master the details.

We acknowledge a deep indebtedness to the instructors, schools and organizations that have cooperated by answering the questionnaire, making suggestions, and sending us information about their equipment, facilities and systems of work; also to the social workers who have gone over the material and have made clearer its practical social significance.

The Authors.

The University of Chicago. 


\section{CON'TEN'TS}

\section{PART I \\ VALUE OF ATHLETIC GAMES}

CHAPTER PAGE

I. Citizenship and Social Education . . . 3

II. Educational Value of Athletics . . . 19

III. Instructors-'Their Responsibility and Train-

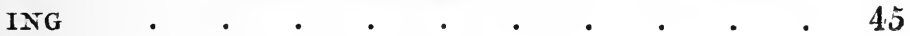

$$
\text { PART II }
$$

\section{PRESENT CONDITIONS}

IV. Athletics in Secondary Schools . . $\quad . \quad 69$

V. Athletics in Universities and Colleges . . 96

VI. Athletics in Political and Social OrganizaTIONS . . . . . . . . . . 110

VII. Conpetitive and Public Ganes . . . . 149

$$
\text { PART III }
$$

\section{METHODS OF INSTRUCTION}

VIII. General Training and Contests . . . . 165

IX. Basketball . . . . . . . . . . 179

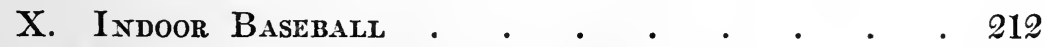

XI. Field Hockey $\cdot$ •

INDEX • • • • • • • • • • • • 


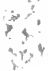

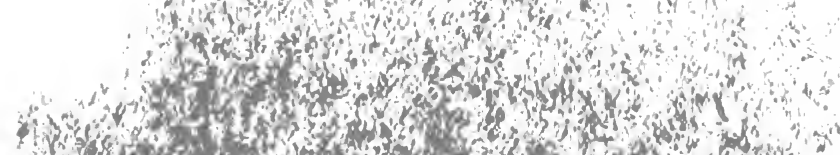

of (a)

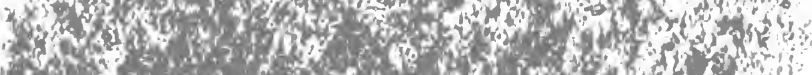
antion Sint

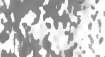

(x) $+x^{2}$ A.

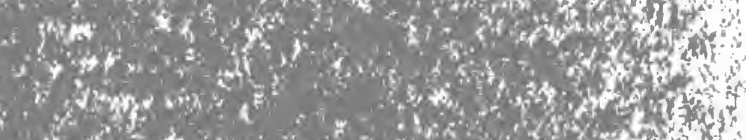
ind is int

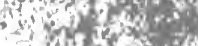
is mofy mofy

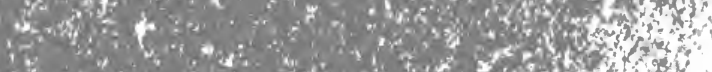

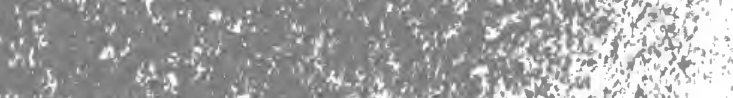

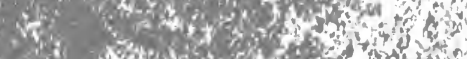

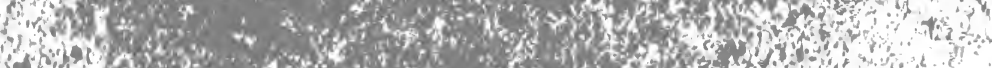

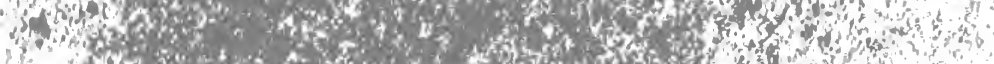

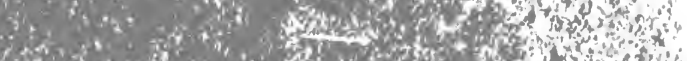

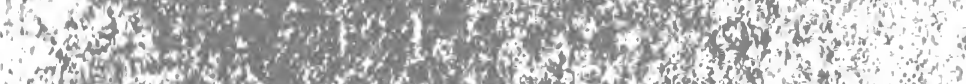

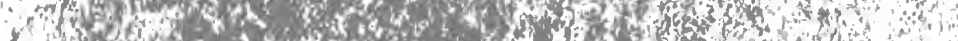

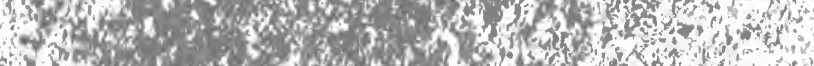

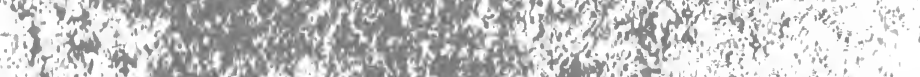

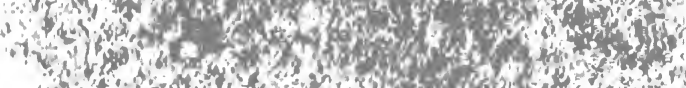

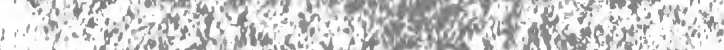

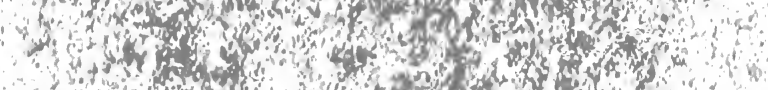

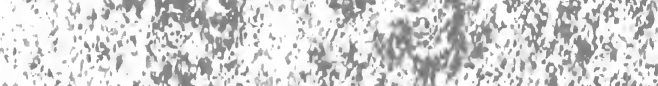

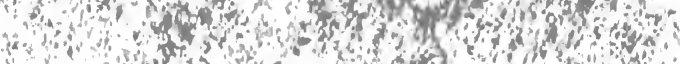

now

(3)

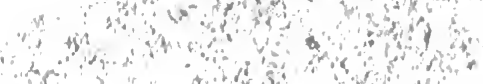

$x_{4}$

a n

$\therefore$ int

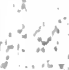

$\because$ 
PART I

VALUE OF ATHLETIC GAMES 


\section{- soly}

(4) ond

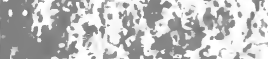

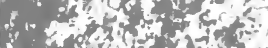
$4 x+2 x^{2}+4$ H. $y^{2}+3 x=$ $\ln x+x^{2}$ ant 6 (i)

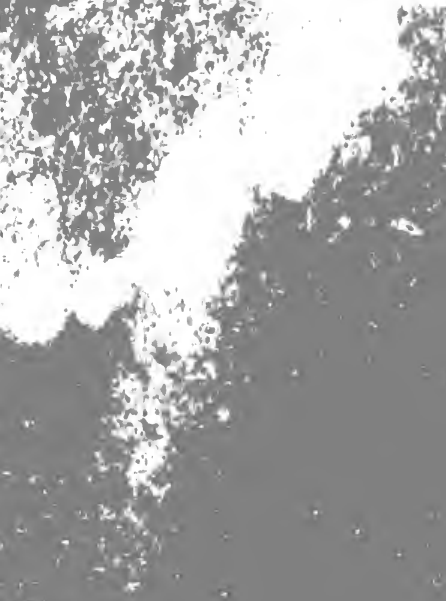
$\frac{4}{4}$ 


\section{CHAPTER I}

\section{CITIZENSHIP AND SOCIAL EDUCATION}

However much individuals may differ in their opinions as to the position of women in society, their rights, their capabilities, their future activities, or the thousand and one other phases of their lives and character which form topics for discussion of seemingly never-ending interest, there are certain existing conditions and well-defined tendencies in society today which cannot be properly met by opinions or prejudices but which demand and should receive judicial analysis, and to meet which women need to be adequately prepared.

Perhaps the most significant change in society's demand upon women to-day is the substitution of cooperative effort for individualistic effort and the development of group consciousness beyond the family circle. This has been a gradual process, so gradual that many women in the more secluded walks of life do not see the need of a change in the training of women to meet a demand, the full meaning of which they fail to grasp.

Social Responsibility of Women.-The most conspicuous change has been in the industrial world. In 1900 more than 5,000,000 women were found engaged in gainful occupations. This by no means includes the 
many who earn money in their own homes or those who supplement their small incomes in one way or another. Neither does it include the many children who are at work. This entrance into the industrial world creates a more complex environment, requires more rapid adjustment, and above all increases greatly the necessity for co-operative work, outside the home.

The extension of the property rights of women in many of the states, and the many estates held by them, have enlarged the group of women investors, capitalists and employers. This has created for them broader social responsibilities and the necessity for group judgments. Such unavoidable responsibility is seen in the wide use which women necessarily make of middlemen. Their interests and activities are so varied that numerous agents are employed to carry out their orders. This removal from the result of their acts-for instance, when they receive rents from tenements but know nothing of conditions existing in them because of their entire reliance upon agentsfrequently makes them "tolerators but not necessarily practitioners" of anti-social acts.

The political field also has been greatly widened. Not only have women the franchise in several of the states, but in others they vote upon educational questions and other public matters such as taxation. The number who now hold political positions of trust or who are engaged in lines of activity which have a far-reaching influence upon political affairs is greatly increased. 
In the field of social service, including professional charity and philanthropy, the ranks are filled with women and many others are seeking positions. Religious activity in many of its forms of ministration is increasingly in the hands of women.

Social life is no longer limited to the entertainment of friends or families, the self-culture club or simple home function. These are varied in a thousand ways by more impersonal and highly organized social activities, such as card parties with their competitive element; club-meetings with their co-operative element; civic activities with their public welfare element; and auxiliary organizations for great state and national movements. Mothers, teachers and workers all have some form of organized effort which calls for co-operation.

This increased participation in industrial life and in public affairs and variation of social responsibility tends at the present time to make women take life too seriously, live too strenuously, and results in a diminution of rest and relaxation. The play-spirit is yielding to the work-spirit and the loss of individual playspirit has not yet found its counterpart in the proportionate increase of the group play-spirit-an essential thing to the best social activity and balance.

Even in the home the demand for co-operative work is growing. In the cities the complexities have so increased that its successful maintenance means dependence upon others in a thousand forms-for service, for food, for protection; and in return additional community burdens are laid upon the housewife-ad- 
justment to her workers, maintenance of a higher standard of living and observance of laws which are made for the equal protection of all. The housewife in the apartment or tenement cannot make as much noise, or dispose of her garbage, or use her fireescapes, as she will, without reference to the comfort of others. Moreover, such are the problems presented by our cities that many live in the closer union of the co-operative home or apartment hotel where an even greater degree of co-operation is required.

But it is not only girls who marry or who earn their own living who are confronted with a greater necessity for adjustment. There is in every community a small group of girls who have just a bit too much money to need to work for a living and too much family to make it easy to become useful. Many of these have been well educated and along with abundant vitality possess the spirit of wishing to do or become something worth while from the point of view of efficiency in the community. Parents, whose goal for their girls is so frequently marriage or social success, cannot understand this new community sense which is a part of the spirit of the age and the resulting moral, social and economic waste is a serious loss to community life. There is enough to do, but neither the training nor freedom with which to do it.

The point is that women can no longer live in such a way that they influence only their own homes, family and immediate circle. The mother who chats with a few neighbors over a cup of tea has not the influence that the club-woman has when she gambles with 
a party of fifty or a hundred; or who attends huge conventions and runs off elections; or that the business and professional woman has who meets hundreds of patrons and must often decide their moral as well as business problems; or that the thousands of clerks and stenographers have who form a part of the mesh of industrial and political life; or that the factory worker has when she toils with a thousand others.

Upon the completion of her education, the girl thus has no longer the simple choice of marriage, teaching or missionary work. She has before her a wide range of vocations and a great array of opportunities in almost every field-all of which offer her a livelihood and practically all of which, while demanding individual efficiency, demand increasingly the power to work harmoniously and effectively with the group.

Influence upon Social Control.-Irrespective of women's occupational opportunities, broad as these are becoming, there are certain forms of social control which they help to create and in a great degree to sustain. Such are the customs, beliefs and traditions which make society stable. The growing publicity given to the doings of women has largely increased their power over the various forms of social control and both by suggestion and example each individual appeals to and influences a much wider circle than in the past.

Chief among these forms of social control is public opinion, which even more than laws makes for the happiness or unhappiness of individuals and for the welfare or disadvantage of the community. When 
women judge within a prejudiced, circumscribed horizon, as where they condemn murderers but not adulterators of food or officials of a trust who put up the price of ice so that babies in tenements die for lack of it, they fail to see that they are condemning the lesser rather than the greater offender, simply because the connection of cause and effect is not so apparent in the latter cases.

While women as a rule are indifferent to any form of morality other than virtue in their own sex, small wonder is it that infractions of public morality are slowly and uncertainly punished by public opinion. It does not change the consequences that women's false social judgments are due not so much to evil thoughts and feelings as to perplexities due to incomprehension of the given elements in a situation or to a defective sense of justice. There can be no efficient social control by public opinion without a deep sense of justice. Sympathy has long been accepted as a substitute for this in women. But the increasingly varied demands made upon them shows it to be an inadequate substitute. Mr. E. A. Ross well states this: ${ }^{1}$

"It is obedience that articulates the solid, bony framework of social order; sympathy is but the connective tissue. As well build a skeleton out of soft fiber as construct social order out of sympathies.

" Not friendly aid, but reliable conduct, is the cornerstone of great organization. Now, sympathy will stay the hand of the wife-beater, but it will not spurn the bribe or spare the lie. It will snatch a child from

${ }^{1}$ Ross : "Social Control," p. 12. 
trampling hoofs, but it will not keep the watchman awake, or hold the contractor to the terms of his agreement. It will nerve the rescuing fireman, but it will not stimulate the official to do his duty. It will relieve the beggar, but it will not stop the adulteration of goods. It will man the lifeboat, but it will not lead men to give just weight, to make true returns of their property, or to slay their country's enemies. . . A person may be 'tender-hearted, and yet do vast harm by dodging quarantine, or smuggling in coolies, or falsifying news, or stuffing ballot boxes. . . .

"Sympathy, then, breaks down at just the point where we are increasingly in need of security. For our social development is marked by the progressive substitution of fixed impersonal relations for transient personal relations. . . With the advent of the time when the most momentous actions will present no more obvious relation to their remote social consequences than does the fingering of the train despatcher to the fate of distant passengers, it will, no doubt, be realized that intermittent sentiment is unable to cope with the problem of subordination, and that other motives must be called in."

Relation to Rules of the Game.-Women then, whether approved or not, are striving for success in almost every field of life and are of growing importance in making forms of social control. Every field, like every game, has its established rules and regulations,-be it domestic, social, professional or industrial. The fact that women have had no large direct part in formulating these rules does not excuse them from sustaining them. It is a mistake to think that the selfish individualist, whether man or woman, can enter any field or game and play fair without a knowledge of the rules and penalties and without training. The welfare of society depends upon the 
rules being upheld or changed only with the full knowledge of all. Competition is the prevailing spirit and the development of co-operation is the problem in every field of activity in which society is concerned. Good clean success requires fair, economical and co-operative rules in order that players may be equal before them and individual waste may be avoided through team work. This being true, is there any reason why women, in their respective fields of activity and thought, should not abide by the rules of the game or contribute to their enforcement and improvement? If they are defective in the qualities which make for rapid adjustment, is it not reasonable to include in their education such training as will increase their social understanding and efficiency?

Personal Morality and Social Ethics.-What is the need? Social problems to-day are ethical rather than economic. There is enough food and shelter for all, such is our control over the forces of nature, if only some of the unethical interferences, prohibitions and inequalities be removed. It is in the matter of social ethics that women are most undeveloped and uninstructed. Their sense of morality is personal rather than social and passive rather than active. To be virtuous is to be good. Vice and crime may be a matter of gossip, but their treatment as problems is considered to be proper only for men. Personal duty obscures civic duty and there is an absence of social courage when community interest conflicts with personal comfort.

It is generally conceded that the standard of per- 
sonal morality, based upon virtue, is higher among women than among men and it has long been the practice to excuse many of the anti-social acts of women so long as they remain virtuous. But greater individual freedom, without a commensurate increase of the sense of responsibility for the welfare of the community, has led to an alarming increase of immorality. Among races where the percentage was small, this has become common when they have come to our American cities to live. The leisure class with not enough outlet for its energy, and industrial workers with too much of a drain upon their energy, both show the increase. It thus becomes clear that this problem of immorality is no longer one for men to solve alone or where the single standard of personal morality will prove all-sufficient. The temptations present themselves in a hundred varied, attractive forms, half hidden under general industrial or social conditions, and the training of the girl, which should enable her to understand and guard against force, brutality and lust, does not readily recognize these in their modern insidious forms.

The Non-Ethical Group.-The socially nonethical group includes women in every station of life. There is the social representative of the family, who maintains an elaborate establishment or who is hospitable, chiefly in order to surpass a rival. There are the mothers, wives and daughters of some of the great financiers, who enjoy the advantages of wealth won under unfair, uneconomic and non-co-operative rules. Women are frequently the cause of the pursuit of 
great wealth and accept it, without sense of responsibility, without inquiry or protest, indeed of ten without interest, so long as they are comfortable and their husbands' reputations remain unsullied. There are women who inherit property which they administer without any sense of social obligation, indeed without any desire to know whence it came or whither it goes. There are others who enter professional life and become a part of bitter professional jealousies and strife and think that an increase of practice constitutes success, whether won by fair rules or foul. The field of politics and government service also contains many who belong to this group. Among these, wages and individual preferment are placed above service to the community and they do not hesitate to recommend themselves and strive for positions of honor and trust which should be the unsought gift of the public. There are working women who take the places of their fellow-workers at lower wages or accept wages and conditions which compel them to supplement their earnings in doubtful ways, because they work for themselves alone rather than for the cause of working women.

The Non-Ethical Organization.-Not only this, but women combine in organizations for which they set the standard and which they alone maintain, and there are thus formed socially non-ethical organizations. Clubs of this order are those which exist simply for the entertainment of their members. Many are willing to pay to have a speaker interrupt his busy hours of social service to come and entertain them 
with "stories of humanity"; but by no means with the idea of doing anything or of sharing the burden, as their shocked expressions reveal when they are asked to render active service. There are other clubs whose public-spirited leaders do the work, while the members pay their dues and only come to hear about the "club's work" at special and annual meetings. There are others which undertake public work but cherish it chiefly for the credit or reputation it brings to the organization. Such jealously guard their "own interests." The bridge whist club which utilizes time and energy out of proportion to the rights and needs of society, and fosters the gambling spirit, falls into this group of organizations. When it averages from four to ten hours of play daily, the same number of hours required of working women in order that they may even live, society has a right to be interested in the consequent waste.

Non-Ethical Acts and Attitude.-The effects of socially non-ethical acts are not so easily detected. A little disparaging remark in an efficient democracy may pút some one out of the game or limit her opportunities. A lie may place some one in a position where her efforts become non-productive. A cheat may displace a better person and retard progress. Never having a good word for any one else may discourage others from working for humanity. Disregard of the rights of others and selfishness set an example productive of endless evil. Jealousy may distort the whole horizon and break the best of fellowship bonds. Cowardice may leave wrongs unrighted and 
make friendship a mere gainful occupation. And when enough women are daily guilty of these things and they are distorted and magnified, there is created an atmosphere of cheating, lying, suspicion and unfairness, which vitally affects every interest-the home, society and the nation, for these can be no better than the citizens who make them.

The socially non-ethical attitude, quite as much as the act, makes possible the continuance of many conditions detrimental to the welfare of society. One cause of the slow growth of social ethics is the individualistic attitude of women and their interpretation of Christian teaching along the narrow path of individual salvation rather than as an injunction to lose one's life in order to find it more abundantly through effort in behalf of the community. Within the family, fairness, co-operation and unselfishness are kept uppermost by the ties of affection. But once outside each member tends to become a bird of prey. The attitude is, what can I get out of to-day, or out of some one else, or what for my family, with little thought of what can be put into the day for the benefit of the larger group. Personal moral excellence may become so narrow as to be socially nonethical, and while such a citizen may rank as " good" she no longer fulfils the requirements of American citizenship. If those who live in good homes and who know the value of fresh air, sanitation and cleanliness, do not lead the crusade against bad tenements, who will? If those who know the effect on children of hard hours of labor do not fight for child labor laws 
and the education of ignorant parents, who will? And if American-born women, with all the advantages of their native country, do not lend a hand to their immigrant sisters, who will make them into good citizens? Women do not protest against adulterated foods and medicines because they do not happen to use them. They do not inquire into the conditions in garment factories because cheapness is their standard or they can afford a dressmaker and tailor. They are not conscientious about their hours of shopping because they have no experience as clerks and have not enough imagination to put themselves in another's place. Irreproachable as their characters may be in their own homes and circle, is their social obligation met so long as they are indifferent to the welfare of the group?

There are many who mistake benevolent and philanthropic impulses for social ethics. To give to others out of an abundance or even at a sacrifice may be an impulse aroused through sympathy, sense of duty or sometimes through a desire for self-laudation and for personal power. The code of social ethics, on the other hand, is founded on justice and equality and has no more sense of giving than of receiving, no admission of superiority, no attitude of judgment, no consciousness of magnanimity, no reliance on patronage. One is highly personal, the other impersonal; one is individualistic and the other social. Furthermore, the benevolent person does not necessarily see inequalities and unfair application of rules as does the socially ethical person. Social ethics is essentially the result 
of team work according to the prescribed rules of the game, each player being equal, fair and co-operative, so that his team or class may also be these; each one being a necessary factor in the group and realizing that the whole group suffers if the enforcement of rules and penalties is not the same for all, and each being willing to insist upon such enforcement.

Social ethics can only be realized in a small measure through legislation. Stealing, homicide and arson are crimes which are dramatically punishable. These offenses are plainly immoral. But socially nonethical acts may affect society as disastrously as does theft or homicide, though no legal punishment is provided. The most serious crimes, judged by results upon the whole community, are not necessarily on the statute books, and the awakening social conscience has begun to perceive this truth. Buying supplies (and women are the chief buyers) made under sweatshop conditions makes it possible for many lives to be lost yearly because the workers are under-nourished. Respectable owners of houses which are used as dens of immorality make it possible for thousands of young girls to be led astray each year. Hiring a lawyer to help evade a law which was drawn to serve a great public purpose, but which has a technical flaw, may leave a whole group unprotected while securing the escape of one individual. Refusal by protective organizations to take in penniless and homeless women at night because they bring no references or because it is in violation of unwise rules, needs no statute to define its consequences. 
While it may be granted that the social consciousness and conscience of women are not proportionate to the needs of society and while it may be admitted that much of their effort will for some time remain individualistic and their organized effort characterized by disorder and waste, there is no need to be discouraged or to neglect social education. Movements and organizations undertaken by women are not the only ones that are content with attacking superficial rather than fundamental evils, with using air guns where only cannon will suffice, and which are so lacking in courage that they retard civilization by a million pinpricks rather than by boldly destroying and rebuilding. The socially non-ethical groups and acts are human imperfections, and we have emphasized them in women because it is their position, influence and activities to which we have confined our attention, and because we believe so deeply in women's importance as factors in group expression and intelligence.

This glimpse of the unlovely picture of the socially non-ethical group has a very bright reverse side which we wish might be presented in as much detail, for it holds out abundant hope for the future. The increasing number of social moral leaders among women, and the growing intelligence, interest and activities of the mass, many of whom are consciously upholding the rules of the game in the group interest, give the courage and faith necessary to present the less hopeful conditions. There are many forces at work in the uplift, and the response, 
if still lacking in power, is sincere and enduring. This in itself refutes any conclusion that the present position of women as group factors is a question of incapacity rather than of ignorance and lack of opportunity. 


\section{CHAPTER II}

\section{EDUCATIONAL VALUE OF ATHLETICS}

Obviously the demands now made upon women are different from those of fifty or twenty-five years ago, when home and social duties constituted the chief claim. We hope the preceding chapter has made the need for training clear. The question is, then, does the education of the day supply such training in adequate measure?

Social Education.-The president of one of the city vacation school systems says: ${ }^{1}$

"Our first sin of omission is not far to seek. It is our systematic neglect of girls. How few have looked with comprehending eyes upon the less aggressive companions of boys and seen their problem also? Modern city conditions, overcrowding, lack of suitable places for play and for quiet normal living are more dangerous for girls than for boys. They succumb more readily to group influences. It is almost impossible to keep their modesty and self-poise in the constant mass living to which they are subjected. They early lose their desire for play. Their imagination is over stimulated in the one direction and becomes nearly atrophied in all others. They are sentimental, clinging, affectionate or hard, cynical and worldly wise, but nearly always old before they are young. Without far more wisdom than we have hitherto shown in their education, their moral

${ }^{2}$ Report on Pittsburgh Vacation Schools, 1906. 
nature will remain undeveloped, unequal to the fearful strain of the temptations to which they are subjected. We now follow the line of least resistance-give them the sweet sentimental books they like to read, encourage them to sit for hours prosaically sewing and allow them to gather in gossiping groups for the play hour, nor realize, because it all works so smoothly, that we have taken the wrong course in every particular. Everywhere the passive, the conventional, the formal. They will have need of bravery in the fight which is before them. Has it ever occurred to us to help them develop the sterner virtues? Have we substituted new ideas for the dominating emotional ones? Have we created in them the passion for a larger life and sense of the social order which gives them mental and moral poise? Have we tried to develop in them a healthy freedom and alertness of mind and body?"

It is not our purpose to criticise present educational methods but rather to suggest a way in which they may be so extended that girls may receive a better social education, thereby increasing group consciousness and responsibility by a sympathetic interest in and understanding of their play-fellows and fellowworkmen. The demand for social education is met now, so far as it is met at all, by instruction along purely intellectual lines, by courses in economics, sociology, politics, etc., in what one might call the technique rather than in the spirit, and little conscious effort is made to increase social efficiency by developing and training the spirit itself. We believe that athletic games-the spontaneous yet directed expression of the play spirit-are peculiarly fitted, if intelligently used, to increase social efficiency through the development of the right social spirit. That this 
efficiency falls short of the need is, in a measure, due to some of the limitations placed upon the education of women, rather than to incapacity. As a result of her studies upon the differences in sex, Dr. Helen Thompson says :

"Psychological differences of sex seem to be largely due, not to differences of average capacity, nor to differences in type of mental activity, but to differences in the social influence brought to bear on the developing individual from early infancy to adult years. The question of the future development of the entire life of women is one of social necessities and ideals rather than of inborn psychological characteristics of sex." 1

Neglect of Athletic Training.-Among these limitations on education, none is more conspicuous than that of athletics, which have received but little recognition as a character builder or as a factor in group training. Games are given a place in the kindergarten and in the primary grades, but beyond these they are not only but little recognized but are frequently discouraged. About the period of adolescence, the tendency is to prohibit them for girls at the very time when group consciousness may be best stimulated or on the other hand quite lost if no effort be made to develop it.

Where organized games are now given a place in educational institutions, emphasis is almost invariably placed upon their recreative and health values. Although our inquiries have been extensive, we have found no schools where they form a part of the edu-

" Mental Traits of Sex," p. 182. 
cational scheme for which credit is given and where they are maintained as a fundamental part of the social education of pupils.

Relation to Pedagogy.-The omission of athletics as a pedagogical factor seems almost inexplicable when it is remembered that they may often succeed where other activities of the school fail, for they can be used to develop mentality and character by means of a discipline which other pedagogical methods do not possess. Many a girl cannot attain high scholarship or social distinction, yet success or prominence may be necessary to her best development. When she is sensitive, shy and socially unsought or unattractive, something aside from books or society is needed. Such a girl may go through life less wearily and monotonously and more healthfully if she has had the friends, success and social opportunity which athletics give.

Influences Which Retard the Adoption of Athletics.-It is by no means agreed as yet that women need social education, so their training is still largely individualistic.|. There also exists much ignorance on the part of educators as to both the value and possibilities of athletics in a scheme of education. 2 . Furthermore, the majority of women themselves are indifferent or content. Any new phase of education has to make its way through custom, prejudice and tradition before it can demonstrate its worth or win recognition. Physical education is now making its way just as mental education had to make its way, and the opposition is as vigorous as that raised against the 
so-called higher education. The arguments that athletics injure the health and unsex women were also arrayed against their demand for equality of opportunity in mental training. There have been some cases of over-play, as there are many cases of overstudy, but they are the-exception and not the rule. This is true, notwithstanding that school authorities have not only refused to make athletics a proportionate part of the school curriculum or have tabooed it, thereby giving it an undesirable and dramatic prominence, but have also declared it not to be a subject for school regulation!

One of the greatest bugaboos that have been raised and have much retarded the use of athletics as a part of the educational system is the fear of public contests. In the light of actual experience, no fear has been more overworked. Adequate supervision and training along educational lines have demonstrated that this is a matter entirely within the control of educators.

A number of schools prohibit all organized games because there are no so-called "girls' games." A "girls' game" almost invariably means the retention of a large individualistic element-a thing impossible where team work is required. This attitude is based upon two erroneous conceptions.

First, it is assumed that boys' games, when used by girls, are injurious to health, deportment and manners. Injury to health is frequently exaggerated. When a girl is hurt in a game, the first cry is, "No more games." The number of accidents to 
women in motors is a hundred-fold greater and no such cry is raised. Neither do the casualties resulting from unprotected machinery lead to greater protection of women than men workers. Much has been written and said about injury to health, but we have found no trustworthy studies upon which such statements can be based. In this age of facts, opinions, no matter how prominent the authorities who hold them, must carry their proof. Facts cannot be gathered by persons spurred on by some personal grievance or by those who have as an incentive some time-honored prejudice or whose point of view is obscured by social barriers. Nor are they to be gathered by groups of society women whose playground is the drawing-room and whose sportsmanship has been learned in pursuit of fads. A study to determine the physical and social advantages and disadvantages of organized games includes the essentials of any fair test, namely, contemporaneous, impartial observations by experienced and trained persons, during a representative period, upon a representative number under all conditions of training and supervision. Such a study will be more accurate if due weight be given to hereditary and environmental influences and if it includes both the educational and recreative features of games.

Second, it is also assumed by the advocates of " girls' games" that social education of women needs to be of a special kind. While good citizenship requires varying forms of expression, does it demand different moral qualities of men and women, considered as citizens? Are not unfairness, selfishness, lack 
of honor, failure to co-operate, the spirit of gain overshadowing the spirit of service, disastrous to the group irrespective of which sex practises them? Are not public opinion and social judgments injurious or beneficial according to enlightenment rather than to sex?

In demanding separate games for girls, one instructor writes: "Women who play the same games as men are constantly compared with them; and as they can never play as well, they suffer by comparison." Nothing shows better the usual shallow conception of the value of games. Are women discouraged in the study of mathematics because they so rarely become great mathematicians; or in music because they so seldom become great composers? Is there any field in which women and men are not and will not always be compared? This matter of playing games is one to be determined, not by comparison of the sexes, but by an educational principle. If women can be trained well enough to make athletics beneficial and interesting to themselves, then it is good for them to play; if athletics develop in women qualities valuable to them as individuals and desirable for them to possess as members of a social group, then also is it well for them to play.

The Standard of Athletics.-A more fundamental explanation of the omission of athletics is the prevailing standard. Changes in both aims and methods along the following lines are imperative before they can become a part of an educational system.

Equal consideration and emphasis upon the educa- 
tional and health values are essential. This implies that the theory as well as practice be understood.

Athletics are a means to an end, not an end in themselves, and are to be conducted for the good of the entire number and not for the purpose of making championship teams and developing record-breakers and pennant-winners.

To be educational and truly health-giving, athletics need to be under the supervision of as careful and well-trained instructors as is any other branch of education.

The spirit to be striven for is not grim determination to win at any cost but the exhilaration and joy of playing. Athletics thus become social and not business arrangements. With such an aim competitive games become a minor factor.

Advantages of Athletic Training.-If social education by means of such a standard is possible, how is it to be accomplished?

First, athletics give a sound body, good co-ordination, normal impulses and control of the appetites and passions. Any social consciousness based upon these is sound to start with. How many women with opportunity and leisure to obtain these can claim them? How many are denied them by the demands of the industrial and social systems and look at life hopelessly and pessimistically, lacking the energy and joy of living which come from them?

But aside from this health value, which is more generally recognized, they develop on the mental side keen perceptions and complex thought processes; on 
13. the esthetic side, good personal habits and improved appearance; and on the social side, a group consciousness, with its many varying expressions of graciousness and power.

It is unnecessary to enumerate all of the qualities developed by athletics. It will be remembered that in this training there is no theory, no text-book, no shady-nook of delusion where the pupil may believe she has become the ideal about which she has studied. The organized game is the active expression of one's natural self, the life in many essential details which is lived later away from school and college and a miniature of the democracy which envelops one in later years.

Individual Qualities and Efficiency.-Some of the qualities which may be used as illustrations of mental improvement due to athletics are observation, attention, concentration, memory, imagination, initiation, judgment and will-power. The result of a combined use of these qualities is the attainment of a presence of mind and self-control in which accuracy, coolness, quickness and good judgment are called into use. Every one knows how essential these are in any field of activity and how indispensable they are to efficiency.

In athletics these appear to be most rapidly developed by the various games of ball, from the simpler ones, such as long-ball, captain-ball, push-ball, volleyball and drive-ball, up to those requiring fine team work, such as indoor baseball, basketball and hockey.

When girls begin to play organized games, even as 
late as in college, they frequently have their minds on something else and lose opportunities; their attention is easily distracted and they "forget to play"; they do not execute commands promptly; they cannot remember rules or instructions; they change their minds half a dozen times while they hold the ball; they imitate rather than originate; or they "play wild."

What happens as the result of athletic training is clearly visible at an early period. In the first games of basketball few players guard their own opponents. Every one minds every one's else business and criticises other players. No one can be relied upon and what will occur in an emergency cannot be foretold. From this, girls grow into cool, accurate, steady players, use good judgment, are ready for emergencies and obtain a poise which cannot be easily shaken. These can never be wholly lost except through degeneration or disease and are certainly valuable qualities to possess in moments of industrial or social stress. The advantage of learning them in a game is that limitations and defects may be detected and to some degree remedied, while in the game of life each failure brings an inevitable social consequence.

Sometimes the distraction of players during the first periods of training is ludicrous. One day, while working with a squad of green indoor baseball players, most of whom were physical education teachers, one of them made a splendid hit, good for at least three bases. She ran to first and when she was nearly to second, turned and went back to first. When asked for the reason of this amazing play, she replied, " $\mathrm{Oh}$, 
I noticed the first baseman was a friend of mine and I went back to tell her something."

During a beginners' game of indoor baseball, a good hard ball was batted past center field and went under a spring board. Two men were standing near and, as the fielder ran up and saw the ball under the board, she hesitated and then said: "Would one of you men mind getting that ball for me?" Of course the result was a home run for the other side. In the economic world such dependence during times of responsibility means inefficiency from the employer's point of view.

Another time in basketball a held ball was called. Taking the ball the instructor said, "Heels together, so I can throw it up between you, and jump and try to bat or catch it when it comes down." Just then some one asked for an explanation of a play. Imagine the amazement when the instructor turned back and found that each player, instead of having her own heels together, had turned her back to her opponent so that the four heels of the two players were together. In this way they were waiting to catch or bat the ball when it came down between them! How many times has such a lack of the use of reasoning power caused social calamities?

Imagination.-It may be difficult to understand how games develop some of the mental qualities, such as imagination. A requirement for successful plays is ability to foresee the results of a given play, as well as to put one's self in the place of another. The penalty for not being able to do this is so instantane- 
ous and direct that the responsibility is immediately fixed, and by emphasis upon group relation players may be led constantly to place themselves in imaginary positions. This leads directly to a sympathy with other players. It is said that the "tap-root of selfishness is weakness of the imagination," and imagination certainly is a great aid in developing sympathy with other players. In the absence of experience, no quality possesses more social value.

Reason.-The ability to reason developed by games is more practical than that gained by mathematics and other studies. It is not so much the power of abstract thought as the control of the instincts and the exercise of common sense and judgment during activity.

Social Qualities and Efficiency.-However much these mental qualities make for individual efficiency, the social qualities which give the right spirit are indispensable. One may have coolness, accuracy, judgment and many other qualities, but unless these are brought into an ethical adjustment team work and social consciousness do not result. Thus athletics have a second great power-the development of moral qualities such as self-control, unselfishness, sense of honor, self-sacrifice, fairness, modesty, decision, courage and sense of responsibility.

3. Self-Control.- This must be learned before a game can even proceed. The first lessons are in promptness and obedience. Take a struggling mass of little East Side children. They want to be "on the go" every instant and to show off, and have hitherto done this 
by chasing each other, shoving, pinching and kicking, complaining, sulking, tattling or even going home with a "mad on." Obedience to orders is the first step out of this maze of energy-obedience when every sense and perception is alert. They must listen to rules, must play the position given, and fouls are called unceasingly when they do not obey. In a little while they are actually controlling themselves and are preventing fouls and delays. At first they complain every time they are run into that it is "on purpose," and refuse to co-operate with other players. Later they regard being run into as an unavoidable accident and work steadily with the team, playing of ten with rivals to whom they have hitherto refused to speak. Oftentimes they have asked to play at opposite ends of the gymnasium because they did not like each other and threatened, "I won't play if I have to be with her." With a little skill, games invariably make them forget such differences. The next thing is to teach them to be cheerful under defeats and erroneous decisions.

Co-operation.-While competition is the underlying principle of all athletic games, it is equally true that unselfishness is the basis of all team work. It may be contended that women are sufficiently unselfish because they are usually self-sacrificing. But their self-sacrifice ordinarily centers about emotion, as love for children, home, etc. The self-sacrifice brought out by team work is quite different, for it is made for something impersonal, as a team victory, an institution 'or a thing entirely apart from one's close 
ties. It is not a supreme individual effort but is shared jointly by others struggling for the same end on the same plane. To share a sacrifice robs it of individual glory and creates a social glory which is akin to the feeling of patriotism. A necessary form of unselfishness to be learned is appreciation of the ability of others. In the beginning players say, $I$ want to play basket; $I$ want to score; $I$ want to play with the bigger girls; or $I$ want to make the team. After a year's team work this largely disappears and quite unconsciously $I$ is replaced by we.

Fair Play.-Closely allied with unselfishness is fair play. A player enters a game with the understanding that all forms of interference are adjusted according to some prescribed rule. This offers good preliminary training for obedience to the more complicated rules of organized society. Fair play does not mean taking mean advantages any more than it means that a team is willing to win by the partiality of the umpire! There are some things not forbidden by the rules which the spirit of fair play discourages, just as there are some anti-social acts which public opinion does not countenance, even though the statutes are silent on the matter. In every game opportunities arise when a trick, some mean little thing or some petty act will bring an advantage. Small cheating and petty meanness are soon detected by an observant instructor and girls need to be held strictly to a fair spirit and to be judged solely by their playing. Pettiness is often more distressing than open unfairness. Small vices, such as narrow- 
ness, spite, ungenerous judgment, intolerance and inability to omit the personal element creep in and should not be excused, for they are the insidious enemies of fair play and can only be eliminated by activities which constantly take players beyond themselves.

Fair play also means willingness to take a fair share of the blame. Among new players is constantly heard: "It wasn't my fault"; "She did that"; or, "I could not help it." There is no more important thing for girls to learn than how to take fair criticism. Many unattractive habits, ungenerous thoughts and unworthy acts are due not to ineradicable things in the individual, but rather to her lack of knowledge of their existence and portent.

Loyalty.-Loyalty and a sense of honor are among the most difficult qualities to develop in girls. They are on the whole not very loyal to each other and are not strongly inclined to organization. In games players cannot cheat or bluff through or get credit for things which they do not do. They cannot lay blame on others. At first when they do not win, they are inclined to sneak off in tears. If a sense of honor and loyalty are made to mean anything, after a little training most girls will be found standing bravely with their team in defeat, congratulating the other team or modestly accepting their share of the team's victory. It is a great thing to learn to be a good loser. It is also a great thing to share victory and feel that some one else has done as much as one's self to win it. There are many girls who never have 
had this sense of sharing victory or defeat in the guise of group loyalty.

At first some girls are inclined to violate the rules laid down for health, such as length of practice, times of playing, etc., thinking " the instructor will not catch me at it," but later they come to feel, "It isn't the square thing to do when I am trusted." After a little training, rules come to be regarded as a mutual agreement and many players even consider themselves a party to their making. It is a great moral gain for girls to feel that these are agreements not to be broken.

Courage.-It takes the finest kind of courage to be fair, to be honest and to be loyal-qualities absolutely essential to good team work. Physical and moral courage and especially the latter are unquestionably among the greatest needs of our modern civilization and among all individual qualities can least be dispensed with in group activities.

It may be thought that prejudices, little vanities and jealousies, unkind words or exaggerated statements have little harm in themselves and that bragging and snobbishness are perhaps pardonable under some conditions. Games reveal these qualities in their exact proportion and without the softening arts of the drawing-room. Nothing is so good for a girl as to find that money, clothes, family, prestige or influence do not help her in the least degree to play good ball or to make a team. When a player stands or falls absolutely by what she is and can do, she realizes that the game makes all equal. Whenever college 
clubs use "influence" to get their members on teams it frequently makes not only a weaker team, but, more important still, it makes it impossible for contests to teach fair play, since it destroys the educational value by making the basis of selection unfair.

7 . Sense of Responsibility.-The player learns many other things. She acquires a sense of responsibility which makes her do her part faithfully and she does not excuse herself on the ground that she thought some one else would do it. All the risks, hazards and opportunities are for her to use on her own initiative. If she fails she must bear the blame and chaffing with the simple resolve to do better next time. She is prompt. Tardiness may mean not only that she will have to wait her turn or not play at all, and thereby lose some of the fun, but she realizes that it may also weaken her team. Then, too, she acquires a sense of proportion. The new player not only dissipates her energy in useless plays and tires herself out without accomplishing anything, but her idea of her own importance is sadly disproportionate to her real value to the team. It is this prevailing sense of difference which gives an excuse for ignoring the rights of others. Games so lessen this that a player soon learns that essential of fairness - to judge others on an equality with herself. After playing for a while she comes to realize the limitations of her importance as well as of her ability, for over-confidence brings sure defeat. Many women who have had the advantages of college training but not of athletics, and who have not'gained this sense of proportion, magnify 
both their importance and advantage to the practical world in a way which sadly handicaps them in doing effective work.

Discipline.-The discipline incident to games is of the utmost value in education. One instructor writes:

"Games do provide this discipline. During a period of twelve years, I can certainly say that they help to create a broader point of view in the school and to promote friendliness, mutual appreciation and forbearance and to lessen the spirit which imparts personal motives into every action."

Development of moral qualities necessarily means control of the emotions. Here games have an especial advantage for girls, for many are abnormally sensitive, introspective or morbid and live too subjective a life. The various ethical and religious cults which emphasize the subjective appeal strongly to them and are frequently made a substitute for healthful normal work and interests. Games are largely objective and afford little opportunity for analysis of feeling or consciousness of the process. The attention is centered upon the thing to be done and not upon the process of doing it.

Training for Citizenship.-These qualities are not essentially masculine. They are but human qualities needed for human fellowship. We have yet to see a group of girls made masculine where the spirit of the training has been that which we have endeavored to portray. 'We do not mean to say, of course, that every individual trait can be strengthened or every defect removed by game work or that games alone 
will do this. But we do mean to say that athletic games, when put on a proper basis and under intelligent trained instructors, will accomplish far more than has ever been required of them.

It is evident that the training obtained through athletics is carried over into the business and social life after the girl leaves school. Other things being equal, she is ordinarily a fairer competitor and better citizen. The responsible, reliable player becomes the same kind of a citizen, for in games moral energy is stored up and habits established which govern the activities in later life. The girl who has learned through the experience of games not to do unfair things under the stress of competition has had the training which enables her to face temptations later in life where the stakes involve large interests. The girl who shirked responsibility on the field does not alter her course in later life. The girl who gave up basketball because she could not get more than her share of praise will still be found baiting for this indispensable necessity to vanity. The girl who was unfair and intemperate in games carries these same qualities over into her social or business world and every one who lives or works with her is affected by them. The girl who failed to do team work or refused to play games at all continues an individualist in her later activities. Whatever is acquired of good social and moral qualities is taken into the home and tends to raise the home standard and so affects the community in a broad way; while if pupils are permitted to become sneaks and cheats and to 
cherish a mean, contemptible, selfish spirit, that likewise influences the community to its detriment. Modern civilization is complex, strenuous and of ten artificial and our system of education needs organized games to prepare the girls for organized life and activities.

General Advantages of Training.-There are also some general advantages which games possess. They afford a healthful, impersonal topic of conversation and this is much to be appreciated in schools where numbers of girls are segregated and in clubs where undesirable topics may arise.

Pride in "good condition" has an ethical value, for it prevents many a snare into which one indifferent to it may fall. The girl who " does not care" or who puts clothes above "good condition" is much in need of athletic training.

The amount of real happiness given by games is often underestimated and this is an important factor in character-building.

More emphasis is needed on leisure, and by increasing play requirements educational institutions may do much to bring this about. The growing commercial spirit in educational institutions so hurries students that they have no time for games. Think of it! The play spirit which should characterize youth has not only to be stimulated but games may really have to be made compulsory in order to retain it.

Esthetic Value of Organized Play.-The esthetic training obtainable by means of games' is 
receiving an increased amount of thought. This includes the personal appearance of players and the spirit of games. In the former, the first essentials are that girls stand well, walk well, run well, throw well and wear a neat and attractive costume. Dress has received much attention as a matter of comfort but not enough from the esthetic standpoint.

The correction of bad habits and manners on the field is also a part of the esthetic training. The absence of uncouth language, squealing and yelling, crying, disagreeable facial expressions, eating between halves of games and boisterousness, is the result of emphasizing the esthetic feature of games. New players are inclined to think that slang is the language most appropriate and strength the main asset for a successful game.

The dignity of play has been far too much sacrificed to the so-called fun of playing which so frequently develops into roughness. A matter needing considerable attention is the conduct of teams between the halves of match games and the attitude of their friends and audience. In one of the most prominent woman's colleges, it was not unusual to see the teams, when resting between halves, lie down on the floor in front of the audience while an army of friends rushed out with lemons, towels and pails of water and began feeding, rubbing and washing them. Only after protests on the part of the players did their captain allow them to sit up. Some of the-players tried to look warm and tired so as to receive more attention. This kind of thing is common in match games between 
schools and is mere gallery play, which is of ten confused with sportsmanship.

The next best thing to getting on the team is to be a sympathetic friend, and this is at present an overworked part and induces players to sham exhaustion and overwork, a practice which hurts the game.

Another thing which frequently occurs and robs a game of dignity is interference on the part of friends and audience. When a player becomes dizzy from an unexpected collision, or a trifling accident happens, or when a player squeals easily over small things, or the instructor lets her go on playing "on her nerve," then the friends and audience begin to protest. "She ought not to play"; "She will hurt herself," etc. When time is called for breathing space or for trifling matters, friends collect about the players and exaggerate the situation. A responsible instructor and captain are the best judges of when players should come off the field or when they are really over-playing or merely shamming. These conditions are to be controlled by right training and responsible instructors and not by the. sympathetic interference of friends and audiences who cannot possibly judge the situation and who thus misrepresent the effect of the game.

In the official rules for basketball appears this statement:

"The greatest danger in connection with athletic sports is not that men will get hurt, but that in the excitement of the game and on account of great desire for victory they will do things that are ungentlemanly and discourteous. This fear is shared for girls and has to 
some measure retarded the use of athletics. This fear will not be realized if the object of all players is good sport and not the mere winning of victory. Sport which violates the principles of courtesy and good character is never good sport."

When we first insisted that form be a requirement of making the university class teams and that no girl who persisted in careless dress and playing should participate in any match game, there was considerable indignation. But before the close of the year scarcely a player needed a reprimand for disorderly appearance; some who had been exceedingly careless admitted that improvements in street dress and manner were due to this training. When a team "straggles" on the field; when players chew gum; when they lie or sit upon the floor or gather in groups and talk when time is called; when they call to each other; or when they clap hands or whistle for the ball,- then the audience may be certain that good form is not considered. Few girls have thus far learned the beauty, joy and science of the silent game. Grace and silence are among the anticipations rather than the realizations, and some still confuse noise with sport and having a good time.

Certainly by paying attention to the esthetic side, grace can be developed. One basketball player rarely stopped a ground ball without falling down and rolling over. When this matter was brought to her attention, she said she was "top-heavy" and could not help it. Her measurements were taken and some special work given, and she was told that she played well 
enough to make her class team but for this unfortunate tendency. In less than two months there was such a decided improvement that she made the team. The esthetic possibilities of games also appeal strongly to many of the little settlement players and working girls who thus have their eyes opened on a new world.

Atmosphere of Games.-The spirit of playing is the second essential in a beautiful game. The atmosphere makes or mars its beauty. This spirit is shown chiefly by the attitude of players toward each other, toward officials and toward their audience, if there be one. It is also made up of the kind of interest and appreciation which the audience gives. Enthusiasm, unfailing courtesy, even under the most trying circumstances, avoidance of disputes, acceptance of decisions, joyous rather than competitive playing, friendliness-these are tests of whether a team has been trained with the idea of preserving the beautiful features. Later, these are also tests of whether one has the right attitude toward one's vocation.

Social Value to the Audience.-We have thus far considered only the education of players. It is said that " the fatal moment for a game arrives when people prefer to see it played by others rather than play it themselves." The day arrived long ago for women; and worse still, many do not care to see games played. At the Brooklyn Bridge any evening during the summer, the parks and streets are densely packed with men and boys. When a roar bursts forth, the stranger may think it is a riot, but it is only the play 
spirit of the multitude, shut out of the baseball field, cheering a good play chalked on the scoreboard,a pathetic sight for one who loves games but hopeful since this spirit can be kept alive under such conditions. But in all this crowd, few passing women or girls even glance at the board. It is true professionals are playing, but in that crowd of men and boys exists group consciousness and through it surges enthusiasm.

Games played by women can be taught and played with a view to making them interesting and educational to the audience; if this be neglected, there is small justification for inviting persons to attend. If small groups are interested here and there many women who would not otherwise attend games might get back a little of the play spirit and enthusiasm which enable them to understand the girls' point of view. Not enough parents now know what athletics mean. If they see that games are rough and injurious they should be able intelligently to lend a hand at regulation or suppression. If games are well conducted and beneficial, parents can do much to further good sport by their interest and approbation.

There are thousands of women not strong or young or interested enough to play organized games who need to understand and appreciate good, clean sport. Audiences which applaud unfair plays or points made on fouls unconsciously become a party to fraud, while the influence of victory won by clean, fair plays is equally uplifting. Every girl who cheers her team at a class contest; who gets out "grinds" to a meet; 
who brings her mother and friends; who arouses club interest; who interests the neighborhood; who gets up songs or otherwise stimulates interest, renders a social service by opening some little corner of a crusted mind or heart to a love of games, and also stirs the group spirit. One of the best ways to keep a good spirit is to have the audience in harmony with the players, and have it respond to good clean plays and discourage " dirty playing."

Because of the great educational value to the audience and the limited opportunities for women to play games, the community or municipality has an obligation in providing and supervising clean games by men to which admission should be free and to which women should be encouraged to come.

The educational possibilities of athletic games, embracing mental, social, ethical and esthetic features, seem to the writers to be very great, and the subject is one to which educators throughout the country may well give thought in their efforts to adapt studies and work in order that girls may be better fitted for their place in life,-be it the home, the shop, the school, the office or any other avenue open to them. 


\section{INSTRUCTORS - THEIR RESPONSIBILITY} AND TRAINING

Whenever any activity possesses the power of being either good or bad for the individual or group, the question of leaders becomes of the utmost importance. Athletics have this power as does no other form of physical activity. On the one hand they are capable of being carried on in such a way as to develop strength, nobility, generosity, truthfulness, fairness and force of character or they may bring out meanness, trickery, dishonesty, viciousness and weakness of character. It is useless to expect that girls will spontaneously develop only good qualities. It is idle to urge that athletics be used for their educational value unless they are under the supervision of teachers who are intelligent enough to understand their full significance, well trained enough to teach principles which make a clean, accurate game and strong enough to exemplify such principles on the field. It is therefore a question of competent teaching and capacity for leadership. Those now in the profession or who enter it within the next decade will, to a great extent, determine the standard of athletics now in the process of making. This standard will depend, among other things, upon: (1) The qualifica- 
tions of instructors. (2) Opportunity and thoroughness of training. (3) The demands of employing schools.

Special Qualifications of Instructors.-What constitutes necessary qualifications are not always clearly defined even in the minds of those upon whom fall the selection and training of instructors. Our replies from about one hundred schools and colleges emphasized qualifications of character rather than of technical proficiency. Many private school principals. showed little comprehension of the question, while a few thought our questions too general to answer. Enthusiasm received the highest number of votes. The others in order were firmness or decision, fairness, leadership, personality, high moral character and standard, good judgment, honesty, justice, tact and good breeding. Sympathy, a pleasant manner, thoroughness, comradeship, executive ability, common sense and courage each received one mention.

In the matter of proficiency, less than twenty per cent. mentioned knowledge of the game, and but two per cent. specified clearly that this meant ability to play the game itself. Four per cent. thought a knowledge of physiology and hygiene desirable and two per cent. emphasized experience. The most frequent combinations of qualifications were: Enthusiasm and good character; decision and honesty; and enthusiasm, knowledge of game and good character. Among the more comprehensive ones were: "Knowledge of game, keen sense of justice, honor, sense of what constitutes good behavior, knowledge of peda- 
gogy and of human nature, appreciation of something better than the commercial spirit" ; " honesty, judgment, quickness, executive ability and enthusiasm for the sport and not only to win"; and "honesty, impartiality, good judgment, tact, physical ability and personality." In contrast with these were: " ability to teach tricks"; " same training as any other teacher in the school"; and "attractive, graceful, refined person who knows her business." The recognition of the necessity for high character, fair play and other ethical qualities speaks well for a high standard, if they are really insisted upon.

On the instructor falls the responsibility of making games educational and of giving them a place in the school's plan as well as of safeguarding the health of pupils. In order to meet her responsibility something more is required than was included in many of the replies, some of which are quoted above.

In our judgment, the qualifications least to be dispensed with are the following:

First and always a play spirit. Only one who loves games and who has learned obedience under the stress of competition can develop the best spirit in others. When women are without the play spirit, supervision is likely to become mere executive detail. They miss the joy of playing and consequently fail to bring it out in their pupils. Where instructors really dislike games they administer them in a purely perfunctory manner. Recently a new teacher discontinued games because "they made the girls more difficult to control,", entirely losing sight of the fact that the 
girls were sadly in need of discipline and of an outlet for energy.

2. Second, ability to do the thing taught. This is the surest means of winning the respect, confidence and loyalty of players, who do not give these to teachers whom they excel and who therefore cease to be an inspiration. It would seem unnecessary to emphasize such a qualification, did not a large percentage of schools employ teachers who lack such ability. Who ever heard of a language teacher who had received no instruction in languages; or a teacher of music who did not know her notes? But a teacher who does not know rules or cannot throw a ball! "Well, the girls can just be turned out to play, you know" ; or, "They can buy rules and teach each other" ; or "Make their own rules." When schools realize that it is just as bad form to make their own rules for a standard game as it is to create their own French pronunciation, athletics may be really taught. Often when girls are quarreling over rules, the teacher who does not play thinks what a good time they are having and wonders what it is all about. Bad tempers and cheating thus go unrebuked, and if accidents occur, bad manners result or character is warped, it is "the fault of the game."

An instructor in charge of a school for girls for many years writes:

"But any school makes a mistake which does not have on the staff some teacher young enough to be a companion to the girls and sympathize with their view of life, and such enjoy games for their own sake and prefer taking their recreation in games." 
Ability to teach implies that the instructor knows the game so well that she is able both to classify and interpret rules. It is also an advantage to know the history and theory of the game; the reasons for rules and their changes; what demands the various games make on the organs and vitality and what their physical, mental and moral advantages are. Among the questions asked in our investigation was: "What rules do you use and why do you prefer them?" A frequent answer was: "We use $\longrightarrow$ rules because they are easier to get."

In the third place, it is desirable that the instructor have an ideal a little beyond that which her players can attain; otherwise they soon get the idea that they know all about it and have nothing to "work up." This often explains lack of interest where competition is not used to stimulate it. 'The instructor's conception of the value of her own work is important. If she regards it merely as exercise or as a subject of minor importance, and if she permits others so to regard it, she does not support the standard which physical educators who believe in athletics are endeavoring to establish.

It will be conceded that the instructor needs to be a disciplinarian. But it is also necessary that she be able to tell when to insist upon the letter and when upon the spirit of the game. A sense of humor is a most helpful factor in this. There are days when she works her players and others when she only plays with them. A sense of humor not only relieves the tension but it tends to eliminate 
that most undesirable feature of instruction-sarcasm or ridicule.

Confidence in herself and players is also helpful. The skeptic, cynic and pessimist do not ordinarily make good instructors, for they have too frequently lost the play spirit. Ability to give frank, honest criticism of faults and appreciation of achievements usually accompanies such confidence, but not when it has grown into egotism.

Personality is an elusive thing. It usually implies a gift for managing people and ability to compel respect, to interest and to inspire. The instructor needs to combine friendliness with these. Whatever she has of social presence, refinement, character and experience is a great help.

At the risk of being criticised for describing an ideal rather than a teacher, there is one other quality which we have found indispensable, that of couragecourage to teach a clean, fair game in the face of discouragements and defeats; courage to be a real person, free from affectation and unworthy ambition and to stand for the square thing even when the school itself may not give its support.

In brief, then, the things to look for in the candidate are: Play spirit (often disguised as enthusiasm); ability to play as well as teach; belief in educational value of games; a personality which has capacity for leadership and ability to inspire; and a character which, in addition to true culture and a spirit of fairness, possesses the somewhat rare quality of high moral courage. 
General Qualifications of Instructors.-These may be called special qualifications. Added to these, are general training such as a fair education and knowledge of such subjects as anatomy, physiology, hygiene, dietetics, pedagogy, psychology and sociology. If it is not possible to find instructors with all of these qualities and of this general training, each school must decide for itself which it can best do without, according to its conditions.

Relation of Instructor to Players.-Not enough attention has been paid to the relation of instructors to players. The athletic field is different from the classroom-just as play is more natural and less formal than study, and suggestion plays a large part. For instance, partiality may undermine the value of the game. The instructor who permits players to do favors for her or who accepts homage or devotion can rarely instill a spirit of fair play. In a measure, the attitude of the instructor also determines that of players to each other. If she is undignified and unfair she may expect these of her players. If she lounges about, uses slang and nicknames, the girls are likely to do so. Topics of conversation that she favors will become the popular ones. Many instructors fail because they cannot distinguish between friendliness and familiarity; while, on the other hand, harshness or indifference greatly lessens free expression of the play impulse.

Men as Instructors.-In any consideration of this subject, an important question is whether instructors shall be men or women. It is frequently contended 
that men are better fitted for this field. This must necessarily be true until the social education of women becomes much broader. But there are some serious objections to men instructors.

Invariably men teach according to prevailing standards for men, while the type of instructor who will teach athletics as a branch of education is most needed. Men instructors train primarily for contests, are interested in developing teams and have little patience with weak girls.

All careful athletic games are based upon physical examinations taken by the instructor. Obviously a woman should do this.

Men instructors show one of two tendencies. First, if they see a real interest, they overwork women because they do not realize their physical limitations. At times there should be a light practice or none at all, and this is a matter which men cannot properly supervise. Second, they go to the opposite extreme and think because. women cannot play as well or as much as men they can play as they please! In that case they assume a gallant and indulgent attitude and permit players to violate rules, "because they will not become professionals and it does not matter." This is really a most serious objection from the point of view of the educational value of games.

Where the instructor is a woman there is, moreover, no possible complication from the question of sex. Some persons in charge of athletics think that men interest girls more in their work and are therefore 
more desirable. Ordinarily the interest should be in the game itself and not in the one who teaches it.

The great disadvantage of women teachers lies in their narrow, individualistic training, which of ten prevents their exemplifying or developing desired qualities of character in their pupils; their inclination to "baby" players and thus strengthen selfish tendencies; and their willingness to teach an inaccurate game. So long as specific attempts are not made to eliminate these defects, men will necessarily keep the lead in both quality of leadership and of instruction.

Schools of Physical Education.-It is one thing to set a standard, and quite another to find instructors to maintain it. Naturally much is expected of schools which train teachers for this field. The present supply comes from four main sources-schools of physical education, normal schools, colleges which require physical training for graduation and schools of elocution and oratory.

We found that the majority of trained teachers were pupils or graduates of schools of physical education either at their regular or summer sessions. With a few exceptions, they had charge of both gymnastics and athletics. This being true, it is important to know what athletic training these schools give. The following are brief statements of the work offered by the leading schools:

$A$. This school offers a two years' course. During the first term of the Junior year, on a schedule calling for five hours of work daily, one and one-half 
hours weekly are offered, but it is not clear if these are gymnastic or athletic games. During the second term, on a schedule calling for four hours of work daily, the same work is offered and athletics are given during one month out of doors, but the amount is not stated. So far as we can learn there are no introductory or other lectures on athletics, no discussion of their relation to other physical work or to education. In the Senior year, during the first term on a schedule calling for six hours of work daily, six hours per week for one month are devoted to training classes in athletics and during the second term some time during the month of May is used for out-of-door work. Doubtless there are extra hours which the pupils themselves give to practice, which however is not compulsory.

$B$. The instruction appears to be graded and the course covers three years. During the first year only practice work is offered in elementary athletics, which is stated to include: standing jump, running jump, high kick, starting in running and running vault, gymnastic games, basketball and minor games of ball. During the second year, practice is given in games and field sports. Not until the third year is any work offered in theory and it is limited to the regulations governing athletic and gymnastic competitions, construction and equipment of athletic grounds and administration and management. Practice work is provided in running, jumping, hurdling, shot put, field sports, out-of-door games, rowing, hockey and in conducting contests. This school 
recognizes the needs of secondary schools by providing supplemental courses so that pupils may be fitted to teach combination subjects, as English and basketball; history and baseball, etc. The postponement of all work in theory until the last year, in view of the fact that many do not take the entire course, and the absence of fundamental lectures are great disadvantages.

C. During the fall term of the Junior and Senior years, one hour a day for three weeks is given to each of the games of tennis, field hockey and golf. During one year a series of lectures was given upon physical training in the public schools in which the problem of athletics for girls was discussed. This school has an outdoor field for field events, basketball and hockey. The pupils are organized into an athletic association which conducts the in and outdoor athletic meets, under the supervision of the director of the school. The catalogue also announces a special course for those who wish to become physical directors in Young Women's Christian Association work, as follows: "Conditions that have demanded this work; its beginnings and development, and the actual present conditions (illustrated by charts); comparison with school and college work; aims and methods of work; qualifications needed in physical directors; possibilities of development and advancement for the physical director; the future of this department of the Y. W. C. A."

D. This school provides thirty hours of work per year which include lectures on the rules of games and 
practice in basketball, baseball, hockey, cricket, etc. During the last two weeks of each year the Juniors are taken to an adjacent field, where they are practice material for the Seniors who instruct them. An indoor and outdoor meet are held, in which the Juniors enter as contestants and the Seniors run off the events. The Juniors are not required to practise for these events. Most of this work is crowded into a short time at the end of the year, and the practice of taking charge of field athletics gives just enough work to enable pupils to say that they have had experience and received training.

Contrast with these what the Y. M. C. A. offers in its special school to fit officers for its work. It emphasizes the community value of games and especially provides courses in construction, location and equipment of gymnasia; object, organization, administration and relation of physical work to other Y. M. C. A. work; organization, grading of classes and conduct of classes; qualifications, duties and relationship of physical directors; and the philosophy of physical training, school gymnastics and public playgrounds. There is a course on amateur athletics which includes organization and management and a course on the history and literature of physical training. In addition to the work in theory, thorough practice and training are given in playing games. The educational and moral values of athletics for various groups, as boys, workingmen, students, etc., are emphasized. Group contests are given special attention in both theory and practice. A course has also been 
added on social service. The work of this school is given in detail in the hope that the Y. W. C. A., settlement associations or other public-spirited organizations will see the necessity of establishing a school for social workers of cities, which will include physical training along similar broad fundamental lines.

Summer Schools.-A number of summer schools have departments of physical education which offer instruction in athletics. The following course was given by the writers in a six-week period: Meaning and values of games; principles of coaching; basketballtheory and team work; instructing green squads; contests - their place and management; hockeytheory and team work; indoor baseball-theory and team work; some problems and conditions in athletics for women. In addition, arrangement was made for demonstration periods when the different games were taught according to the theory given. The students were also taught to play. Lectures on track and field events and practice were given and additional work offered to pupils who were interested in special games. Examinations in both theory and practice were required before the student received any credit.

Another summer school offers two courses, one on the "Principles of Physical Education" and the other on "The Theory of Play." Practice is also given in track and field events, baseball and basketball. The short course makes it impossible to give much work and is primarily intended for public school teachers.

In a third school the work is arranged so that it 
may cover four summers. It is similar to that previously described under $B$. A distinction not emphasized in other summer schools is the following:

"Although many of the courses may be taken in common by men and women, it has been deemed advisable to limit the heavier forms of gymnastics, athletics and antagonistic exercises to men, while the lighter calisthenics, Delsarte exercises, elementary apparatus work and esthetic dancing are adapted and confined largely to women. Where men are expected to instruct women, and women are called upon to teach men and boys, as is the case in many of the State Normal Schools, a judicious selection from both programs will be allowed in order to meet the requirements of the teacher's position."

The difficulty with this arrangement is that many do not know whether they are to teach boys or girls until they obtain their positions and thus may not elect theory of athletics and practice. Later, notwithstanding this, they take charge of athletics and " antagonistic exercises."

In a fourth summer school there is a department of physical training which offers only such limited work as "special instruction in the theory and practice of basketball and hockey."

There are other schools of physical education which do not provide any work whatever in athletics. One was organized a half-century ago, and has a long list of graduates and pupils who hold high school positions where athletics are permitted.

Defects in Methods of Schools of Physical Education.-The absence (1) of graded, systematic and 
consecutive work throughout the year; (2) of fundamental lecture work on the history, theory, place and influence of athletics; (3) of discussions of the organization and administration of athletics and their relation to the school plan; (4) of all reference to playgrounds, recreation centers and other social movements, which employ trained teachers; and (5) of special consideration of the problems which athletics for women present, shows clearly that these schools are not meeting the demand for trained instructors.

Little or no attempt is made to train pupils to become good officials, although every instructor has to officiate at contests. Officials, quite as much as instructors, have not only a responsibility to those who engage them but also to the community for making good or bad citizens, according to the standard they set and to the fairness of their decisions. Women are not used to positions requiring instantaneous judgment based on accuracy of observation and fairness, and many blunders costly to the cause of good sport result.

Schools of physical education should be given full credit for valuable training in such subjects as physiology, anatomy, hygiene, psychology, anthropometry and pedagogy - which are intended to and do make the pupil intelligent upon the care and use of the body. But this special training may fall on barren soil, owing to the varying entrance requirements. The least that can be required is a high-school training or its "equivalent." While most schools insist upon this, the substitutions permitted under the head 
of " equivalents" do not always constitute a general education on which specialization can be well founded. The greatest defect of such schools, however, is the almost total absence of any realization of their responsibility to teach athletics as a branch of education and of any emphasis upon their value as a means of social education. Many teachers are called to settlements, social education institutions, playgrounds, etc., with little or no idea of their aim or methods or of their place in the social structure. Sociology is in no case included among the subjects of training. It is a serious question whether a special effort should not be made to include these when so many women are entering this field, who ordinarily have not a fund of general information which enables them to take a broader view of their work than as a means to an end.

It is for this, among other reasons, that so many instructors live within a narrow horizon and lose their perspective and the relation of their work to citizenship and progress. One leader in physical education says: ${ }^{1}$

"I find few among my professional brethren who have any far-reaching interest beyond their specialty, few whose hearts throb in unison with the great movements of the time. I see men and women whose minds only revolve around drills and exercises, lessons and exhibitions, visits of the superintendent and rules of the board of education, the return of payday, the possibility of advancement, the victory of yesterday and the contest of to-morrow."

${ }^{2}$ Jakob Bolin, "Mind and Body," Vol. XIV, p. 234. 
So long as these conditions exist, schools of physical education constitute the greatest obstruction to the adoption of athletics as a part of the educational system and to raising its standard above the plane of commercial competition. It is not a question of their disapproving of or restraining athletics, for beyond all power of their control, it is settled that girls will play-just as settled as that women will work. The question is, will these schools become an intelligent force in creating and maintaining a high standard of athletics or will they belittle, exclude or ignore them and confuse the public mind as to their value, because they are not strong enough to meet the problem of their danger?

Schools of Elocution and Oratory.-While these do not ordinarily profess to train instructors in athletics, as a matter of fact many of their graduates are required to take charge of them in conjunction with other subjects of instruction. Furthermore, in many private schools their training is considered sufficient, and their graduates are unhesitatingly accepted as teachers. In reality they offer no instruction whatever in either the theory or practice of athletics. Furthermore, their training is opposed to social education. Oratory, Delsarte, vocal expression, dramatics, music, reading, etc., and the emphasis placed upon presence, grace, poise, are intensely individualistic. Valuable as these are, they do not train teachers to develop group qualities in players. Even when courses are offered in physiology, anatomy and psychology, they retain their individualistic stamp, as 
where psychology is made to mean chiefly "psychic development" or "soul expression."

Our purpose is not to criticise these schools, but merely to point out the necessity for avoiding a confusion of teachers of " physical culture," trained in schools of elocution, with instructors of physical education who are capable of teaching gymnastics and athletics as a means of social education and as a basis for health and recreation.

Normal Schools.-A number of normal schools, including some of the best in the country, have practice classes and frequently maintain teams which play match games with other schools. But none of those answering our inquiry maintains courses of instruction in athletics. Basketball is usually the one game played, theugh hockey is growing in favor. Graduates of these normal schools are constantly required to teach "main subjects," as history, English, etc., and to take charge of basketball and other games.

Universities and Colleges.-These also supply teachers, but few maintain courses in athletics. One of the best offers a course in physical education which includes personal hygiene, school hygiene, gymnastics ( several courses), anatomy, anthropometry, diagnosis, corrective exercises, history of physical education and kinesiology. Notwithstanding this broad cutline, only practice is offered in athletics and fundamental theory work is, as usual, absent. Ordinarily the course in colleges gives a working knowledge of games, though they are in all cases elective while gymnastics are required. So the student may under- 
take to give instruction upon the representation of so many years of "gymnasium work" without having had any practice in athletics or any theory, or lectures on such subjects as anatomy, physiology or hygiene.

It is a common occurrence for universities to receive a request like this from its students or graduates: "A good position has been offered me to teach history and English in X- high school, but I have to teach physical culture too. Can you send me good books on the subject or make suggestions? I wish now I had taken some athletics while in college." The college can do much to raise the standard by refusing to recommend its untrained students for teachers' positions.

Sometimes colleges undertake to add physical education departments without understanding the situation. One Southern college for women makes this announcement:

"With the growing interest in out-of-door sports throughout the country there has come an increasing demand for trained teachers of athletics. It is our purpose to prepare teachers to intelligently direct this department."

Then follows an outline of a two years' course, consisting entirely of gymnastics with this one provision for athletics:

"Students desiring this certificate must have one year of physiology and hygiene and two seasons' work on the hockey team. In addition all the students are or- 
ganized into an athletic league having for its object the control of the sports."

Employing Schools.-It is undoubtedly true that the present standard of athletics is, in a large measure, due to the foresight and conservative attitude of some of the institutions that train teachers, and some have shown much courage in preventing unqualified persons from entering the profession. But this is not true of all and should not relieve the employing school of its responsibility. It has in too many instances been content to rely upon the reputation of the training school and to assume that having a graduate or pupil of this or that school left nothing more to be desired. The employing school can assist in maintaining high standards in the following ways: Before engaging an instructor, it should know fully what her training has been, see her credentials and know personally that she is what she is represented to be. In order to select teachers intelligently, heads of employing schools need to know the requirements of the position and not ignore or belittle the work as is sometimes done. For instance, from private schools frequently come such requests as this: "Can you send me some one qualified to teach mathematics and history, stating her experience? She must also take charge of basketball."

Increased care in the selection of teachers is also made necessary on the part of the employing school because deceptions are sometimes practised upon them. In their competitive desire to place teachers, 
some training schools are likely to recommend pupils, thinking they are more capable than they really are. Again, pupils in their desire to obtain positions are unsportsmanlike in trading upon the names of wellknown instructors and training schools, and thus hurt those who really desire to place only competent teachers. A person who has made charts or kept class lists or schedules of swimming or has recorded measurements taken by prominent instructors will advertise herself in school catalogues and letters as " assistant to Dr. X_—" or as assistant in "School A-, "when she knows nothing of the principles for which they stand and was not selected by them because of general proficiency. Others attend athletic practices on the note-book plan but do not hesitate to say they have "taken the work." Such pupils have missed the training which develops modesty and gives a sense of proportionate value. This dishonesty may be prevented by employing schools exercising more care and by instructors and schools combining to raise the standard and punish misrepresentation. It is true misrepresentations occur in all lines of teaching, but the person who obtains a position in athletics in this way is hardly one to use games to bring out the noblest qualities.

Summary.-In a word, then, if women are to receive social education, by means of athletics as a part of their general training, the prime essentials are wellqualified instructors who have received broad, fundamental training in schools of physical education; a higher standard of athletics maintained by these 
schools; and greater care and honesty in recommendations as well as greater intelligence and discrimination on the part of employing schools. Without these, athletics may never rise above competitive games played to win-where and how players choose. 
PART II

PRESENT CONDITIONS 



\section{CHAPTER IV}

\section{ATHLETICS IN SECONDARY SCHOOLS}

\section{HIGH SCHOOLS}

THE increasing participation of high school girls in basketball and other athletic games led the writers to make an inquiry into the condition in high schools. Owing to the lack of supervision by school authorities and the great variations in the control of athletics, it was difficult to obtain a satisfactory and representative view of the situation. The material gathered is therefore presented quite as much in the hope of stimulating further investigations as for the purpose of urging the adoption of a more uniform system of control.

A discouraging number of schools provide athletics for boys but none for girls. Among the others two extremes are apparent. In the first group, there is an absence of school regulation, no object other than to win games, and the whole matter is in the hands of the girls or of the "professional coach." In the second, all use of the school gymnasia or of the school name by teams is forbidden. Schools outside of these two groups adopt various plans, as for instance that of placing athletics under the supervision of an outside organization such as a public 
school athletic league, or permitting pupils to practise wherever they can find a place and to maintain teams under the school name. Wide variations in control are found sometimes in cities where the schools themselves are all under one management.

Conditions in Schools.-Nowhere else are to be found such contrasts, lack of system and absence of intelligent supervision as in high schools. This is best shown by some of the answers to our inquiries:

" The girls who play basketball are formed into an athletic association. The school asked me to take charge of the games, which I did. I found that I had no official position, the school no power, and that the girls had entire control. They practised in an armory twice each week, coaching themselves or paying a man to come in for extra practices. They averaged one competitive game each week with other teams, during the season. There were no examinations made of the girls and they played at all times and would not submit to any withdrawal from contests. The permission to play games and the challenges passed through the principal's hands, but there was no restriction, and no teacher was required to attend the games, although the girls made journeys frequently to other towns to play high school teams. They would start off attended by groups of boys and often return late at night.

"The games were always public and many were played in the evening. Any one who paid for his ticket could attend. We frequently played double headersthe girls' teams would play one half, then the boys' team one half, etc. If both the boys' team and the girls' team from the same town won, they took all the gate receipts, otherwise it was divided. In this way the teams covered expenses and divided the surplus if there was any. The game was usually followed by a dance at one of the men's clubs or in the hall where the games 
were played. If in the hall, the men in the audience indiscriminately joined in the dance. These games were characterized by much unfairness and scrapping. Coaches ran up and down the side lines giving instructions, roughness was unchecked, and the players boasted of their ability to trip players and not be seen owing to their baggy suits, or afterwards described mean tricks that had won the game."

"We have no department nor gymnasium, but the girls play basketball, though not in the name of the school."

"We have no gymnasium or instructor, but the girls have a basketball team, which is partly regulated."

"The captain and girls have charge of basketball and use the gymnasium twice each week. The school has nothing to do with the matter. The girls belong to an inter-school athletic league which runs the contests."

"The manager of the debating society has charge of the games.".

"The county league arranges all details of contests, players, etc."

So far as it is possible to make any general statement summarizing the conditions, the following seems to be fair:

The instructors were mostly " coaches," engaged by the girls to win games, and were often without academic or special training. Where instructors also taught other subjects, they were often untrained in athletics or did not take them seriously. Where members of the faculty were placed on executive committees and boards of control of county and interscholastic leagues, they frequently had no general or technical knowledge of athletics, and lacking a veto 
power had little authority. Athletics had little or no part in the educational system, and were rather looked upon as exerting a harmful influence upon studies and the general intellectual work of the school. In many schools there was not only no relation between gymnastics and athletics, but in some there was constant disagreement between the gymnastic instructor and "coach" as to who should use the gymnasium. Eligibility to teams was in a few instances based upon academic standing, while in others this was true only in theory. In most cases, contests being outside the control of the school, academic standing was not considered at all. General ignorance existed on the part of school authorities and parents as to what was going on. The officials were chiefly men, and with few exceptions the games were open to everybody. Many favored pay games and as a rule prizes were offered. The captain, "coach" or girls selected the teams, and physical examinations and tests played no part in this selection. Where leagues and associations existed they were primarily for the purpose of increasing and managing competition and for raising money.

The returns from the various high schools showed a general neglect of such fundamental matters as preliminary gymnastics, relation of athletics to diet, rest and study, limitations of practice periods, and of excessive physical exertion and high nervous tension. In some instances from five to twenty match games were played during a season, interfering with study and causing over-exertion on the part of the girls. 
The increase in professionalism was clearly indicated. This is detrimental to moral growth, since no standard is set before the players except to win by fair or foul means; and to refinement of feeling, because of the bad spirit engendered. Furthermore, in some schools the monopoly of the gymnasium by the teams prevents the mass of girls from receiving adequate physical training.

Undoubtedly, even under these conditions, considerable experience is gained, but it may be bad or good, and in either case it is at great physical cost. It is not infrequent to see young girls collapse in these high school contests. A typical list of ref reshments eaten between the halves of a hard game or immediately afterward includes pie, cream puffs, chocolate éclairs or charlotte russe, varied with peanuts and popcorn; and a championship contest is often followed immediately by hours of dancing. High school contests are also conspicuous for the bad spirit shown. Attacks upon officials, wrangling of teams, calling of names, bitter denunciatory remarks about opponents, intentional roughness, fault-finding, " rattling of players" by school girl or boy audiences, and personal characterizations are common in games where players alone are in control.

There are, of course, many schools where such conditions do not prevail, but this is a fair statement of general conditions, and is indicative of the growing tendency, especially in schools of the Middle West. Wherever these conditions did not prevail, we found not only that the school authorities had a voice in the 
management of contests but that they maintained some supervision of practice periods.

The responsibility for these conditions rests primarily with school authorities, but also with parents who do not insist upon proper regulations. That many of the former recognize the need for improvement the following replies show:

"This year I made two stands-first, that of the requirement of a physician's certificate for basketball practice, and second, the prohibition of practising or playing during menstrual periods. These two points are not insisted upon in all our high schools and I have seen some girls collapse on field and suffer illness of days from lack of oversight on part of coach, physician or mother. Lack of observance of a girl's condition is sometimes amazing. I believe that every coach should be merely assistant to the physical training instructorthe latter having full charge of every phase of work. This for development of physical, moral, social qualities of girls."

"I regret to say that no provision at all is as yet made for the girls. As regards teams and match games among girls, I am fully convinced that great care is necessary in the selection of girls for such teams and as to procedure in such contests. In my judgment no match games between girls of different schools should be permitted. I should encourage games between girls of the same school; I would restrict admission to invitation. We hope that we can have physical training for our girls in the near future under a competent instructor."

"Organized games in the open air take the place of formal gymnastics for one half of the school year. These games are not optional but are a part of the regular school work and taught by the physical training teachers. Girls are not asked whether or not they wish 
to play; all the twenty-four hundred play except the very few excused for good reasons by a physician. As far as can be arranged, each class has two forty-fiveminute periods weekly during school hours for this purpose in the last ten weeks in the spring and the first ten weeks in the fall. Four teachers and four classes may be seen in the yard during most of every day."

"We have considered the question of athletics for girls and passed the following: "Resolved that all interscholastic competition is unwise under the present conditions; that the same results can be obtained by interclass games; thus avoiding all the adverse conditions and results of inter-school contests.' We also took a stand against all publicity."

Public School Athletic Leagues.-A movement which is regarded as a solution of some of these problems takes the form of public school athletic leagues. A girls' branch was started in New York City in 1905, and is maintained by a group of public-spirited citizens along the following lines:

"First-That it has to do with the pupil's free time rather than with school activities. Second-That, in the nature of the case, participation must be wholly voluntary. Third-That it might be possible to cooperate more perfectly with existing athletic organizations, both in and outside of this school system, than would be possible if the organization were official. Fourth-For financial reasons, for while public sentiment and precedents with reference to the support of athletics remain as they are, it would hardly be possible to secure from the Board of Education, nor would it be justified in appropriating the very considerable sums needed for the development of these athletics. If the League were officially under the Board of Education it would not be possible to solicit funds for the support of 
the League, charge admission to games, give prizes having intrinsic value and the like. Fifth-It seems necessary that there be an organization in addition to those which are carried on by pupils themselves, because the financial and administrative problems in such a city as New York are altogether too great to be handled successfully by the comparatively inexperienced and rapidly changing group of pupils. This must be done by a body having the financial confidence of the business men of the community, and of the school authorities themselves." 1

The aim is stated as follows:

"To devise and promote athletics for girls which will make for health, stamina and grace in the elementary, high and collegiate departments of public educational institutions of the City. To encourage the development of forms of exercise and recreation suited to the needs of the mass of schoolgirls, and which will secure for them the benefits and avoid the evils which have been developed in connection with athletics for men. The general principle followed by the Girls' Branch is to develop work within the school rather than competition between schools, and to select events in which teams rather than individuals may compete." 2

Active membership is based on subscriptions and honorary members are elected. Membership confers no ownership in any property. The management is vested in a board of directors, elected at the annual meeting of members, and consists of not more than forty-eight persons. An executive committee has all the powers of the board of directors when the latter is not in session. The president may appoint a game committee to consist of three directors which shall have charge of all games authorized by the League.

${ }^{1}$ Report of Board of Education, 1906.

${ }^{2}$ Report of New York City Athletic League, 1906. 
It is the policy to provide trophies for which the various classes compete. These consist of bronze plaques, silver cups, etc. Some of the girls are organized into various leagues which contest for these prizes, as do also the various classes. A League pin also is to be presented to each public school girl who is able to pass certain prescribed qualifications.

For admission to classes every girl must have attended school for one month and must have received the mark of " $\mathrm{B}$ " for the month previous and " $\mathrm{A}$ " in effort and deportment. One of the interesting and valuable features is the method of training teachers. The Girls' Branch offers :

"A course of dancing and athletics, free of expense, to public school teachers, who will give in return one lesson per week to girls of the schools from which the teachers severally come. It is a remarkable fact, and one significant of the benefit and pleasure derived by them from this training, that one hundred and seventyfive teachers with endless demands upon their strength and time should voluntarily elect to attend these free classes, and give in return an equal amount of time to the instruction of girls of their own schools, thus giving up two. afternoons each week to the work."

The Public School Athletic League of Cleveland, which is still limited to boys, differs in its organization in that it is within the school and is controlled by a Senate which consists of the supervisor of physical training, two members from the faculty of each high school, and one representative from each elementary school. The high school members are appointed by the principal of the school and may be retired by him. 
The funds are raised by a finance committee appointed by the chairman of the Senate. Membership in the League consists of such athletic organizations of the public schools as are approved by the principals concerned. Honorary members are elected and all persons contributing over $\$ 50$ become patrons.

Those interested in the recreative features of athletics will find ample cause for congratulation in this movement. On the other hand, those interested in social education cannot but be disappointed. We have been unable to find that much emphasis is placed upon the educational value of athletics for girls, or that those interested in the movement are endeavoring to prepare them to meet the increasing social and economic demands which will be made later after they leave school. The plan of excluding from classes pupils not having an "A" or " $\mathrm{B}$ " standing, especially in deportment, may shut out the ones most in need of them. There is a tendency, made necessary to some extent by the limited space and great numbers of pupils, to minimize the value of organized games and to emphasize dancing and class athletics. The competitive element and prizes are also conspicuous.

At this time, when the interest in athletics needs stimulation it is perhaps necessary that a group of interested citizens should support a work which doubtless could not otherwise have been started. But we believe that the principle should not be lost sight of that the control and support of this branch of work should rest with the school system. The number of pupils is so great and the educational possibilities of 
games so broad that athletics should be included as a part of the educational system and be supported by taxation or by gifts directly to school authorities. Their social educational value is so fundamental that their continuance should not depend upon a philanthropy which must vary with stock markets and business depressions and commercial fluctuations. As the best exponents of democracy, games should be incorporated in our most democratic of institutionsthe public school.

Country School Athletic Leagues.-The public school athletic movement is not confined to city schools. In one state it has been extended to small towns and country districts. One of the normal schools started the movement, and with the co-operation of the district school commissioner conferences are held which are attended by children and parents. It is an all-day affair and practical demonstrations of school work are given, including athletics in which the girls participate. Besides fostering clean athletics, it brings the schools together at least once each year in a field day and picnic. At the second field day held by this League there were present 1400 school children, 200 high and normal school children and about 1400 adults. Girls as well as boys took part in the contests. Owing to the expense of paraphernalia, no very wide use has been made of the highly organized games, but they are to be introduced. ${ }^{1}$

'Scudder: "Field Day and Play Picnic for Country Children," pamph., 53 pp. 
If the use of athletic games can be widely extended in villages and small towns by some such movement within the schools it will prove a strong socializing influence, brightening farm and village life, and training school children in many of the qualities necessary for group work and useful citizenship. Nowhere are the training and play spirit more needed than among girls in small towns and rural districts. While they live more out of doors and under better conditions for health than the children of cities, these very things tend to make parents feel that play is superfluous. Parents in rural districts are especially out of sympathy with play, and think if a girl is strong enough to work it is enough. But the country girl is often unevenly developed, and sometimes organically weak while she is muscularly strong, and moreover needs the exhilaration, interest and joy of games. She is perhaps even more individualistic than the city girl and more in need of group training. Games in small towns and rural districts now possess little variety and so give little opportunity for team work. Both the girl and her parents need play, and organized games and country school leagues are taking a long step in the right direction.

Suggestions for Improvement.-On the whole, notwithstanding these and other efforts to improve present conditions, athletics in high schools undoubtedly present serious dangers. There is the greatest need for regulation, supervision and the relating of athletics to other school work, etc. We do not believe this will be brought about until a thorough in- 
vestigation is made of the subject, including a careful and impartial study by a well-trained investigator of existing methods, rules, requirements, conditions, instruction, practice, competitive games, surroundings, organization, control, etc. If the results of such an investigation could be laid before a conference representing the various boards of education some uniform standard and regulations might be adopted.

In the meantime it may be far wiser to abolish entirely or greatly restrict all athletic competition by girls in high schools unless the following minimum requirements are made: All practices and contests to be under the control of a trained instructor who is approved, paid by and responsible to the school authorities; no girl permitted to play basketball without a physical examination and unless she has had some previous setting up gymnastic work; abolition of pay games and professionalism; and a wise restriction of the number of interscholastic contests.

No one wishes to see athletics for girls degenerate into "win at any cost" contests, and there is yet time to give them their rightful place in the high school educational system, where they are greatly needed for training in citizenship, if the school authorities and parents will but take the matter in hand.

\section{PRIVATE SCHOOLS}

Private schools present a most important phase of the question, as their pupils have less opportunity for social education than girls in public schools. They are frequently spoiled and petted at home or have 
been so pampered with luxury that their point of view is largely individualistic. The opportunity and responsibility of the private boarding school is greater than that of the public school, for it has the entire training at an impressionable age.

Whatever its size and purpose, wherever its location and no matter how varying its methods, the function of the private school in the educational system is the same from the community's point of view, namely, the development of each girl as an individual factor, as a social factor, and increasingly as an industrial factor in our civilization; and the development of the social as well as individual conscience. That some of them fail so to regard their function or fail in its accomplishment does not in any way change their responsibility to the community which makes this demand. The school which considers that it has no obligation other than to the pupil and her parents and that the community has no interest in its methods or " business with its affairs" is not discharging its indebtedness to the same community which provides it with facilities, protection and a hundred things which make its material success possible.

Conditions in Schools. - What part have athletics in meeting this opportunity and responsibility? We believe that the conditions found in nearly two hundred schools are fairly typical, since our study has covered every kind of school in nearly every state, including the seminary, day school, boarding school, academy, co-educational institution, small college conducted on boarding school principles, out of town 
school with broad spacious grounds, and the city school which uses its roof as a playground. That athletics have an increasingly important place in the school life is shown by three things : increased athletic facilities; wide adoption of games for recreation; and the beginning of a belief in their educational value. Fully ten per cent. stated that they were building new gymnasia, acquiring grounds for games or that they had made arrangements to use other gymnasia. Sixty per cent. had some kind of an indoor place for work, but unfortunately not all made provision for games. Indoor tennis, ring hockey, indoor baseball, longball, captain-ball, etc., are therefore unfortunately omitted.

The grounds of many schools afford good facilities for such games. Seventy per cent. make provision for games out of doors and the remainder insist upon walks or individual sports ; seventy per cent. have tennis courts; 65.7 per cent. basketball courts; 23.5 per cent. hockey fields; and nine per cent. provided for baseball. The athletic field is also gaining a place, and fifteen per cent. have real fields and field days. One city school utilizes its roof and others maintain summer camps.

When the facilities have been described, practically all has been said about athletics in many of the schools. There are exceptions, but the great majority think they have done enough when they make it possible for girls to play. The prevailing sentiment is that the function of games is to provide recreation. This is, however, a distinct gain within 
the last decade, for previously the majority did not even consider games and much less "athletics" as deserving mention in their announcements. A few of the typical announcements, taken at random from the catalogues, show how very limited the idea of athletic training still is :

" The object is to develop strength, elasticity, proper breathing and correct position in walking and standing, thus giving natural development, ease and grace of manner."

"We mean by physical culture the development and refinement of the entire physical person through cultivating it to express the purpose and emotions of the soul."

" Our system aims at co-ordination, control and symmetry rather than over-development, provides for those who wish to build up their physique and to keep in healthful condition, and furnishes a series of esthetic movements as a means of obtaining poise, grace and suppleness."

A second group puts more emphasis upon the maintenance of health:

"Our effort is to give enough physical culture to maintain an excellent average of health."

“ The object in physical training is all-round development. In order to work intelligently" and avoid injury from improper exercise a careful examination is made at the beginning of the year by the medical examiner. The results with the various strength tests determine the character and amount of exercise."

"We have a teacher, not to emphasize the athletic side, but to prevent excess by her presence and influence. We also recognize the importance of health and a happy, 
life and believe it is the foundation for the best intellectual work and for strong character development."

In but one case was physical training decried as " unladylike," but others made it clear that it was merely tolerated and that a great deal of ignorance exists as to its value even for purposes of recreation. Some of our correspondents thought because our inquiries emphasized athletics that we were looking for a school or sanitarium for a delicate girl, not realizing that athletics should be a normal part of her training. Typical of the replies of this discouraging group are the following:

"Much injury is done girls by gymnasium work in groups. During this developing and formative period of a girl's life when her strength is at its lowest ebb, the general course of work should be entirely individual. Another means of injury is this-the stimulation and competition natural in a group of girls incites the less strong to overdo in order to stand on a par with the others or to excel."

"I should regard measurements as unwise and needless in the case of any girl whose health admits of serious study. The place is really a school, but not in any sense a sanitarium."

"Encouragement is given to athletics so long as they do not interfere with school work."

"Pupils come primarily for work and no work time can be devoted to games."

Some of the schools make a clear distinction between gymnastics and athletics, the former being required and under supervision while the latter are 
not. One instructor writes: "Gymnastic drills are given under competent instructors and the gymnasium is open at other times for the recreation of students." In co-educational private schools the facilities for athletics are frequently better, because the demands made by boys lead to some recognition of the needs of girls. But even here girls have less opportunity. One school announcement says: "Athletics receive proper attention but are not carried to excess. Young men are taught to be manly and fair." But no mention whatever is made of their ethical or other value for girls. Another announcement makes this rather astounding statement: " He who educates a boy educates an individual merely, whilst he who educates a girl educates a family."

Such statements as the following show that the belief in the educational value of games is slowly growing:

"Baseball, basketball, captain-ball and tennis are popular. They teach quickness and loyalty to each other, fairness and unselfishness and earnestness of purpose and desire to do one's best for one's self and team."

"We believe that physical culture should be adapted to the development of girls and should train the mind to quick decision, alertness and poise, as well as give strength and grace to the body."

"The aim of the school is to develop the girl ethically, mentally and physically; to teach her moderation, self-control and poise, to point her to the perspective .which determines relations and responsibilities, to enable her to meet situations, to understand life and to live." 
"It is perfectly possible for a girl who develops most in mind and body to develop also in the fine and womanly art of being charming."

On the other hand, we suspect that the schools are somewhat hampered in their progress by the attitude of parents, as is illustrated by the following statement :

"We did require gymnastics and athletics of all girls, but found parents so indifferent and a physician's certificate for excuse from physical training so easy to obtain in spite of good results that we reluctantly gave it up for day pupils."

Many parents do not recognize play as an essential part of childhood, while others are afraid that their daughters will be injured. Too often the girls themselves are lazy and are excused on one pretext or another because they do not like the work. Instead of supporting the school, pupils, physician and parents together frequently resort to deception to obtain an excuse. If parents and physician would make careful inquiry about the work, insist upon a high standard where poor work is given and support the school in upholding a good system, much more could be accomplished both for health and character.

Our study shows two great defects : First, that while girls have opportunity for play they are not taught as is seen by the qualification and attitude of instructors; and second, that the use of games is limited to recreation, as is seen in the methods of instruction.

Instructors.-The first defect is clearly shown by the requirements for teachers. It has been difficult to 
ascertain the training of instructors. In some cases the replies have been full; in others we have been assured that the teachers "are specially trained," while no details appeared in the catalogue or letter. Ordinarily in the private school catalogue the name of the physical training instructor appears near the foot of the list and often without the history which accompanies in full other teachers. To the lay mind the school announcement may also be misleading. It understands that training in Latin means Latin, and mathematics means mathematics, but " physical culture" may mean Delsarte, oratory, musical or vocal expression, gymnastics, athletics or corrective work, but not necessarily any one or all of these.

We found that in fifty-seven per cent. of the schools the instructor had attended schools of physical training; in thirteen per cent., schools of elocution; in twelve per cent., seminaries, colleges or similar institutions; and in twenty per cent. no training was claimed other than general education. In two the faculty and students had joint charge of the work.

It was found that where there were both basketball and baseball, all the instructors had attended a school of physical training. Where basketball and hockey were played, sixty-one per cent. had attended such schools. Where basketball alone was played, fortytwo per cent. had attended physical training schools; ten per cent., schools of elocution; ten per cent. had received only academic training; and thirty-eight per cent. had no training other than general education. All of these instructors took charge of the games, al- 
though less than half had received training qualifying them to do so.

In twenty-one per cent. of the schools, the instructor taught no work other than physical training. In thirty-two per cent. she had elocution, dramatics and physical culture; in fourteen per cent., physical training and hygiene or physiology and mathematics. In the others, history, English, grade work or languages were combined with physical training. In twentyfour per cent. we were unable to get definite answers as to whether the instructor had other duties. One reply was, "The instructor is available for any service she may be called upon to render."

As a number did not answer the question, we believe that these percentages are above rather than below the number of those who have received training. It does not always follow that those who claim training are better instructors. In one school where the instructor had charge of baseball, basketball and hockey, she appeared in the catalogue as a graduate of a physical training school and also as having attended a summer school. In the first she had received no instruction in athletics and in the second she failed in her examinations and could not play one of the games that she " coached."

The chaperon "coach" is still a feature. She sits on the lawn by the courts, reading a book and from time to time observing that no bad language or disputes occur, but what does she know of the meaning of the game or of team play or of exhilaration or strain? Are the girls being educated in fair play or simply. 
finding an outlet for a petty, mean spirit? Are they playing according to rules or making their own rules? Are they gaining in discipline or simply wasting energy? One correspondent sent in this definition of the supervisor of games: "A person to see that the girls have proper clothing and change it properly." In physical and moral development what is the relative importance of taking a cold or of becoming a sneak and a cheat?

Such a game as basketball, played in sixty-five per cent. of the schools, presents such important physical and ethical problems that it should not be played by girls without competent supervision. It is not entirely the fault of training schools and of teachers that so many positions are filled by untrained persons. Some private schools furnish such poor facilities and interfere so much with the work of the instructor that a trained person cannot afford to accept the position. One teacher refused to admit girls to basketball practice because they were physically unfit. They appealed to the principal and she decided that they could play. In another instance the principal objected to a strict observance of rules and upon a protest from the instructor said, "Well, they can get some exercise, no matter how they play." Physical training is considered so unimportant in some schools that the most trivial things are permitted to interfere with the classes-a thing not tolerated in any other department.

It would be a good thing if private schools would abolish the use of the term "physical culture," which 
has come to mean almost anything. There are physical culture systems, restaurants, furniture and magazines. Less than one-fifth of the schools designated their work as physical training, not one as physical education, and the rest called it " physical culture," whether it included Delsarte, elocution, reading, dramatics, breathing exercises, medical gymnastics, athletics or simply walks.

Methods of Instruction.-The prevailing methods of work in many schools are open to much' criticism. In a number, an extra charge is made for athletics or for the use of paraphernalia. In some the girls are able to pay; in others those who most need the games do not choose them, as they are considered a luxury. Class distinctions, 'based on purchasing power, are thus raised. It is desirable that schools give the matter careful thought and endeavor to bring athletics within the regular tuition. The practice of requiring pupils to furnish their own basketballs, tennis nets, etc., is open to the further objection that a few control their use and it is more difficult to supervise the work properly when the school does not own the outfits.

A second defect lies in the relation of gymnastics and athletics. The latter are almost invariably elective and girls are permitted to go into strenuous games without any preliminary training. In some cases athletics are substituted for long periods for all regular gymnastics.

The importance of measurements and of examinations of heart and lungs, in schools where there are 
growing girls, cannot be overestimated. Great care is now taken that a girl's eyes shall be tested before she undertakes study. Why not be equally sure that her body is sound before she makes great demands on it? Of the schools reporting, fifty-three per cent. take "some kind of measurements"; eight per cent. " make examinations"; five per cent. give "special examinations for medical and corrective work" ; fourteen per cent. mention no examinations and measurements; and twenty per cent. do not make any whatever. No instructor can intelligently work with each girl without an intimate knowledge of her condition. A few schools realize this and have placed special emphasis upon it, including also blood tests and detailed family history. There are several percental charts which make it easy to take these measurements, and their intelligent use would eliminate many of the evils of over-work.

The average amount of time given to physical exercise (if we include walks, upon which much stress is placed by many schools) is fair. The prevailing plan appears to be to have out-of-door sports and work during late fall and early spring and gymnastics during the winter. Very few of the schools give systematic daily work. It is usually two or three times a week. The time required to be spent out of doors averages between one and two hours daily. Where gymnastics and athletics are combined, about one-third of the time is given to the latter.

Some of the schools appear to have no system whatever so far as athletics alone are concerned. The 
girls play when they wish or when they can find time. A few city schools that have no facilities encourage their pupils to use private gymnasia. This is ordinarily at the individual's expense, there is no school supervision and the girl chooses both the amount and kind of work. The school makes careful inquiries into the reputation of the gymnasia but does not extend them to an intelligent scrutiny of the work offered.

Athletic Organizations. - Not the least important is the increased emphasis that is being placed upon the social side of athletics. Formerly no commencement or class day recognized them in any way. The formation of athletic associations, which encourage student self-government, and the introduction of field days and athletic events on social programs, are now quite common. It is gratifying to find that so many schools have these associations. They are helpful in stimulating interest, in developing school pride, in taking the girls out of doors and in bringing people together in pleasant democratic relations. Where some of these results are not accomplished, it is because the organization has fallen into the hands of a small clique or something else is wrong. Athletic associations accomplish many other things. In some schools they have charge of the sports or furnish the trophies for contests; in others, where interscholastic contests are played, they arrange for the contests and entertain the visiting teams. They may also arrange for field days, class games, banquets, etc. One school association in Colorado is equipping a small gymnasium with apparatus for one of the city 
settlements. The heads of schools speak well of these associations, as is indicated by these statements from principals :

" The athletic club stands for the best physically, mentally and morally, and by admitting to it girls who have proved themselves superior it is a strong influence for good."

"The athletic association maintains the rational and sound love for out-of-door sports."

" They create the love for being out of doors, and their moral value is in teaching self-control under defeat and in being courteous to visiting winning teams."

"Healthy competition within the school is encouraged and is a matter of school pride and is a strong stimulus to increased zeal in preparatory work. Athletic honors won by our girls in college are a cause of congratulation, implying as they do that examinations have been passed, and a good all-around development maintained. Some girls who have won such honors have also become president of their class."

Most of these associations have fees varying from fifteen cents per term to five dollars per year. Care needs to be exercised that the fees are not prohibitive. It is more important that many girls should be members than that a large number of entertainments be furnished with the funds.

Suggestions for Improvement.-From a careful study of the situation the following needs appear to merit serious consideration:

1. Increase in the variety of games, and the introduction of minor games of ball, as long-ball, captainball, etc., and the wider use of gymnastic games for small girls. 
2. Use of organized games to a greater extent indoors during the winter.

3. A closer connection between gymnastics and athletics, and use of the former as preparatory work for organized games.

4. Introduction of measurements, tests and examinations which will make physical training more intelligent and effective.

5. Co-operation of parents and physicians in establishing good systems of physical training. It is a question whether under any circumstances a girl excused from all physical training should be permitted to take full mental work. Some pupils obtain such excuses in order that they may give more time to their studies. The adoption of a rule that any girl excused from physical training should take only a minimum amount of mental work or less than a full year's work would tend to lessen unnecessary excuses.

6. Physical training as a part of the recognized educational work and compulsory for at least part of the school period and in charge of a competent instructor.

7. Abolition of athletic privileges and opportunities based on purchasing power.

8. Increase in the number of summer camps maintained by the schools, where girls can be out of doors. In these camps, organized sports and recreation should have a prominent place. 


\section{CHAPTER V}

\section{ATHLETICS IN UNIVERSITIES AND COLLEGES}

IN one respect colleges occupy a most important position. Secondary schools invariably look to them as guides and take pride in having their students make a good showing in the college they enter. Their athletic standard is therefore largely influenced by the conditions prevailing in colleges. Secondary schools do not lay much emphasis on social education, and it is therefore in the college that the student finds her last chance for character-building through athletics before she becomes an active and important factor in the world at large.

A few colleges have measured up to their opportunity by creating departments of physical education with faculties similar to those of other departments and whose instructors are members of the college or university general faculty, with a voice in the administration of the entire institution. But in far too many of them, the " coach" idea is still prevalent and athletics are encouraged because they furnish good exercise and maintain health. Athletics are not only entirely elective, but in many instances no efforts are made to make them attractive. Great scholars and good libraries attract to the courses in 
literature and philosophy, but any one will do to teach athletics and any old shed or corner is considered good enough for practice.

When cities were smaller and there were vacant lots and yards and wide halls and big rooms in which to play, children received more of the much needed group training in a natural spontaneous way. But now many girls who go to college have been brought up without a playground. The absence of the play spirit and opportunity for play are bound to make a difference in the character and to increase strenuous living. Groups of college girls turned loose in the gymnasium to play for the first time stand about awkwardly, asking each other if they know a game or what to play and usually the experiment is a flat failure unless a leader is provided. When girls lose the play spirit so young, one cannot expect much from them as mothers except a loss of companionship with children and an increasing interest in nursemaids and attraction toward a business life.

Small Colleges.-Our problem has been to find out what colleges and universities are really doing by means of athletics to set a standard and to influence public life by turning out good citizens. We find that midway between the secondary schools and universities are a large number of institutions which give degrees and call themselves colleges. In athletics they are best classed with private schools. Very few provide systematic instruction; some have no work whatever; while in others it is voluntary play. It is not our purpose to discuss conditions in these colleges, other 
than to note that the conditions here are similar to those previously described for private schools.

Graduate Schools.-Other institutions which neglect athletics are graduate schools. Graduates are rarely required to take physical training, have usually acquired the study habit and are not interested in athletics, a condition as bad for them as for the community. The college as a rule does not make physical training sufficiently interesting to attract graduates, nor does it adapt it to their needs.

There remains, then, a large group of private, state and city institutions which represent the collegiate world, to which the state looks for well-trained citizens and secondary schools for guidance. In our study we found that the usual games were basketball, which was played in every college studied; hockey in fifty per cent.; baseball occasionally; and minor games of ball in a few. In contrast with other institutions most of the colleges admitted that it was necessary to stimulate interrest. This was done in various ways, the athletic association being of most help, prizes second in importance, competitive games third and inter-collegiate contests last.

Instructors.-The instructor has a much greater authority in the training and selection of teams than in any other institution. In some there is no appeal from her decisions. There is one group, chiefly Eastern colleges, in which much of the authority is vested in the athletic association, as is shown later. In less than five per cent. the instructors were men. In twenty per cent. they had had no special training and 
of the remaining eighty per cent. about five per cent. had had only summer school work. While this is a good standard, one would hardly expect to find in this group men " coaches" who trained girls for outside contests; or instructors who had had no special preparation. The tendency is to require academic degrees, but less than ten per cent. of the instructors stated that collegiate training had been part of their preparation.

The most discouraging features found were the absence of an educational use of games and isolation of the department of physical education from other college activities. This is partly the fault of instructors who still continue to emphasize only the health and recreative features and who seem to fear the power of athletics. The competitive element alarms them, and in some instances restriction more than regulation is the method of control.

Inter-Collegiate Contests.-The colleges are divided on the question. Most of the women's colleges in the East and many of the co-educational institutions do not play outside games but have inter-class contests. Occasionally they play a game with their preparatory school or with a normal school. In the Middle West and West, inter-collegiate contests are more common, but the percentage playing them there is less than one-half. With the exception of an occasional ball game, the officials are generally women and the audience is admitted by invitation. Very little of the evil of pay games exists and the spirit of professionalism seems well under control. This is partly 
due to the financial support given by the college, which is absent in high schools and only partial in private schools. The college demonstrates that athletics can be successfully conducted and large numbers interested by the substitution of inter-class games, class prizes and athletic associations for interscholastic competition and public pay games.

Systems of Work.--These vary greatly. In about ninety per cent. of the colleges, uniform standards, with varying degrees of thoroughness, exist. Measurements are made and training is based upon them. Few allow girls to play basketball without heart and lung examinations. Gymnastics are ordinarily required. In one institution a year of gymnastics is required before such games as hockey and basketball can be played at all. In another, they can play all other games but basketball without having had gymnastics. The proportionate amount of athletics and gymnastics is unequal, being about thirty per cent. for the former and seventy per cent. for the latter throughout the year. It is not the rule to have athletics during the winter. One college requires that gymnastics be taken for two years before athletics are permitted, then all gymnastics may be omitted. In colleges where men and women used the same gymnasium, the arrangement was usually unsatisfactory. In one such institution the "only hour available for women is the lunch hour between one and two o'clock." Then those in charge of the work wonder why women are not interested.

The variety of games which students play does not 
seem to be carefully regulated. In some instances they may elect as many as are offered; in others two; in still others one " heavy game"; and in a few they are limited to one game. There is much wise supervision of practice periods, the average for basketball being forty minutes twice each week. The halves average twelve minutes, with ten minutes' rest. Most colleges permit extra voluntary practice and this privilege does not appear to be abused. The average hockey practice is one hour and baseball one and one-quarter hours. Only one of the colleges reported games daily, the rule being twice or three times weekly and often but once. But one college appeared to be indifferent about times of playing. The others required that from two days to one week each month be given to rest from physical training. A half-dozen insisted upon baths after practice and the majority advised or urged it, while many were indifferent or left the matter to the girls.

Colleges, like private schools, have difficulty with girls who wish to be excused from all physical training, and physicians' excuses play an important part. One physician asked to have a student excused on the ground that she had trouble with her lungs! After a careful examination this request was refused and work prescribed. Later she was put into basketball and at the end of the year, upon her physician's own statement, showed an improvement of fifty per cent.! The college, in order to work for the best interest of the girl, needs to convince the family and physician of the'value of physical education. 
It is impossible to give in detail the varying systems, but judging from the most successful ones in use, from the point of view of both education and health, it would seem that the following experiments have worked satisfactorily:

One college considers athletics and gymnastics as of equal importance and divides the periods equally on alternate days. When the teams are practising for finals, the gymnastic period is reduced to one day. Another college requires four periods of work each week for the first three years, and in two of these periods athletics may be elected. A third provides graded athletics, which increases the variety and makes it possible for the less robust girls and freshmen to begin on minor games of ball. A fourth institution has included short lectures upon the purpose and value of athletics, and special lectures upon the games played.

Some form of athletics, elective throughout the year, is desirable. Ring hockey and indoor baseball may be substituted during the winter for the corresponding outdoor games. This not only gives all girls a chance but the group training may be begun at once and carried throughout the year. Under no conditions, where there is any gymnasium, should all athletics be omitted during the winter semester, even if the place is only big enough for volley-ball, captainball, etc. One highly organized game and one minor game is a wise limitation. An average of three days excuse per month from all physical training is the practice. 
Athletic Associations.-It is impossible to discuss athletics in colleges without considering athletic associations and clubs, which exist in more than eighty per cent. of the large colleges and exert a wide influence. This tendency is seen also in a number of the small colleges. They may have but one game, oftentimes no gymnasium and but superficial instruction, and still maintain flourishing associations. Some so-called athletic associations have really very little to do with athletics. Sometimes they are merely informal clubs with no object except to stimulate interest or the debating society adds athletics to its other activities. In a few instances our correspondents described these organizations as "weak"; "inchoate" ; "demoralize the school in the name of class spirit" ; " pernicious in stimulating competitions" ; "ineffective" ; or, "6 bad for the school," but in the majority of cases they were considered of great assistance.

Membership is generally made up of undergraduates, but the administration varies. Ordinarily the control is vested in one of the following groups:

(1) Officers of the association and captains of teams and manager. This represents entire student control and is rare. (2) Officers of the association, captains of teams and physical education director. (3) To this second type are frequently added members of the faculty, elected by the association. This is the most common type and is effective. (4) Officers of the association, one representative from each game, including indoor gymnastic group and physical education director. In this last group, members 
of the faculty are only elected by the association to the advisory committee. One college varies this by having the three lower classes represented, instead of the game groups; another by adding to the officers and representatives from each sport a member at large for each class. One university has, in addition to the executive committee of the association, a faculty athletic committee and a board of control appointed by the president of the college, consisting of two faculty members, a graduate student and the president and treasurer of the athletic association. They have charge of funds and grounds. Under some associations each game group is organized into a club and the various officers who have control of that group represent it on the executive committee of the general association. In others, there is no formal club, each team being the center of the group and directing its activities through the captain. In one college the system is quite elaborate. There are seven organized sports, each constituting a department, which is under the direction of the captain and head. Each sport has its own set of regulations and the duties of its officers are carefully defined. The captains and heads give the instruction in each department. All of these various types of organizations are found in the various colleges, but (3) and (4) possess the greatest interest for new organizations looking for a model. The combination of officers of the association, physical director, and one representative from each game group and from each class with faculty on the advisory board is exceedingly valuable. 
The duties of these executive committees or boards vary, as the following show:

"Its duties are to formulate rules for governing athletics and athletic honors and to enforce these rules. It consults with the advisory committee regarding the welfare of the association but there is no appeal from its decisions."

"To make appropriations, to appoint all committees for the control of athletic fêtes and contests, and to have the supervision and final decision in all affairs pertaining to the interests of the association not otherwise provided for by the constitution. Appeal from any decision of the executive board may be taken to the association by twenty-five members."

"Organized sports shall come under the supervision of the executive board. Each organization shall constitute a separate department, having the power to elect its own officers and make its own rules and regulations, subject to the approval of the executive board. Any sport may be authorized by the executive board."

"The executive committee shall be in charge of the four regular meetings of the association and shall meet the expenses of such. These regular meetings are a gymnasium meet, an open meet, reception to freshmen, and annual business meeting."

Associations are usually supported by membership dues and have for their object " improving conditions of health" and "attracting girls to the department of physical education." A few make improvements in the courts and purchase paraphernalia. Some are close corporations and no one can enter athletics or use the courts or equipment except through their doors. 
In one college, the association selects student leaders who also instruct the players. Where undergraduates have such a responsibility it is impossible to educate girls through play. Under this system, a college freshman just out of preparatory school had charge of freshman basketball. She was a good player but a hard one, had no knowledge of games other than their physical value and while fair and courageous, was far too young, inexperienced and untrained to teach a game like basketball. It would seem that the selection and training of teams, determination of number of games and other matters affecting the health and education of players, should properly be vested in the department of physical education, while field arrangements and all social functions could properly be in the hands of an association.

This belief is borne out by the experience that the greatest service which associations now render is executive social work. The influence exerted by them in selecting players, arranging schedules, etc., is small compared to the need of arousing class and college loyalty and spirit; of stimulating interest; of breaking down social lines; and of making games fair, attractive and wholesome. This is the opportunity and responsibility which no instructor or department can meet alone. The following are illustrative of the annual activities of some of the active associations, showing how they accomplish these results :

A. (1) Freshman social and reception, given early 
in the fall, to which all women in the university are invited to meet the freshmen. The object is to interest the freshmen in the department of physical education and in the association. (2) A carnival, consisting of folk dances, short local play, booths of different nations and other entertainments. This is given to raise money for the pins and numerals which the association presents each year to those who make the teams. (3) Mid-year entertainment by the members of the association to the teams. (4) May-fest, consisting of Maypole dances and final games in basketball and hockey. About one hundred of the association members and others took part in this. (5) Banquet at close of the season when the banners, cup, pins, numerals and other prizes and trophies are presented. This is a formal affair with speeches, toasts, etc. (6) There are contests including three interclass championship games each of basketball, hockey and indoor baseball and one gymnastic contest. At all of these the association has the responsibility of bringing out an audience, getting up enthusiasm, decorating the field or gymnasium, calling for invited guests and arranging advantageous seating for them, leading class and team songs and cheers, and providing ushers, programs, etc.

$B$. There are four general social days under the supervision and arrangement of the association: (1) Tree day, in which the dancing classes largely participate. (2) Float day, in which the rowing club members take a prominent part. (3) Field day, in which the basketball, hockey, tennis and other sports 
predominate. (4) Indoor meet by the gymnastic department.

$C$. The association gives a reception to freshmen and has charge of all the social and executive details of the under-class championship between sophomores and freshmen, which includes one basketball and two hockey games; and of the college championship between Juniors and Seniors, and between sophomores and freshmen, which includes basketball, hockey and field and track events. The association provides and presents the pennants, numerals and letters to the winners.

$D$. The association has charge of the gymnasium meet, the open meet and the reception given to freshmen in the fall.

Athletic associations could very well give more time and thought to developing good songs for field days, championship games and meets. They might also induce persons interested in the play movement and in games and their social expression to give lectures or addresses under their auspices.

There is not much variety in athletic games or events now used for field days. An association can do much to stimulate interest in minor games and class contests, and in working out athletic events which will be good substitutes for such individual contests as shot put, etc., which are now used.

Another function which might be undertaken by such athletic associations is a field day for secondary schools, similar to those now given by universities to high school boys. In place of having only competi- 
tions between the various schools for prizes, the class teams of the hostess college could give exhibition games and the schools be invited to do likewise. A prize might be offered to the school playing the best exhibition game with its own teams. Perhaps one inter-scholastic competitive game, for educational rather than for competitive purposes, might be added. If the ideal maintained by colleges is to mean anything, their work and spirit must be presented in some concrete way to the various schools and all of these brought together socially under the guidance of the college, but always with the social, educational and esthetic values emphasized. 


\section{CHAPTER VI}

\section{ATHLETICS IN POLITICAL AND SOCIAL ORGANIZATIONS}

Is it enough that athletics be given a place in the educational system? Do not persons who have learned to play need an outlet for the play spirit after they leave school? Furthermore, many never reach the high school or college, and city grade schools at best offer but meager facilities for play. Aside from its educational value, play bears an important relation to many city problems. For instance, it is a great safeguard against immorality, since it provides a normal, wholesome outlet for physical energy. Many short-sighted city administrations leave the matters of recreation to dance halls, where the fee for the use of the hall consists of the drinks that are bought. Speaking of their influence, Miss Jane Addams says: ${ }^{1}$

"The public dance halls filled with frivolous and rapid young people in a feverish search for pleasure are but a sorry substitute for the immemorial dances on the village green in which all of the older people of the village participated. . . The modern city is content, however, to turn over all the public provision for dancing to the proprietors of 'halls,' who deliberately use it as a snare to vice and at the best make money from this

${ }^{1}$ Charities, Vol. XVIII., p. 494. 
insatiable desire on the part of young people. We have no sense of responsibility in regard to their pleasures and continually forget that amusement is stronger than vice and that it alone can stifle the lust for it. We see all about us much vice which is merely a love for pleasure 'gone wrong,' the illicit expression of what might have been not only normal and recreative pleasure but an instrument in the advance of a higher social morality."

There are no public gymnasia for women in most of the cities and very little opportunity is provided for organized play for adults. ${ }^{1}$ A number of political and social institutions are undertaking to meet this need, and it may be of interest to show something of the scope and methods of their activities and to suggest some ways in which both the recreational and educational advantages may be increased.) While it is not possible to include all, some idea may be gathered from a brief outline of athletics in municipalities, settlements, vacation homes and camps, Young Women's Christian Associations, industrial welfare movements, trade unions, schools of philanthropy and reformatory institutions.

\section{MUNICIPALITIES}

Recreation, supported and controlled by the people themselves, is necessarily the most desirable because it is the most democratic, comprehensive and stimulating. The significance of the general movement by and for the people cannot be overestimated. It started with a demand for "breathing spaces," until now the

${ }^{2}$ For plan, Kellor, "Experimental Sociology," pp. $271 \mathrm{ff}$. 
playground, recreation center, gymnasium, vacation school, athletic field, etc., are recognized as of vital social importance.

Playgrounds.-It is scarcely necessary to emphasize the need of playgrounds, for the movement on the part of the cities to obtain them is general. But there is great need to emphasize increased use of playgrounds for girls. Because the boys wait around in scores to get in and the girls have to be induced to come is no argument that they do not want or need them. A prominent leader in the school garden movement in New York writes:

" The first thought is always for the boy along these lines, generally because he is sure to smash something if space is not allotted to him in which to work off his - animal spirit. The girl has her domestic duties. After five hours of schoolroom she must help mother by taking care of the baby or washing dishes; and then must sit down to study her lessons before going to bed; and if her animal spirits break loose and childhood's rights assert themselves, she is termed a tom-boy. If she will quietly walk up and down, interchanging confidence with some other girl, it is considered the proper thing."

A director of a playground says in a letter to the writers :

"Girls have far too little desire for play, far too little imagination and do not care for active games. They know very few and these are almost exclusively ' ring' games, with stupid or vulgar songs to accompany them. Many children have lost the spirit of play from always having the care of babies. Our efforts are directed toward encouraging activity, teaching new games, reforming vulgarities of street games and giving 
physical, social and mental development through games."

The Playground Association of America, which held its first annual meeting in Chicago in June, 1907, is in a fair way to crystallize the sentiment and to give the entire playground movement great impetus throughout the country. Its objects are "to study playground construction and administration, to collect all available publications and material, to give publicity to its information and to register and keep account of all trained playground workers." It is to be hoped that this organization will do much for girls both in the presentation and discussion of their needs and in urging the use of organized games. ${ }^{1}$

Without the playground to keep the play spirit alive, maintain health and give the preliminary training in citizenship, organized games reach but few people. Unfortunately, so far as athletic games are concerned, the city playground does not offer a wide opportunity. Few are large enough to provide for more than a basketball court, though there is a growing tendency to introduce the less highly organized games. The number wishing to use them and the presence of mothers and babies have led to the substitution of games which admit large numbers. Where playground work is not supervised, graded or systematized, children, schoolgirls and young women all come together and highly organized group games are not possible.

Notwithstanding the present limitations in ath' Publishes a quarterly magazine, The Playground. 
letics, the playground is an influential factor in social ethics. It is the natural place for both girls and boys to learn right from wrong and to understand their rights and duties. Social morality is not inborn, and if play is not directed it may not be learned until too late, for to many the playground presents the only opportunity. Smart tricks will take the place of a square deal; good minds will cover small morals; and the girl will grow into one who brags and bullies rather than one who respects the rights and attainments of others. "Directed play" is the ideal toward which superintendents of playgrounds are aiming, though they still discriminate and offer games to boys and unorganized play to girls.

Park Gymnasia.-Parks offer better facilities for girls than do city playgrounds. They could be used even more for organized play than they are without impairing their esthetic value. No city offers a better illustration of what may be done in the utilization of parks for play than Chicago, and so far as we know no city has provided such nearly equal facilities for men and boys and for women and girls.

These parks contain athletic fields where baseball and tennis are played in summer and football and tennis in the fall. Women do not ordinarily use these. There is also an outdoor field and gymnasium for men. Not far from these are smaller ones for women, similarly equipped but with more provision for play and less for heavy apparatus, which also contain swimming pools and shower baths.

There is a separate playground with wading pools 
and sand piles for small children, both boys and girls, where mothers accompany them.

The most interesting features of these parks are the field houses. They contain a library, restaurant, club room and auditorium open to both sexes. At one end is a gymnasium for men and at the other a similar one for women, somewhat smaller. These are completely equipped and instruction is provided in basketball, baseball, gymnastics, etc., in winter and summer. Contests are played here between the various teams. The regular hours are from $2: 30$ to $9: 30$ in summer and from 3:30 to $9: 30$ in winter. On Sundays there is a special director. A report of the work bears testimony to the social value of athletic training. ${ }^{1}$

" The regular class work for girls is supplemented by inter-park basketball, long-ball and other games. These games are arranged in the manner of an invitation from one park to play as guests of another park.

"It is the plan to conduct out-of-door work from May 1st to November 1st. Much of this work will be informal and undirected except that the gymnasiums will be under the supervision of the instructor at all times. In addition to the informal and-undirected work, formal class work in free exercise, apparatus work, games and athletic events will be conducted afternoons and evenings at stated hours.

"Emphasis will be placed upon the organization of track athletic teams, the holding of dual, triangular and inter-park meets, arranged and conducted with reference to group interests.

"Invitation athletic meets of suitable character will be conducted among the girls. The guiding principle in

${ }^{2}$ Report South Park Commission, 1906. 
conducting all out-of-door work will be to involve great numbers, to organize, along the lines of simplicity, large groups for interesting and beneficial gymnastic and athletic activities.

"The value of the gymnasium and playgrounds as agencies with which to combat the tendencies toward social and physical degeneration which inevitably accompany city life, has been emphasized by many eminent pedagogues, scientists and sociologists. Our public schools are first in combating and delaying the effects of these tendencies. But the valuable physical, mental and social training given by the public schools ends with the vast majority of children when they are still in their most plastic stages of development. Their school and play time is cut short because of the necessity for seeking work in office, factory or shop, there to become a cog in our complex industrial life. The park gymnasiums may and do at this time furnish the training needed in the children's muscular and neural development; and with the gymnasium conducted with reference to the sociological factors involved, it may be claimed that this work is a valuable adjunct to the public school system."

There is a growing tendency in most city parks to provide athletic facilities for girls, especially in basketball and tennis. Hockey is used occasionally and can well be urged, for by frequent changes of field it is not hard on the turf. One city park provides an out-of-door gymnasium with a canvas top and open sides and also an open space $350 \times 150$ feet as an exercise ground for girls.

Athletic Fields.-Outside of parks, it is only here and there that much attention is paid to girls, and there are few athletic fields for them. We have been able to find but one municipal athletic field and that 
is not in use because there is no money to put it into condition. Even where facilities, such as tennis nets and basketball courts, are provided, girls are too frequently left to play by themselves. When an enthusiast or even director or patron of athletic games is asked about such work for girls, he usually looks distressed and says: "Well, now I don't know about girls, but for boys!" And then for five minutes there will be an eloquent description of facilities provided for boys. Girls have been neglected so long that it is not enough to put in the equipment and say " now play." The subject needs especial attention to devise ways of making games attractive, beneficial and more varied.

Not only are cities interested in this matter of play, but there is a growing interest in town gymnasia in small towns of from 1,000 to 5,000. Unfortunately again, this is chiefly confined to men, and there are few or no places of recreation for the girl after she is out of school.

Recreation Centers, Vacation Schools, Etc.These are ordinarily a part of the school system and are largely for children. The growing use of schoolrooms and roofs where girls are taught games is a matter for congratulation, and most of the large cities make some effort to maintain recreation centers. Without the use of school buildings, much of the athletic work would be impossible. So rapidly has this been extended that in some cities not enough supervisors of play can be found to take charge of those willing to come and play. 
In one city, there are twenty-one such centers', twelve for men and boys and nine for women and girls. A principal, club director and athletic instructor are provided. Those who attend often form clubs and sometimes assist in the discipline of unruly members. The following description of the work in these evening recreation centers for women and girls shows how little educational work is considered even in the most progressive schools:

" The work in the recreation centers was organized into four distinct departments - the reading and study room, the literary and debating clubs, quiet games and gymnastic teams.

" The program for girls' center differs but slightly from that of the boys. Their athletic exercises are always taken in classes with an instructor, and their club work is distinct and progressive. They care less for games of skill and more for reading. The last halfhour of each evening is spent in graceful dancing. It required this to eliminate the romping of which they are so fond, and the stately, old-fashioned minuet has been serviceable in this direction. The women are quite as enthusiastic as the men over their club. They are fond of games and like gymnastics."

The vacation school has made games a large part of its work in many cities and has helped to solve the summer problem. Occasionally definite periods are set aside for organized games. Another feature of some vacation schools is the excursion, where the greater part of the time is spent in playing games.

School Gardens.-Only an occasional school garden considers play for girls. The out-of-door work in caring for the garden is usually considered suffi- 
cient. One superintendent of a school garden, who sees the need clearly, writes: ${ }^{1}$

"After garden hours, the older boys and girls hung about helplessly, looking for something to do. The ground adjoining the garden is hilly and was covered with a rank growth of weeds, but after weeks of hard work, two tennis courts and basketball ground were evolved. The boys formed a baseball team and secured the use of the grounds a short distance away. Through the courtesy of an owner, a plot of ground adjoining the garden was laid out.

"The main feature of the playgrounds has been the team work. The garden pupils are girls and boys of the grammar grades, soon to leave school and enter the working world. There they have two great lessons to learn; first, to do one's own work well; second, to work with others, subordinating individual interest to a common end. The first lesson is begun in the garden, in the care and responsibility for the individual plot. The second is begun on the playground. The end of team work is the joy of winning and to attain that end all must work as one. This is a far harder lesson than the first. No one save the attendant teacher knows how often a team threatened to go to pieces because 'Mary was mad at Kate,' or ' John told Fred last night he wasn't any good anyway.'

"In spite of such difficulties, two baseball and six basketball teams were organized and did very good work. Scorebooks were kept to show the result of each game. An examination of the scorebooks shows a total of 103 children engaged in team work during the season. This number does not include those children using the tennis, quoits, etc. After garden hours, young people from neighborhoods near both gardens used the tennis and basketball grounds, bringing their own nets, balls and racquets. When match games were played between the two gardens enthusiasm ran high. Usu-

${ }^{1}$ Report, School Gardens, Philadelphia, 1905. 
ally there was an attendance of several hundred parents, friends and interested neighbors at each game. "That baseball has been the making of my boys,' remarked one enthusiastic mother."

A leader in the School Garden movement in New York says:

“During 1902, when I started the Children's Garden, there was no provision for gymnastic exercises in the neighborhood. One day the police called my attention to an over-grown girl of fourteen, who was having a most enjoyable time sliding head first from the roof of our cottage. He asked if I thought that proper. I looked over the lots. Some men were playing ball at one end, some boys were intent upon their games at another. I thought of this awkwardly tall girl trying to reach womanhood through the environment of a poor tworoom home, with no fresh air or sunshine, and I replied to the officer, "No one seems to be looking at her but you, and if you look toward the river you will not see her, and she slid up and down that roof happily oblivious of a weary world. I very soon had some simple gymnasium apparatus placed, and the weather never seemed too cold to keep the girls off the lot."

Summary and Suggestions.-This brief account of municipal activities shows a little of what is being done and holds out high hope for the future. There are, in addition to extending the movements described, many other things which the friends of games for girls may urge:

There are many vacant lots in cities which the owners, if rightly approached, would permit to be used for such games as basketball, indoor baseball, hockey and less highly organized games. Settlements could undertake to provide supervisors of play. 
Play festivals, including organized games and exhibitions by municipalities of their work in vacation schools, recreation centers, etc., would assist in stimulating interest. One city conducts civic games for men; why not play festivals for girls?

Germany has a "Central Committee for the Promotion of Games," which consists of prominent government officials, physical trainers, educators, etc. Its work is to study the games and sports of other countries and to introduce them into Germany. It has also not only systematized and graded games but has urged shorter school hours so there will be available time for play. It has also held normal schools of play, thereby training several thousand teachers, conducted play congresses and published excellent periodicals and reports in the interests of play. Some such movement is needed to develop the play spirit and' provide additional training and facilities for girls in this country.

The limited space available in cities for playgrounds has led the Director of Physical Training of the New York City schools to suggest a twenty-story playground. He estimates that below Fourteenth Street there are fully 225,000 children and that the city provides playgrounds for only about seven per cent. of them. So far as we know the need of cities and the slender resources in time and money of those whom it is sought to reach, smaller buildings more convenient to the crowded neighborhoods, with provisions for organized games and equal facilities for girls and boys, would more adequately meet the need. 
In the smaller cities, a wider use of schoolhouses and the establishment of small simple playhouses for women are within the immediate possibilities. Any floor space which will provide for a basketball court, small indoor baseball diamond, ring hockey and for less highly organized games and for folk plays and dances is highly desirable.

\section{SETTLEMENTS}

Settlements were among the first to provide games for girls. In many cities they have stood behind the playground movement and have made it possible. They have also acquainted the neighborhood with its opportunity or taken parties of small girls to the centers provided. Some of the settlements maintain country houses or summer camps where games are played. During the summer, excursion parties constitute a large part of their activities and organized games are made a prominent feature for boys, though not so much for girls. Where settlements have a small yard it is usually turned into a playground, furnishing a practice field for the battery of the settlement nine, or is used by the small children for minor games. The residents also take the settlement teams off to vacant fields where they can practise. This is not always an easy thing to do. One of the women residents was invited to accompany the ball team to an outlying park in one of the large cities on Sunday. Thinking baseball was prohibited there, she declined. After much urging she told the team to have its first practice alone, and if there was no trouble she would 
go the following Sunday. They returned jubilant, with the announcement, "Say, you oughter gonewe only got chased five times by the cop and got over the fence every time. We's had a grand game and can play dere."

Facilities.-In the matter of athletics settlements have not only been pioneers but continue largely to influence public opinion and to take the initiative. Of the one hundred settlements responding to our inquiries, sixty per cent. provided some facilities for organized games, independently of the neighboring parks and recreation centers; twenty-eight per cent. had no work; and twelve per cent. were building or equipping gymnasia. Of the twenty-eight per cent. a few stated that they had given up their work because playgrounds had been opened in their neighborhood. Forty-five per cent. had a playground of their own in addition to a gymnasium, or were near playgrounds which they used.

While the amount of work provided for girls is encouraging and is increasing, a considerable proportion of the sixty per cent. which provided work did not extend it to girls and did not appear to realize its value, though they were sure it was " a good thing for boys." Not one settlement stated that it shared the gymnasium equally between girls and boys and but few said that a special effort was made to interest girls so they would use the time already allowed them.

Basketball is so popular that some girls will play no other game. Gymnastic games are sometimes used, but there is a deplorable lack of variety and absence 
of any educational idea. Of the sixty per cent. of the settlements which have gymnasia, only a trifle more than thirty per cent. provided for organized play, and that chiefly in the way of basketball.

There is also a definite need for supervision and trained instructors. Many settlements have not enough work to afford a paid instructor. Most of them are located in the crowded sections of cities, where rental of floor space is very high and must content themselves with the use of a small room, roof, or by covering a small yard. Thirty-six per cent. of the instructors are college girls who may or may not have had athletic training; thirty-seven per cent. have had some training in schools of physical training; eighteen per cent. are residents with no especial training and the remainder are "professional men coaches." In only about seven per cent. are measurements or examinations required or any special study made of the needs of working women and badly nourished girls. This is perhaps the chief oversight, as the dangers from over-exertion are so great. Almost every settlement surely has some physician sufficiently interested to take up this matter.

Contests.-In the matter of contests there is a somewhat conservative attitude. One half do not play outside teams, and of the other half, about five per cent. discourage but do not prohibit them and emphasize inter-class games. In one settlement we found teams playing three or four match games a month, during the season, with outside teams, but such excesses are not common. One to three inter-settlement contests 
a year seem desirable, for inter-class contests are not always possible, as where the small gymnasium accommodates but one class. Inter-settlement contests serve a necessary purpose, for the interest is difficult to keep, owing to the competition of dance halls and other places of amusement in neighborhoods filled with daily dramatic incidents.

Athletic Associations.-It is regrettable that so few settlements have any kind of athletic associations to stimulate interest, develop social qualities and teach the girls self-government. At present the whole matter is usually directed by residents and the social features are consequently much neglected. Exhibition games, field days and meets have almost no place, and in some cases the gymnasium is to the girl simply a place where she may dance.

Systems of Work.-These vary so much that it is impossible to give an accurate general account of them. The usual amount of time given to girls is two evenings or afternoons per week. One settlement gives but one and one-half hours a week while another gives three evenings a week, and some have afternoon classes and grade the work. The usual plan is to have the first part of the hour devoted to gymnastics and the latter part to games. The classes are frequently made up by the various clubs. One settlement has early afternoon classes for women; late afternoon classes for school girls and evening classes for working girls. In another the gymnasium is used during the year by about five hundred different women and girls and cannot meet the demand. 
In a few the systems, in spite of the limited facilities and great numbers using them, are so good that they may be helpful to others, whose available space is perhaps limited to a single room.

In one, classes are divided into women's senior and women's intermediate classes, and into intermediate school girls' and junior girls' classes. Each meets twice every week for an hour. The first part of the hour is given to gymnastics and the latter part to games. Saturday evenings are left open for contests and about three contests a season are played. Evening classes are reserved for those employed during the day. Physical examinations are made by a physician, corrective work prescribed and games are supervised by a graduate of a physical training school.

In another, two afternoons and evenings a week are given to girls and women, one afternoon and evening is given to gymnastics and the other to children's games and athletics. One inter-settlement contest a year is played, measurements are taken before a girl is permitted to play and the work is under the direction of two physical training school students.

A third, with a comparatively small gymnasium for girls, has so good a system that it has eighteen classes a week. One afternoon is reserved for contests.

Defects and Suggestions.-The defects, if they can really be called such, in view of the signal service rendered to the playground movement and of what has been accomplished in the face of limitations of 
space and equipment and lack of competent supervision, are the following:

Not enough thought is given to work for girls. The temptations due to crowded quarters of cities are quite as great for them as for boys and their morals quite as easily corrupted.

Too little attention is paid to the needs of working girls. A variety of games, folk dances, etc., adapted to their needs are essential. Basketball, as the only game, is too strenuous for those who have had no training and who work from eight to fourteen hours per day.

Some of the disadvantages are due to the acceptance of the professional "coach." It is feasible for several settlements to combine and engage a trained instructor. These instructors, as one settlement worker writes, should be "trained to handle working girls' classes ; if they are not, they are often failures."

Organized games have too small a place in camps, country houses, excursions, etc., conducted by settlement workers. Girls off on vacations are too much inclined to indulge in "horse play," or sit about exchanging confidences, talking of young men and "relating experiences."

There is a tendency to discontinue the gymnasium when a municipal playground is started and to trust to the latter to do the needed work. This seems to be a mistake, for there are many mothers who will not let their daughters go to a public playground and are just as careful as though they could afford a private instructor. The settlement that keeps up its 
own athletic work while assisting in obtaining a playground has a much better chance of retaining its hold upon the young girls in the neighborhood.

A wider use of roofs, vacant lots or vacant rooms could be urged. Hockey can be played on vacant lots until winter. Indoor baseball and ring hockey can be played in quite small rooms. As no equipment is needed, the use of some of these vacant spaces might be obtained free or at a small rental.

Exhibition games, field days and meets which afford social features need emphasis. Folk dances could be made an attractive part of these and would help to attract the girls.

The educational and social value of athletic clubs could be increased by interesting lectures under their auspices. There are inter-settlement associations for boys, why not for girls? These could be under the supervision of the combined settlements, and might assist in obtaining a higher standard and in regulating contests and developing social features. A conference of settlements in each city to discuss, not only the value of athletic work, but to help each other work out better systems, might lead to a wider adoption of games, played under better conditions.

\section{VACATION HOMES AND CAMPS}

These do not offer so good an opportunity for sustained education as do playgrounds and settlement gymnasia. Although the period of the outing is short, usually limited to one or two weeks, the girls during that time are entirely under the influence of 
the homes, and it can be made the most of in every way. The director can introduce games at least once each day, and if minor games are used, twice or oftener. For working girls, suddenly having all of their energy released and needing some outlet, games offer a splendid opportunity. They help to solve the problem of discipline; furnish a good alternative to dancing, which is becoming far too much emphasized; make an excellent topic of conversation; and in even this short time some idea of the social qualities required in group work can be gained. Employing a game director is an experiment worth trying in each vacation home.

Summer camps for girls, both for study and recreation, are growing in favor, and many institutions are establishing them. The demand for persons capable of taking charge of them exceeds the supply. The plan deserves a wider extension, not only to working girls but to the leisure class as well. Many girls are only made more individualistic by sending them abroad at an early age with a chaperon, while a little group training and closeness to nature would be a greater benefit in many ways. Such camps ordinarily have all of the individual sports, such as riding, canoeing, swimming, etc., which are excellent recreation but are not socially educational. The "athletic tutor" of the right kind is much needed here.

\section{YOUNG WOMEN'S CHRISTIAN ASSOCIATIONS}

The influence these associations may have on the social education of women can be paralleled by no 
other group at the present time. There are large numbers of working girls of the middle class who have no other social centers. There is a considerable number of unemployed girls of the middle class who are not permitted to work whose homes and social activities do not satisfy them. There are girls who wish to contribute to social betterment in activities other than those of the church. There are also graduates from high school and college who have played games in school and take up work in the city. What place is there for them to continue their physical and group activities? There is still another group greatly in need of some social outlet, namely the factory and shop workers in small industrial centers. All of these are in need of the training as well as the recreation which athletic games provide. An investigation made by one of the Association members shows something of this: ${ }^{1}$

"City life is each year crowding more people into smaller space with consequently diminishing opportunity for out-of-door work, and artificial means must be provided to induce a sufficient amount of exercise indoors. The total population of the United States has increased twenty per cent. during the last ten years, but the city population has increased thirty-six per cent. during the same time. About ten million. American women and girls live in cities. For many of these a gymnasium would provide a most wholesome health measure. It is within the reach of some, though not a large proportion. In this country the number of wage-earning women above fifteen years of age is almost five million, and the number of wage-earning girls between ten and fifteen years

${ }^{1}$ Special Report of Y. W. C. A., 1905. 
is almost half a million. For most wage-earners the daylight hours are the working hours. Rest and recreation must come after dark, when many kinds of outdoor exercise are out of the question. Pleasant and safe and wholesome good times are needed, and for most of these women the expense must not be great. Many of them are supporting others as well as themselves."

Some of these women need recreation, some education, some a good time, some social expression, some happiness, while others are full of pent-up energy which is likely to lead them to the dance hall or other amusement places where they can make a noise and "have a good time." It becomes a question not solely of exercise and recreation but of morality and public concern.

Now the girl who has worked all day in a stuffy shop until her eyes and fingers and back and head ache; the girl who has only a four-room apartment which she shares with many others; the girl whose body is tried by physical exertion and spirit by its yearning for something bright, relaxing and beautiful,--these cannot be expected to choose the Association's rooms (not because their intentions are bad) unless it has some way of understanding their life and of meeting their needs. The Bible, sewing or cooking classes may or may not do this, for they may not be ready for them. But the gymnasium and games will do it if they are open to them.

Facilities and Methods of Work.-What is being done to meet this need? Their investigator says further of the Association work: 
"Of the 100 largest cities in the United States, 43 have no gymnasium work; of the 77 cities having a population of 50,000 or more, 33 have none, and no Association gymnasium in a city often means none at all.

"Between February and May, 1905, I received from nearly all the Associations under the International Board and under the American Committee answers to a lost of questions in regard to the physical work. The replies represent 139 city Associations under both boards. From 10 no replies were received; 52 are attempting no work at present; 4 send their pupils to a college gymnasium; 33 have a room or gymnasium part of the time; 50 have a room or gymnasium the whole time. This gives 83 doing more or less work. Thirtynine of these have a teacher for part time; 37 have a teacher or physical director whole time; 7 have a physical director with one or more assistants.

"Seventy-seven Associations report 708 weekly sessions with an enrollment of 9,515. As to the equipment, I did not state. Eleven have none, 11 have 'light apparatus' only, 60 have small to complete equipments.

"These facts give us some cause for pride in our Association, and more reason for hope and courage, and still more occasion to redouble our efforts.

"With only two Associations doing gymnasium work sixteen years ago, we now have over 80 doing more or less in this line."

The inquiries made by us verify these statements. Speaking of the growth of physical training and the difficulties, one of our correspondents says :

"The beginnings of the gymnasia were necessarily small. First, the Associations found a few rooms where meetings for young women could be held. These meetings were usually of a religious or social nature. As the meetings grew, larger quarters were secured. Oftentimes the boards of managers were fortunate enough to raise money to erect Association buildings. Although 
there were some who recognized the need of physical training, the quarters given for it were the places which could be converted into something else should the 'fad' pass; or when rooms were not needed for other purposes, they were used for gymnastic work.

"For the most part, in the Associations recently built the gymnasium is given the proper space and place, not in the basement but on the ground floor or higher up; not a place that can be converted into something else, but a gymnasium well equipped with locker and dressing-room accommodations. The newer Association gymnasiums have swimming pools as well as baths."

The work being done in one or two of the association gymnasia shows the possibilities. One has a floor space of $65 \times 45$ feet, excellent shower baths, etc. The work consists of Swedish gymnastics, games and basketball and fencing. There are also medical examinations. The only objection to this plan, which prevails in many other associations as well, is the high fee, which in many cases makes the work prohibitive. The initiation fee is $\$ 1$ and for two lessons a week is $\$ 5$ from September 25 to May 5. A locker costs $\$ 1$ more. The average pay per week of the factory worker is about $\$ 5$; the average pay of the clerk in the store is $\$ 6$ to $\$ 8$. The average rate of board is $\$ 3$ for the former and $\$ 4$ for the latter. Now girls earning these sums and most in need of physical work cannot pay $\$ 5$ a season. Many of them cannot even afford to go to a dance unless some young man takes them. Cannot some means be found to bring working women into the gymnasium without such high fees? This is not a question primarily of education, as are clubs and classes-it is a question of citi- 
zenship, of social morality and often of virtue as well. Here settlements and institutional churches are clearly in advance.

Another association in the West offers some excellent opportunities. It provides gymnastics, basketball, center-ball, scrimmage, gymnastic games and children's games. The gymnasium is open eight months of the year, the classes meet twice each week, and twenty minutes of class time is given to games. An examination of heart and lungs is required and other measurements and strength tests are taken. It has classes for business women in the evening, and for women of leisure, high school girls and children in the afternoon. Class contests in ball games are occasionally permitted. There are occasional meetings of classes in a social way, and an effort is made to promote good-fellowship through the gymnasium.

Defects. - The investigations made by association members and by us on the whole show discouraging conditions. In the first place, there is a well-defined antagonism to athletics in many associations, due to the fear of the effect of competition and to an ignorance of their value as training for good citizenship. Less than one-third of the eighty-three associations who offer gymnastics include any athletics whatever, confining their work to formal gymnastic classes. In the three main seaport towns where great numbers of young immigrant workers arrive yearly, and where thousands of working girls live, but one association offers any work in athletics. In the second there is no gymnasium and in the third athletics have been dis- 
continued because the director is not in sympathy with games and because in her judgment they "make the girls rough."

We have been unable to find any such emphasis upon the educational value as exists in the Y. M. C. A., and there is an utter absence of any general lectures or real instruction even where games are played. Little attention is paid to the qualifications of instructors.

The Young Women's Christian Associations, in common with the settlements, have by far the greatest opportunity for making athletics a means of education. Fair play, regard for the rights of others, self-reliance and toleration, honesty and many other qualities previously emphasized, may be brought out as in no other classes. The Golden Rule and many of the precepts taught in Bible classes are but half appreciated, until applied in games to daily competition. There are no other organizations to meet this great need, and the social responsibility therefore rests for the present with these two organizations.

Remedies.-In the report previously quoted, some valuable suggestions are made which we repeat here in the hope that some, who have not seen the report, may become more deeply interested in the work.

"That the physical department be an integral part of the Association work. It is not just physical work, and girls should be made welcome in this if they cannot give time to other things.

"Our gymnasiums must provide as good work as the very best if they would hold their own, and they must add a real sympathetic love for each girl.

"Every class session should have in it some element of 
friendliness, sociability and recreation in addition to well-planned exercises.

"There are many details in which physical directors need the help of each other. Could we not plan some regular means of conference and mutual help? A clearing house of ideas and suggestions is also suggested! Valuable conferences are held each summer in which games play a large part, as a means of recreation. Could not these develop something of the educational value and be made more helpful?'"

To these we may add the following:

In building a new Y. W. C. A., build the gymnasium first and add the other parts of the building afterward.

Obtain an instructor who believes in both gymnastics and athletics and who can make them so interesting that she can compete with the dance hall and other places frequented by those in search of recreation.

Learn the need and shape the physical education department to meet it, instead of planning a scheme of work and trying to make girls fit into it.

Make the fees so low that they will not be prohibitory.

Make some use of the gymnasium during Sunday. Girls who work six days a week must be appealed to by some real relaxation from the work of the week. The dance hall, the picnic, the excursion all run on this day. Why not be practical Christians and understand the methods of business competitors and counteract them at every vulnerable spot?

Emphasize the social features. Encourage teas and banquets and dinners and social gatherings in 
the gymnasium, given by the different classes to each other and to their friends. Exhibitions and contests between classes can be made into attractive social functions. Much or all of this is now lacking.

Make a special effort to reach the working girl who receives a low wage and who lives in a boarding house amid bad surroundings and without home ties, and do not have so much red tape that she cannot or does not want to come in.

We earnestly urge that associations make an effort to reach immigrant girls whose energy needs guidance, but who by reason of the difficulties of language and a different standard of living are not able to choose their work or recreation wisely. A gymnasium (which may be one large room), with classes in English, is enough of a plant to start in a neighborhood where they live.

A further need is the establishment of a school for the training of workers, of which physical education should be an important department. Courses in physical training schools are not enough, although they are a fair beginning. There should be an historical, cultural and religious background which existing physical education schools necessarily lack. Such a training school, on the plan of schools of philanthropy and of the Y. M. C. A. training schools, could well be patronized by those desiring to go into other institutions to teach. 


\section{WELFARE WORK FOR EMPLOYEES}

One of the most important phases of welfare work supported by employers is the gymnasium. Many of the large factories and shops have them for men, and in some few instances their use is shared by women employees. As a rule welfare work for women has not included physical training, and welfare secretaries have not much knowledge of athletics. But the tendency is strong in that direction and the demand is already making itself felt. There are gymnastic classes on roofs, in basements and lofts and other rooms of the factory during the noon hour and in the evening after work, and young women from neighboring colleges who have had physical training are in demand as teachers. While it is not possible to play highly organized games like hockey and baseball in the small areas at the disposal of the company, basketball and minor games of ball are being added to the attractions. In one laundry, part of the noon hour is devoted by some of the employees to reading while others play basketball. The irregularity of laundry work, the long and short shifts, the night work and waits render it possible to make considerable use of games if only the space is provided. On the roof of another company's building, gymnastics and handball are popular; while on a third such simple games as tag, throwing the ball, etc., are permitted. One firm gives the use of its well-equipped gymnasium to women one afternoon each week from $4: 30$ to $\%$. Considering that they employ about 1,800 women this 
is a short time. Unfortunately no instructor is provided and the work is disorganized. Another company provides a gymnasium, tennis court and athletic field and has an instructor in charge. Another has a roof garden where handball is played, and one end is set aside for game tables.

Some of the roofs are so arranged that minor games of ball can be played and varied with dancing and gymnastic games. Many industries have available rooms which can be used. Some of the department stores have already utilized the top floors and vacant rooms of their buildings for gymnastics and athletics, and even employ teachers.

The use of gymnasia, roofs, etc., during the noon hour keeps the girls off the streets and gives them a wholesome interest as a substitute for gossip. Breaking the long five-hour period with a half-hour of exercise or rest would be a gain rather than a loss to the company. One company requires that some of its employees shall have gymnastics while standing by their chairs, as school children relax by their desks.

Some employers who have no facilities in their own plants have set a good example by obtaining accommodations elsewhere. One English firm provides tennis and cricket courts, a large covered ground and a special gymnasium. Unless prohibited by the doctor, all girls under fifteen attend two classes weekly during. work hours. A committee of girls entirely controls the athletic club which organizes all of the games, including basketball. It has also a swimming tank and shower and vapor baths under its charge. 
Every welfare secretary, whether in direct charge of the work or employing specialists, needs to know the value of physical training and to urge organized play among employees.

\section{TRADES UNIONS}

Combinations of working people, as well as of employers, can build up group activity by recognizing the socializing value of organized play. The woman who works in the trades has little time for recreation, and practically none for education through games. The problem of trades unions for women is to develop the consciousness of a common cause. This may be a simple matter for men but it is not so for women. They change more rapidly from one occupation to another, regard employment as a means to an end and consider first whether they as individuals need the union, not whether the movement for bettering conditions needs them. Women's trades unions have an opportunity open to no other organization in reaching working women. At the very basis of their struggle for better conditions, higher wages, more leisure and better citizenship lies the necessity for team work and group loyalty - two things which games are preeminent in developing. This may seem a long way around, but its effectiveness makes it a factor to be considered. For this reason, these organizations should be interested not only in forwarding athletic movements in other institutions, but a gymnasium may very properly be made the nucleus for their own work. It makes a good place for meetings and 
social gatherings, can be used by the children for class work during the day, while its evening athletics may be the direct means of bringing workers together. Folk dances appeal to the various nationalities and some may understand the purpose of the union better through its simple appeal to their love of their home country and its associations. One or two settlements have understood this and provided athletic classes for various local unions. The need of recreation as well as of education and the present wretched amusement facilities for working girls are a further plea for trades unions to take an interest in games as a means of making a more efficient democracy.

\section{REFORMATORY INSTITUTIONS}

Social education is not always a question of making citizens; it is frequently the problem of reclaiming them. Tremendous sums and huge institutions are required for this purpose. The girl who needs reclaiming has usually set her individual right above the social right and has refused to do " team" work. Although athletics possess such possibilities for social education, the gymnasium is about the last thing one finds in reformatory institutions. Discipline by the rod instead of by teaching self-control, is more popular. A few schools and homes use drills and simple gymnastic exercises as a matter of recreation and health, but directed play is rarely found. Some let the good girls play in the yards, but without supervision. The amount of play time is proportionately small and young girls committed to institutions enter 
upon a dull, monotonous, deadly routine which turns out a machine, which without its operator either runs amuck or becomes a mere automaton. One superintendent writes: "This is not a place where girls come for fun and to have a good time but to be punished for their misdeeds and to learn to do right." Fortunately this does not represent the attitude in all institutions.

It is amazing that such a large percentage-more than three-quarters of the institutions studied-have neglected physical training entirely, abandoned it, or consider it unimportant. The physical condition of many young girls, their moral obtuseness, extreme individualism and mental dulness on arrival would lead one to think that a bright sunny gymnasium, with corrective and preparatory work and games, would be regarded as a first essential. Disordered emotions, pent-up energy, vicious desires and habits and distorted view of life can often be understood and corrected in the gymnasium when the schoolroom is a failure.

It is also curious that many probation officers so ignore the value of organized play. The probation officer for boys puts them in settlement gymnasia, takes them off to camps or goes to vacant lots and plays with them. But the girl is frequently returned to the same district, same home, same everything, with no change in the outlet for her emotions, with no effort to reclaim her as a social being-and then it is said: "When a girl goes down it is almost impossible to save her." Wise probation officers who have put 
their wards into playgrounds and settlements and endeavored to develop the sterner qualities, tell a different story and one fraught with great public interest.

It is truly astounding that so many institutions, which have reformation for their object, do not recognize that a person without self-control is not a good or safe member of society and that where there is no freedom there can be no self-reliance. These institutions by their discipline shackle the mind and body, govern the girl by fear and force, leave her no power of choice and then expect self-control. The game gives freedom and opportunity for choice, and if players are insubordinate at first, the chance is there to teach the girl to guide herself aright. Once acquired this ability will continue when the removal of bolts and bars opens up a great freedom unaccompanied by means of control other than that exercised by the girl herself.

The best corroboration of the value and need of athletics comes from some of the reform institutions themselves, even where they have no trained teacher and do not emphasize the social and educational features of games. The testimony of the twenty-five per cent. who believe in and use them is most suggestive:

"We have a gymnasium, also playgrounds which are used by girls. We have in all 312 girls between the ages of twelve and sixteen years, who live in cottages averaging from twenty-four to thirty-four each. We have eleven classes, each of which meets three times a week during the winter months and twice a week during the summer months. Through the winter the work in 
the gymnasium consists of drills with apparatus such as wands, dumb bells, Indian clubs, bar bells, etc., and heavy work as on bars, jumping, climbing, etc. This is lightened by games such as basketball, Newcomb, center-ball, shuffleboard, ring-toss, etc. We have an instructor for our work. We have public contests in that we give exhibitions. Our game contests are among the different classes. We never play with other schools."

"The results obtained from games are very valuable from an educational and ethical standpoint. When we began with our games the girls were wild, selfish, quarrelsome and boisterous, but now we notice a great change. They are gaining self-control, alertness, honesty, endurance and a strong class spirit. They are learning to play through a game without losing their tempers or taking unfair advantages of their opponent."

" There are playgrounds for each cottage and a general baseball field, used by all the girls, where competitive games between the groups of cottages occur. There are gymnastic classes twice each week, in the winter, for each of the seven cottages. The recreation hours of each day are spent with baseball, basketball, tether-ball, croquet, tennis and dancing. There is an average of twenty-five girls in each class or cottageall girls supposed to have some part in the games. No contests are held with outside teams, although visitors are invited to witness the competitive meets between the groups of players within the institution. The educational and ethical value to our girls is most apparentin the unfoldment of their better natures by giving them happiness - teaching them intuitively to enjoy the vigorous and healthful out-of-door life-balancing whatever nervous tension they may have in schoolroom, sewing room or kitchen by a sense of freedom and relaxation in the open air."

"We have no gymnasium at the present time but have the plans and expect to erect one 50 by 80 floor space in the near future. We have a large play- 
ground about 400 by 380 feet. We have four classes using wands, dumb-bells and Indian clubs. We have three basketball teams; some of the girls play volleyball, lawn tennis, tether-ball and croquet. Our basketball team is under instruction of a professional trainer. We thoroughly believe in the educational value of games and gymnastic work. I do not think it injurious to a comparatively weak girl. We have within three years had no ill effects; we have at the present time several girls who a year ago were comparatively slow in their movements. They are now erect and better all-around students than they were on entering the institution."

"The number of games in general use among the girls are as follows: Baseball, basketball, lawn tennis and croquet. The various games and clubs are under the supervision and management of the family managers and matrons, and under the instruction of the Superintendent, who has had practical experience in nearly all games, especially those herein mentioned. We frequently have public contests. This is especially true of the holidays. Then prizes are awarded to those successful in the contests. Regarding the educational and ethical value, I cannot speak too highly. The girls look forward to these sports and contests with the greatest expectation. It absorbs all their time and energies while on the playground; it helps our discipline a hundred fold; and at the same time, gives that exercise that all girls should have, and it is done in a manner that does not require coercion. During the winter months when the girls are largely confined to the indoor life, we have similar games to fill up the long hours of the winter evenings that are just as interesting and entertaining. We also indulge in a great many entertainments; ninety-nine per cent. of these are given by the girls themselves. Would say in reference to the games during the summer, that we have four families, each of which have two baseball clubs, two basketball teams, one tennis club, as well as the croquet club. I personally select these girls at the beginning of the season, 
keep a list of the names, select the captains of each club, instruct and train them, and require them to practise just as religiously as they eat when they go to the table and sleep when they go to bed, and consider it just as necessary and obligatory on them to do so as the foregoing. While there may be isolated cases that would demur, yet, a little common-sense, practical talk along these lines by way of explanations regarding the good that is to be had both from the physiological as well as the psychological and ethical point of view, soon brings them to easy co-operation with us in carrying out our plans. We have very little or comparatively no difficulty in carrying these games on, especially as they are interspersed during the summer by public contests and awarding of prizes such as named. We remove all the bars, have no locked doors, no incarceration, no bread and water, nothing that will degrade the girl or detract from her pride or womanhood. We lay it largely, if not altogether, to the methods herein resorted to, filling the girl's working hours with a healthful and reasonable amount of school work and study along the lines of domestic science which, of course, she should know; and her hours of recreation with the methods herein stated. I think that the matter of discipline will adjust itself, to say nothing of the immense value of the exercise, sunshine, fresh air that she will derive. Indeed, it is these games and exercises that enable us to get good results in the schoolroom, in the kitchens, dining room and laundry and dress-making department and every vocation that they are engaged in.".

No testimony could be stronger than the last letter, to the effect that social morality would be greatly strengthened if girls could have athletic training before they return from these institutions.

One reason that social and reformatory institutions do not place more emphasis upon the value of athletic training and use it as an agent of social 
morality is that the schools in which its teachers and officers are trained almost wholly neglect this phase of social education. Is it not feasible to add to the courses in the schools of philanthropy such additional ones as the value of play; education through means of games; direction of playgrounds, recreation centers, etc., and a gymnasium where practical floor work and gymnastics and games can be taught and the right social spirit developed? Settlements and other organized social movements offer ample opportunity for field and experimental work, if the preliminary and fundamental work in theory be provided. The Y. M. C. A. schools do not meet the need, for they train especially for their own work, and can barely supply their own demand. Moreover, but few of their graduates teach women. The demand of the playground and recreation center and of the settlement alone, to say nothing of that of welfare work, institutions, etc., would seem to justify some such extension of work on the part of schools of philanthropy, or the starting of special schools for this purpose.

These movements indicate something of the use that is being made of athletics in public institutions. While this use is significant, it is still a mere beginning compared with its possibilities. One difficulty is that women do not stand shoulder to shoulder and say intelligently, definitely, insistently and emphatically, "We want and need this thing." We believe that if women really set about demanding group honesty and fair play among women and the training necessary for it, they would get it. If they insisted upon civic 
virtue as they do upon personal virtue, it would be forthcoming. If the women of the community would get together and do team work instead of dissipating energy on new clubs, or even if they would just understand the great necessity and be sorry a little while for their deficiencies as citizens, the problem of the need of play and games in cities would be far on its way toward solution. 


\section{CHAPTER, VII}

\section{COMPETITIVE AND PUBLIC GAMES}

Much of the objection to any athletic training for girls centers about the fear that they cannot play games without entering into inter-scholastic competition. It is remarkable that the amount of such competition is so small, compared to the number who play. Less than one-fourth of the colleges and private schools play inter-scholastic contests. In public schools, however, where there is no school control the percentage rises to seventy, chiefly basketball.

Class Contests. - It has not been found desirable or necessary to eliminate class contests, and fully ninety per cent. of the institutions admit their value. Many reasons for the retention of class contests exist:

(1) While the greatest value lies in the daily training, match games played under the intense desire to win are necessary to test this daily training in order to see how fundamental it is. This is best ascertained by contests under the control of the instructor, who can thus use them for educational purposes. Rivalry may run as high in an inter-class as in an interscholastic game, so the test and training are equally good.

(2) Contests of some kind are necessary to stimu- 
late a group spirit and to increase social activities among classes and institutions.

(3) Match games direct the attention of those who are not players or especially interested to this branch of the work, and the department of physical education receives recognition where otherwise it might be neglected.

(4) Contests strengthen the opportunity and necessity for social expression through athletic associations, and the desirable group experience of student government is thus made possible.

Disadvantages of Inter-Scholastic Competition.The objections to public inter-scholastic contests are for the most part well taken, although there is a tendency to exaggerate the danger in institutions other than public schools:

(1) The physical and nervous strain upon young girls who journey from school to school, or from town to town, followed by a hard game is a severe one. It is also difficult under these conditions properly to supervise and safeguard teams and accompanying enthusiasts.

(2) The lack of uniform rules and co-operation between competing organizations and the emphasis laid on winning prizes tend to delay placing athletic instruction upon an educational basis, lead to notoriety and invite much adverse and unfair criticism.

(3) The character of the audiences cannot be controlled where the contests are open to the public upon payment of an entrance fee.

Some of the instructors in schools which encour- 
age inter-scholastic contests speak in no uncertain terms of their effect:

"Few girls are ready to play outside teams. They lack the spirit of the sport and need to be trained in that more than in the liberal construction of rules."

"We are advocating the abolition of the high school league. Girls take things so seriously and the members of the defeated team cannot concentrate on studies for several days, especially where prizes are offered."

" There is a great danger of sacrificing some of the finer traits for the peculiar boldness which outside contests bring out."

One instructor writes at length that they do not encourage contests for the following reasons:

"There is a great tendency to overdo themselves physically, which cannot be controlled as they play on outside teams.

" They get interested in their game and spend so much time at it that they neglect their studies.

"Their behavior generally is demoralizing to the school; they try every means to meet in the library, halls and lavatory and talk game, of course.

" They very often go insane on their particular game, and do not care for any all-around work.

"A team always consists of those members that are naturally strong and robust. This shuts out the more needy, who are anxious to use the gymnasium for optional practice after school.

"We have hundreds who would like to use the gymnasium but are unable to do so after school because the ten members of the team monopolize it.

" This training to professionalism is to be condemned; too much time is lost, carting around the country. This race for the championship makes it a too strenuous affair 
and relations become strained. The losing team pick out coaches, teachers or umpires as targets.

" If we must have contests, it would be better to have them among the pupils of the school among the different years.

" Our girls need good sound all-around work, work suited and conducive to health, etc."

Under present conditions we believe that the conservative attitude of the majority of the institutions which include colleges, private schools and a small percentage of high schools, is the best for the future good of the girls and of athletics.

Audiences.-A question that always arises in connection with contests is whether they shall be open to the general public. The majority favor audiences which are selected by invitation and not by purchase ticket. The majority also favor limiting invitations to men who are members of the girls' families or of the faculty. Some schools issue all of the invitations to men in the name of the school and carefully supervise the list. Unfortunately in the high and normal schools, with a few exceptions, no such care is taken, admission being by purchase, so that any one is admitted. As a result many boys attend and by their noise, "rooting" and roughness discourage class songs and cheers by the girls. The class and institutional spirit which makes games so attractive may be quite lost where outside persons, who have no particular interest, make up the bulk of the audience.

At the present time there seems to be no justification whatever for pay games. Dues of members can 
be made to cover ordinary expenses, and the schools should provide the gymnasia and instructor. Abolition of admission fees would do away with the abuses due to too many contests and to mixed audiences.

Prizes.-This is becoming a serious matter in high school contests. There is a tendency to reward teams with articles of value instead of those rich in associations and inspiration, such as attaches to the college banner or cup which the class and not the team alone holds. The championship desire is thus becoming a work spirit for reward rather than a play spirit for the game itself.

Essentials of a Good, Clean Game.-The general approval of inter-class contests narrows our problem to the best way in which they can be made educational and successful. There are at least three indispensable essentials: (1) Good, clean playing. (2) A well-conducted game. (3) An inspiring audience.

The ability to play a good, clean contest depends upon the standard required by the school and upon the character of the training. Players in perfect physical condition are a delight. With gathered-up strength and a fair amount of muscle, good mind, elastic step, good clear skin and bright eyes, they are in good spirits and good humor and not too confident. Contrast such a team with one which looks dull, languid and listless, with slouching demeanor, a sour or bored expression and a take-it-for-granted air! Every one knows how distressing it is to see a player collapse and be taken off the field or to have her put out of the game because of "poor condition." Such 
scenes are long remembered and do a great deal of harm to the cause of good sport.

The appearance of the team has much to do with a good, clean game. If the color and style of the suits is uniform and they are simply made and well put together, the hosiery black, and the hair dressed so it will not cause trouble and if players come on the field in an orderly way, a good impression is made at the start. Contrast this with a team that comes on the field in suits and hosiery and hair ribbons all colors of the rainbow, straggling in one at a time, some chewing gum, some fixing their hair, others stopping to talk or wrangling with each other over positions, etc.! Some players like to wear jewelry, which not only looks out of place but frequently causes injury. During one contest side combs were picked up twentyeight times. These and other interferences detract from the appearance and good playing of the team.

Good, clean playing depends upon another thing as important as fine physical condition, and that is the spirit of the game. A good spirit is shown by such things as the following: Allowing each team sufficient time to warm up; absence of all complaints " that the other team has had more preliminary practice"; greeting of the teams by shaking hands, always at least on the part of the captains, and at the close of the game by the winning team giving the school or class yell or song of the defeated team; by refraining from uncomplimentary speech and action in case of interference or accidents; by accepting defeat without grumbling, complaining, or explaining 
or depreciating one's self and team; by accepting victory modestly and not using it to anger or irritate the defeated team.

To obtain such a spirit, the thirst for victory must become secondary to the sense of joy and the exhilaration of play. Grim determination to win and irritability because an opponent is outplaying her in place of feeling the exhilaration of having a worthy antagonist, charge the atmosphere with the unmistakable spirit of bad sport. The thirst for victory tempts a player to unfair and dishonorable acts, to take advantage of the rules, to attempt sly violations of the rules and even to make deliberate fouls. Unfair acts are more possible here than elsewhere because, in the excitement of the game and mass of players, it is difficult to detect the unfairness. But whether called or not, it is the making of fouls that creates the bad spirit. This atmosphere frequently breaks out in personal antagonism, recrimination and anger and then a good, clean game is no longer a possibility.

Essentials of a Well-Conducted Game.-The second essential to a successful contest is a well-conducted game. This depends chiefly upon players and officials. If the players are in good form and have the right spirit and the officials are competent and fair, the audience will also be orderly and well conducted.

Officials are necessarily an important factor. In all of the institutions, barring high schools, with few exceptions women act as the officials. On the whole, men are better officials at the present time, for women have received no special training and a good player 
does not necessarily make a good official. Women are also less exact, less firm and less businesslike in running off games.

It will not be possible to have good, clean, wellconducted contests unless certain conditions are maintained during practice. These may be summarized briefly: Compulsory gymnastics for every girl who plays in a contest and limitation of the number of contests to an average of three per season (this does not include practice games within the school); academic standing above sixty-five, so a proper balance between athletics and study may be maintained and making the team may be considered an honor; form as well as skill and good spirit as the basis of selection for the team; all arrangements for contests, rules, etc., under the direction of the school authorities.

The Audience.-Hitherto very little attention has been paid to the contribution the audience makes to the game. Much can be made of this in institutional contests in a way not possible in professional games. It is of the first importance to interest the audience. Too many teams think they are doing the audience a favor merely to admit them, then they put up a poor game which many cannot understand. It is a good plan for pupils to seat themselves among the audience in such a way that they can explain the game and interest the spectators in it. When women so largely make up the audience this is most necessary.

A good visible scoreboard, designation of opposing teams by color of suits, careful announcement of fouls and of the points scored so the audience can hear, will 
help to interest it. One college gives a two-minute talk to the audience, explaining what teams are playing, what the prize is, which goal belongs to each team and how the game is scored.

The second need is to please the audience. The use of colors and other decorations, of songs and musical cheers and of demonstrations of class spirit is especially helpful in doing this.

The officials can also contribute to the good conduct of a contest by keeping the audience in bounds, prohibiting hissing and catcalls, discourtesy to players, and by starting the games on time and having them played without unnecessary interruptions. It is a great pleasure for an audience to be fresh for the game instead of tired out with a long wait. On one occasion when contests had just been introduced in one of the colleges, about half the audience were late, thinking a "girls' game would not start on time." They were much chagrined and wanted the first half played over.

By attention to these details the school gives to the audience not only pleasure but a deeper interest in games and creates among women an appreciation of good, clean sport while it also lessens the skepticism with which men regard women's activities-all of the utmost value to the development of a good standard of athletics.

Athletic Organizations.-The most influential factor in developing these essentials of contests is the athletic association, league or club. These organizations are of two kinds, those within the institution 
to which only its students belong; and inter-scholastic and inter-collegiate associations to which the teams or pupils of the various schools belong. The financial responsibility assumed by some of them and the amount of social activity give them a wide influence. Complete control of contests, financial responsibility for them and absence of social activities tend to make them commercial organizations and to destroy their highest usefulness, by making contests, awarding prizes and stimulating competition displace all other functions. ${ }^{1}$

Field Days.-Of growing popularity in many institutions are the field days. Their chief importance is the social opportunity which they furnish as well as the development of the esthetic sense. They bring together not only the students and faculty but friends of the school or college and of the girls. The records made and prizes offered are of comparatively little value, as compared with this. They may also be a means of education and enjoyment to the audience if the athletic association is active and efficient.

When field days were first introduced, indoor and outdoor meets were the type most popular. The former consisted entirely of gymnastic competitions, -ladder, horse, rope climbing, traveling and flying rings and other apparatus, contests; relay, obstacle, club and other races; and broad and high jump, hurdles, etc. The outdoor meet included dashes, shot put, hurdles, relay races, etc. Basketball has now been added and in some instances hockey and baseball.

${ }^{1}$ For description of associations and their influence, see p. $103 \mathrm{ff}$. 
Field days leave much to be desired. It has been difficult to interest outside audiences of women who do not especially enjoy individual contests, for at the present time too much emphasis is placed upon individual events and not enough on class events and team play. The average field day is frequently not representative of the entire department and is lacking in variety and beauty, for such individual events as broad jump and shot put do not possess either to a marked degree. There is also an absence of fun and exhilaration.

The ideal field day could with advantage substitute for such individual events as shot put, hammer throw, etc., which are tests of strength and for which records already exist, events emphasizing skill, grace and the esthetic features. A field day should represent the entire work of the physical education department. Gymnastics, by class exhibitions, marches, Maypole or folk dances, etc.; athletics, by team and class games such as basketball, hockey, tennis, etc.; and such individual contests as hurdles, relay races, and short dashes as may be needed for interest and variety.

The following outlines of field days show how limited some of these still are and also indicate the possibilities:

School $A$-Outdoor meet-including competitive games, races and exhibition of gymnastics; basketball game between house and day pupils for a cup.

School B-Making of records in running, jumping, etc.; basketball game, luncheon out of doors, 
basketball dinner in the evening, presentation of cup by the athletic association.

School C-Forty-yard dash, running broad jump, relay race, running high jump, basketball throw, gymnastics, shot put, potato race, basketball game, luncheon out of doors.

School D-Military drill, figure march, track and field events including dashes, hurdles, shot put, broad and high jump and relay races.

The following rules and regulations for a tournament day show how well such events may be prepared:

“I. In order for a class to compete in a given sport the following number of entries must have been received at the gymnasium office not later than October the seventh:

1. Basketball .............. 12

2. Field hockey............. 15

3. Tennis ................. 6

4. Tether-ball $\ldots \ldots \ldots \ldots \ldots \ldots$. 4

"No class shall be allowed to compete if before Tournament Day the number of regularly practising members drop below the above requirements. All applications must be qualified by the Department of Physical Training.

"II. A cup shall be awarded to the class winning the greatest number of points, the championship value of events to be as follows:

1. Basketball, 1st place 7 points; $2 \mathrm{~d}$ place 5 points.

2. Field hockey " " " " " " " "

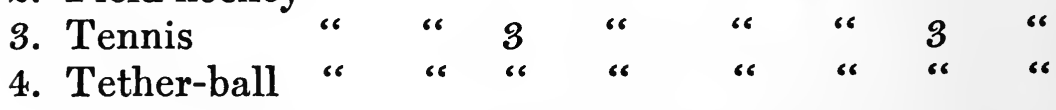

" The cup shall not be the property of any one class, but shall remain permanently in the gymnasium, the 
numerals of successive winning classes to be inscribed upon it.

"III. Two hours of practice each week shall be required of every one entering any of the organized sports. Failure to comply with this rule means disqualification.

"IV. Every member of a class team shall be awarded her class numerals and the initial letter of the sport in which they were won.

"Judgment in awarding positions on the various class teams shall be based on official record as follows: 1 . Health. 2. Submission to discipline. 3. Technical skill."

Summary.-From the data submitted by the various schools it would seem that the matter of inter-class contests in the colleges and most of the private schools is an important element, is well under control and is exerting considerable influence on the total life of the school. In some of the private schools, high schools generally and political and social institutions, the problem has not been squarely faced and many dangers exist. Recognition, regulation and proportion are far more necessary at this stage of the development of athletics than is suppression, for contests have their own value and place in social education and the tendency is to increase rather than diminish this value. 

PART III

METHODS OF INSTRUCTION 
$\sin x+4$

.

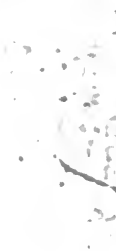

ing

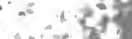

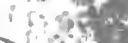
ifl

$\therefore \frac{1}{20,}$

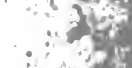

$\therefore \frac{1}{2}+\frac{1}{20}$
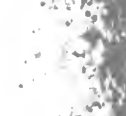

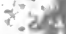

$+2 x^{2}$
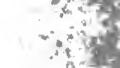

$\rightarrow$ inces $x$

- 4 ax $+x$

tons

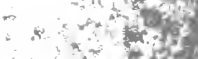

inatson:

ifiets:

siterty

sis.

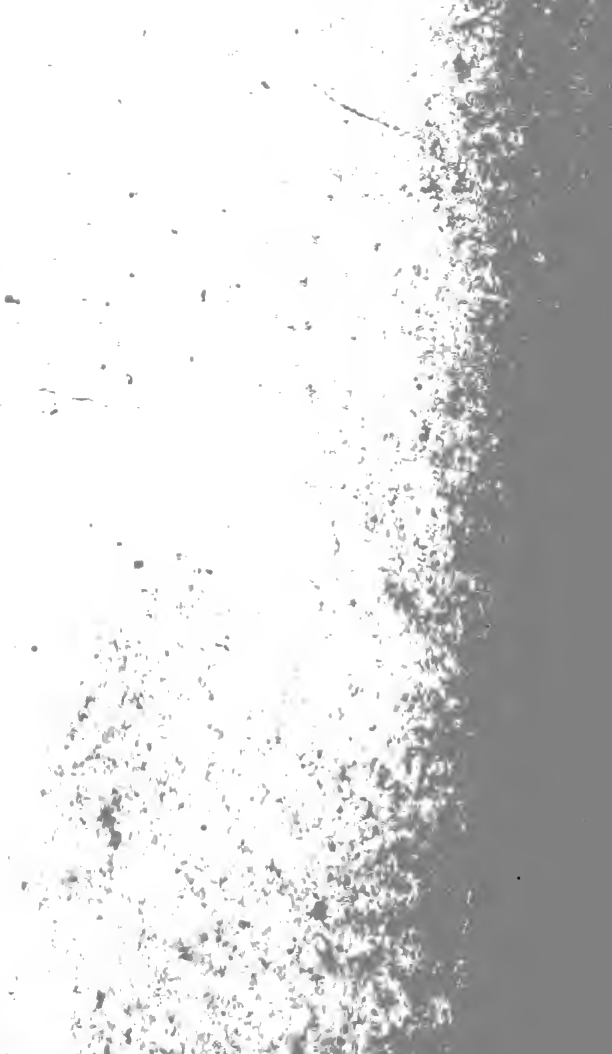

$\because-9 !$

s.

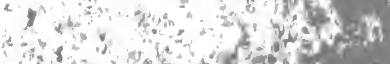

3

Tor 


\section{CHAPTER VIII}

\section{GENERAL SUGGESTIONS FOR GAMES AND CONTESTS}

To teach games so as to develop character and social spirit, within the brief time at command and so as to retain the play interest, is the real problem of the instructor. It is difficult to offer satisfactory general suggestions, since each instructor has more or less "her own way of teaching." Nevertheless, in games used for educational purposes it is necessary that attention be given to many details other than mere teaching of rules. From our varied experience and that of ${ }^{\circ}$ co-workers we have found that certain methods have been most effectual. Our suggestions are the result of constant experiment, different methods having been tried with different groups of girls in all kinds of institutions and the results compared.

Minor Games.-The full value of the use of athletic games for educational purposes as well as for recreation, we have found is best brought out by the combined use of the highly organized games with what are called minor athletic games. The minor games which we suggest as combinations possess a high degree of team work and have a strong social organization. In schools one highly organized game a season, varied with one or more minor games, is a good plan. 
The minor games are less difficult to learn and are not taken so seriously as are the more highly organized games, so they quicken the interest and stimulate the play spirit. They can frequently be played in a smaller place and in less time. A baseball practice of less than an hour is not very profitable for beginners and not satisfactory to players.

Among the minor games used successfully in combination with basketball, baseball and hockey are polo-hand polo, wicket polo and water polo all being desirable; volley-ball, long-ball, captain-ball, passball, battle-ball, center-ball and many other related games of ball.

Lacrosse ranks more with hockey and highly organized games, but is very little played by women. It may be included with great profit where the outdoor space will permit but is not possible in city spaces. It is a game schools should consider with more favor.

These and many other minor games, which will occur to the reader, make a desirable variation with those more particularly discussed here.

Instructors.-Opinions differ as to the prominence of the instructor on the floor or field. As a rule, players do better work and develop initiative, selfreliance and other qualities more rapidly when they are not dominated by her presence and personality. Some instructors go about the field talking constantly, commanding here, admonishing there or attracting the girls' attention by calling while the game is in progress. This distracts players, prevents them 
from planning plays and makes them dependent and self-conscious. The instructor should be the least conspicuous person, talking in a low conversational tone to a player while the ball is in play in some other part of the field or stopping the game and calling a foul and explaining it. Where a player's faults are in violation of the rules or cause her to make bad plays, such as fumbling the ball, inaccurate throwing, etc., it is a good plan to criticise her publicly so she will learn to accept criticism with good spirit. On the other hand, if she has mannerisms or faults peculiar to herself and not likely to be held in common with other players, we have obtained better results by talking to her alone about them. It is one thing to tell a girl before others that she fumbles a ball and quite another that she is selfish or cowardly. The other players have a common idea of fumbling the ball, but do not necessarily so easily or impersonally understand the other criticism. It is possible also to obtain impersonal criticism from class members. One instructor required all class members, not participating in the practice game, to attend and at the next practice they were asked to criticise one bad play and give the reason for its being such, irrespective of who made it. It is better that the instructor give commendation or criticism directly to players than to others with the idea of having them repeat it to the players, a process through which much is frequently lost in both spirit and accuracy.

When for any reason the game lags, the instructor can become'an inspiration by getting into it herself, 
for players are always ambitious to score against her.

It is unwise to permit one player to instruct another, unless at the instructor's suggestion. Even this is a doubtful exception, as players like to feel that they are doing equally well and such a method savors of criticism rather than of real instruction.

Do not permit " answering back," and insist upon deference to decisions even if they are wrong. For this reason it is necessary that the instructor give intelligent, accurate rulings and not opinions.

Players should recognize each other's rights and all rights should be equal. Rights of weaker players who do not make the team are not respected when others take their practice hour or use all of the balls.

"I can't" should be eliminated early, so that players may become responsive. The instructor should endeavor to have a girl carry out her instructions but should not insist upon plays which it is impossible for the girl to make.

An unfair or mean play should not go unnoticed on the field unless it is a temperamental matter to be dealt with individually. Some instructors think these tendencies will remedy themselves, but other players feel the injustice, and if they are not corrected there is a tendency to resort to similar methods.

Do not grant requests to play coveted positions unless it is a "fun day." Granting such requests destroys discipline, gives rise to suspicions of partiality and hampers the instructor. This tendency is easily cured by assigning to such players positions 
they least like. At first they may sulk and declare, "I won't play," but in a little while they take the advice of the old players: "Don't ask for a thing, just work for it." Trying players out in all positions is a very different thing from letting a girl play the position she likes even when it is not the one in which she plays best.

Although not called upon to explain changes in line-up or criticism of plays, the instructor should always be ready to do so, as it keeps a good spirit to have the faith and expectations of the players justified. Nothing is more detrimental to the spirit and democracy of games than the superior cock-sureness of the instructor who, when asked for a reason for things, says, "Because $I$ ask you to do it," or, " because $I$ want it done that way." This attitude does not educate players. One instructor in a school of physical education called players out because they dropped their bats after a hit. He insisted that they carry them with them to first. When the players protested that this was not in the rules, he flew into a rage, and said it was enough that he said so. An instructor who cannot discuss and explain rules, or who has not a rule for every decision, can never bring out character through games, though it may come out in spite of such training.

As instruction progresses, persistent faults or defects appear. A prescription card is of much help when the instructor is sure these faults are characteristic. Such a card may be given to each player, with the request that she make a special effort to overcome 
the faults specified. In one college, when the plan was first tried a disaffection immediately appeared and then quite as suddenly disappeared. Afterward it was found that each girl thought she was the only one selected and did not wish the others to know. When it was understood that every player had received a card, the attitude immediately changed. Some of the girls posted them in their mirrors as a constant reminder.

The following is a typical card for basketball:

Name:

Game:

Physical: Inaccuracy - throw too hard, run too hard. Practise jumping, starts and circle throwing.

Mental: Lack of attention; reaction too slow; bad judge of distances. Practise line work; catching and throwing ball from wherever get it.

Social: Co-operation is weak-practise with forward and center. Lacking in loyalty-refrain from laying the blame on others for your bad plays. Vanity-as shown by choice of positions. Selfishness-sulk when reprimanded or position is changed.

Esthetic: Stand badly while waiting for ball; squeal when running; clap hands and call names to attract player's attention; open mouth when catching balls.

A good list of don'ts for instructors to keep in mind includes: "Don't scold, nag, or show impatience; don't use sarcasm or ridicule; don't compare players with each other; don't be too self-assertive and conceited; don't make promises; don't pass judgment too quickly; don't be afraid to admit yourself in the wrong; don't be afraid to speak out; don't teach plays you are not sure of yourself." 
Instructors as Officials.-In inter-scholastic contests, instructors of the contesting teams should not officiate, even by mutual agreement. It is almost impossible for them to see faults equally well for both teams and there is a strong temptation to "even up fouls" if one side calls more than the other. Even when there is a fair spirit, players and audience have an air of suspicion. Where inter-class games are played the danger is not so great, as both teams belong to the same instructor. It is preferable, however, that instructors train some of their pupils to act as officials. They are thus free to observe the playing and observe players under competitive stress and in team work.

During a contest, there are instructors who "coach" on the side lines, give tips, direct the play, criticise decisions, are much in evidence and talk about the teams and their playing. There are no strong enough words of criticism for such practices, which make a good spirit and fair play impossible.

Never as instructor or official is it wise to tell a player immediately after a contest that she is responsible for winning or losing a game. Disappointed and inefficient instructors sometimes seek in this way to lay the blame on the team. Furthermore, do not allow other members of the team to tell her so. If she has played well enough to make the team and been rightly trained, she will discover it; if not, it will take more time and coolness to explain than is possible at such a time. 
Rules.-Thoroughly know the game and teach all that is known, including history and value of game, reasons for the rules and their changes, etc.

Line up a class in athletics at attention, as is done with gymnastic classes. This assures full attention and an opportunity to see that all are in good form. This is most important in settlement and other classes where players like to wear jewelry, high-heeled shoes, etc., which are not always discovered in the rush of play. A two- or five-minute quiz on rules, with the class in line, is a good practice.

Classify and teach rules in groups of similarity, giving but part each lesson. Avoid going over the whole game at once. It is easier to adjust individuals and teach the necessary preliminaries before the excitement of play begins, if players work together on simpler parts of the game, throwing, catching, running, sliding, batting up and catching, etc.

A practical division of playing time for new players is one which gradually increases the playing time and shortens the preliminary practice and rule reading, as players gain in endurance and skill:

10 minutes: (Basketball, throwing, running, passing, jumping.

(Baseball, throwing, batting, catching.

(Hockey, stick positions and swings.)

5 minutes: Play.

10 minutes: Rest-rule instruction and verbal quiz.

10 minutes: Play.

5 minutes: Rest.

5 minutes: Game for points. 
Managers.-An easy way to distinguish between the duties of manager and captain is to remember that the manager controls or arranges all details off the field, while the captain has charge of the team and gives all instructions on the field during the game.

The main qualifications of a manager are executive ability, mastery of details, tact and a genius for getting other people to work. Where schedules for games are arranged, she should be sufficiently clearheaded to always protect her own team and should be one whom all the players like.

Her duties are to see that all of the details of the game are arranged, including decorations, programs, music, cheers, leaders, ushers, good support for her team, well-drilled rooters or encouragers and that enthusiasm and good spirit exist. She also arranges schedules of games and is responsible for the good appearance of her team. She selects referees and umpires, and the scorer and time-keeper subject to the approval of the referee.

Captains.-The captain should have personality and self-control and not irritate the players with her commands. Her duties are to give the signals and see that they are instantly obeyed; address all officials; select the team plays; change players and positions; get the best out of the players, by suggestion rather than by criticism; hold the players together in team work and steady their plays; and work out new plays and carry out the instructor's orders. The captain has charge of all preliminaries such as tossing for goal or choice of field. She also represents the 
team in all discussions, arrangements or agreements when the game is in progress.

Officials.-In the games under discussion officials include umpires, referees, time-keepers, scorers and goal tenders. These are in charge of the game from the time it starts until the final score is announced. The referee is the superior officer and is primarily responsible for the good conduct of the game. The duties of umpires are primarily to call fouls or put players out. It is essential in selecting umpires that they be persons (1) who will not become so much interested in the game that they will forget to see fouls; (2) who will be strict and impartial in calling fouls; (3) who will call fouls clearly and indicate their nature; and (4) who will keep their tempers and not be overbearing in making their decisions understood.

When training girls to become officials the following are among the qualifications the instructor should seek to develop:

(1) Knowledge of rules in letter and spirit. Backbone and character. (3) Ability to interpret rules and enforce decisions in such a way as to leave the team and audience in a fair frame of mind. Ability to convince others that the decisions are fair. (5) Ability to control the audience as well as the players. (6) Kindness, courtesy, dignity and a businesslike attitude.

Having these qualifications, the duties seem clear:

(1) Stick to the interpretation of a rule unless it is clearly wrong. (2) Never permit argument. Listen to the captain's calling of a foul and allow or 
refuse to allow the foul promptly and proceed to play. Allow no one but the captain to speak. (3) Never threaten a player or team. Do not lose temper but persist in a quiet, dignified way, and if the game cannot proceed in an ordinary fair way, call it off.

Never permit bullying by team members or officials or sulky play which delays the game. (5) Demand instant recognition of the violation of a rule. Abstain from fault-finding. The official's business is to make decisions, not to lecture players. (7) $\mathrm{Be}$ ready to explain in a few words a questioned rule and be willing to produce the rule, but know the rules weil enough, so reference need not be made to them when giving decisions. (8) Be impartial in decisions and do not exceed authority or make it obnoxious.

Do not be too friendly with the players. (10) When officiating in such games as basketball and hockey do not stand rooted to the spot; follow the players, so you can see the plays. (11) Do not get interested in the game but follow each individual play. (12) Do not undertake to officiate unless there is a thorough understanding about the rules under which the teams are to play and unless the official is familiar with them. Patching up rules and differences, so the game can go on when there has been a misunderstanding, leads to bad feeling and inefficient officials.

The scorer is not generally considered of much importance and is seldom trained to do her work well. The score form provided for the various games, but so often ignored, should be used and the number and nature of the fouls and the player making them indi- 
cated. This helps an audience to understand the game and is a valuable record for the instructor. Scorers who are also players are ordinarily the best. Keeping a baseball score is so complicated that it should be made a matter of careful instruction. Scorers should also know how to work out percentages, averages, etc., so that the records will be of interest to the players and to the school.

There is a prevailing belief that any one can keep time, and that a variation of a few seconds is immaterial. This is a great mistake and may lead to bad feeling and charges of unfairness. It is better for a timer to use her own watch or a stop-watch which she understands. It is a good plan to invite some one who is interested in the opposing team to keep time with the official timer. Only the latter's decision is accepted, but it is a pleasant little courtesy and holds the official timer up to the mark. The farther removed the timer is from the audience, the more accurate is her work. Her whistle should be distinguishable from that of other officials, otherwise players do not quickly recognize the time call.

Timers and other officials should work in harmony, lest the timer " extend the time so as to right the decisions of a distasteful referee." Timers should be honest and certainly at all important games should be experienced. There is a strong temptation to throw the game or even up the score when one side is being beaten, by adding time. Absolute accuracy should be insisted upon and small errors never countenanced or excused. Class members who do not make 
the team and have the spirit of fair play may well be trained to become timers.

Field Etiquette.-Select competent, impartial officials. If there are none among women, train some.

Play with teams that abide by rules and play a good, clean game. Do not play with every one for the sake of a game. If a mistake is made do not "slug back." If teams that play a clean game would consistently refuse to compete with those who play " dirty ball," a great improvement would be made. There is too much getting even at the expense of the sport itself. A good plan is to watch a team play before challenging it. In inter-class games these conditions do not arise.

It is a good plan to have each contesting team go off the field between halves and rest alone. Do not permit talking to the audience or to the other team. Give them a real rest during which time the instructor may talk to them, encouraging or shaking up the team.

Numerous protests of decisions during a game are bad form. In the nature of the game itself every wrong cannot be seen and righted. When an official is manifestly incompetent and unfair, do not have her again. The great desire to play at any cost permits the toleration of poor officials.

The attitude of rival teams on the field should be friendly and not that of "hated rivals" until one team has won, when it so often changes to magnanimity on one hand and sullenness on the other. Teams that are not friends to start with should not play. 
Extend every courtesy in the way of quarters, rest and attention and avoid hampering a team by giving it poor facilities. Reserving the best seats for the friends of visiting teams, and other similar small courtesies, add much to good spirit.

We are confident that these few, among many suggestions that might be made, are not only essential to good training but will go a long way toward preventing "scenes" at match games, bad feeling and bad sportsmanship, and will make for cleaner playing and a group interest in group contests. 


\section{CHAPTER IX}

\section{BASKETBALL}

\section{VALUE OF THE GAME}

Basketball, as compared with many other games, is new, having been invented in 1891. This is the most popular athletic game for girls. Nearly every school and institution having any facilities now has this game, and there are also many independent clubs.

There are three recognized sets of rules, and these have so many variations that the game is sometimes recognizable chiefly by the ball. These are Spalding's Rules for Men, called the Official Basketball Guide; the Intercollegiate Rules, used chiefly by men; and Spalding's Rules for Women, adopted in 1899 and used. by a number of secondary schools and colleges.

Comparison of Rules.-In Rules for Women, the field is divided into three equal parts. Forwards and guards must remain in the end sections, and centers in the middle section. It is a foul to cross these lines. This necessitates additional officials called linesmen. The maximum field contains 6000 square feet. As many as nine may play on a side. The time of the halves is fifteen minutes. Dribbling is defined as bouncing. or touching the ball more than 
three times in succession after it has been caught with both hands, unless it is touched by some other player. Unquestionably the most important regulations are that two hands on the ball are necessary to secure it; the ball may not be batted or snatched or taken away from any player's hands; no guarding may be done over the body of an opponent who has the ball; and the ball may not be held longer than three seconds.

In Rules for Men there are no lines, the men playing wherever there is an opportunity. The maximum field is 4000 square feet. The number of players on a side is limited to five. Any one may throw for goal. Dribbling is defined as a play in which the player advances more than two steps while throwing, rolling or bouncing the ball against one or both hands one or more times without the assistance of another player. The ball may be batted or snatched from another player's hands, but not more than one player from each side may tackle the ball at the same time, if a player from the opposite side is also tackling it. There is no limit to the time a ball may be held.

The introduction of lines and the adoption of a non-interference game (by prohibiting snatching the ball and close guarding) are the essential differences between the two sets of rules, which have provoked discussion and materially changed the game. The alleged advantages of the other changes do not appear to be of sufficient importance to justify their discussion.

It is claimed that these two changes prevent 
fatigue, roughness and injury, lessen personal contact and further team work. Are such claims justified by the conditions? A typical statement of the advocates of Rules for Women is this :

“ Under men's rules our girls were not successful. They became exhausted before time was called, due to the excitement of the game, but as well to loss of energy owing to confused and purposeless movements, a characteristic of the schoolgirl age." Or, "Since each player is limited to a certain territory, severe strain is alleviated."

The Rule of Lineball.-Let us take, first, the use of lines. The average basketball court does not exceed 2000 square feet. In some favored institutions, like colleges and private schools where there are outof-door courts, they are larger, but the majority of girls play in public schools, city gymnasia and in city private schools. There are many courts having less than 1200 square feet. According to Rules for Women, this is divided into equal blocks, and in this small area three girls are expected to remain and play!

But were the area three times as great, we believe that the use of lines has been advocated under a misunderstanding of the possibilities of the unlimited field. "Lineball" has really been created to meet the defects of supervision and of training rather than the defects of the game itself, and at a great educational cost-that of highly organized team work.

At one university where supervision and training are of a high standard, an annual average of one 
hundred girls have played the game by Rules for Men for the past nine years, and during that time not one serious accident, not one broken bone, and not one collapse from overplaying have resulted. It has also been used in various settlement classes with the same good results, but always under careful direction and supervision. Rough play has been almost entirely eliminated, so much so that the fouls, though carefully called for this, average about four per game during contests. In other institutions where much attention was given to education and team work, guards and forwards rarely crossed the center line, except when making a five-girl team play, or in an emergency, simply because it was bad playing. Lineball increases the number of fouls. We have seen as many as twenty fouls called for crossing the lines, so that the game was made up chiefly of fouls. Some players are willing to commit a foul to which no odium attaches, like crossing the line, in order to have the ball go up in the center if their side has a superior center, rather than have a good forward keep the ball at the other end.

These good results have been brought about by training the girls to play their own positions and of their own volition to stay where they can play or protect their goals; not because they cannot go down the field, but because it is bad team work. Of course they do not do this at first, but it is made a part of their training. Inhibition is invaluable as an element of team work as compared with prohibition.

Nothing can be more harmful than to have players 
straining across lines in every conceivable position, trying to maintain their balance, without committing a foul. This is an unnatural expression, without joy or exhilaration, while running freely for a ball contains both. One player says: "Nothing tires me so much as the strain of balancing across a line." Another says: "I am exhausted by the cramped-up quarters and nervous expectancy." Another thing, when players give so much attention to getting as near the line as possible without going over, they do not follow the ball or game and play " ragged ball." Where lines are used, the placing of as many as nine people on a side, as sometimes happens, is a disadvantage, for they are of ten only in the way of each other and make team work impossible.

How much of the exhaustion is due to an unrestricted field and how much to unscientific training? Under Rules for Women do players better direct their energies or are the opportunities for its expression simply limited? Are players taught enough real team work to equally distribute the responsibility or do one or two players do most of the work? These questions are not so easily answered, for we have seen better results under Rules for Men than under those for women, and vice versa, depending on many things other than the rules used.

There is an erroneous conception of what constitutes team work. Simple passing of the ball, irrespective of plan or method, does not, in our judgment, constitute team work. The best team work, under all rules, réquires guards and forwards voluntarily to 
play near their own goal and not to recklessly follow the ball, leaving their own territory unprotected. It is just as possible to teach this under one set of rules as under another, making limitation by lines unnecessary. That this principle of good playing is violated so much under Rules for Men is the fault of training rather than of rules. In order to win games, beauty, science and education are sacrificed and the players resort to any play which will win. Massing players at one end, combining the strength of all the team against a few, getting in the way, etc., use of brute force rather than skill, are frequently a part of the tactics taught where victory is the only object.

Instead of possessing a superior advantage, the greatest disadvantage of Rules for Women is that a high order of team work, which equalizes strain and trains individuals to work together, is impossible. "Team work is as possible under women's as under men's rules," say its advocates. A reference to the diagrams on pages $202 \mathrm{ff}$. will show how impossible three- and five-girl plays, on a mathematical basis, are with lines. Why is it so difficult to teach girls indoor baseball? One reason is that the order of team work required is very complex. Why do one or two or three women work well together, but when increased to a small group they fall out? Because the team work they have been taught is very elemental, requiring few adjustments and little planning. Two forwards, having the same duties and tactics, may work well together, but add a center and guard, and the 
discriminative and associative processes are much increased. Many of the three-girl plays, even among three forwards, are not possible owing to limited space and similarity of positions which give little variety in tactics. The tendency is to have one forward throw most of the goals, and all the others accept the simple duty of "feeding" her the ball. As for lessening strain, the guard or center may stand a few feet away and see her forward straining for the ball and be powerless to co-operate, although the expenditure of energy on her part would be much less.

In addition to preventing team work and not being adaptable to a small field, "lineball " has other disadvantages. It is a less open and attractive game. Short passes, aimless passing among forwards to get rid of the ball and dribbling are encouraged. While more persons can play, they frequently do little more than stand around in each other's way. This was the case in one game played by nine on a side on a 900-square-foot court. Add to this number an additional linesman, and the floor is pretty full and the game somewhat confusing to an audience. In playing without lines, the apparent disadvantage of accommodating a smaller number can be met in practice by playing ten girls and then have ten others play while the first ten rest. In an hour and twenty minutes, forty different girls can be played. Eighteen persons are usually too many for the average instructor to teach at one time, especially young girls. 
The Non-Interference Rule.-From the educational and esthetic standpoints, it is a matter of wonder that a committee on rules could have chosen so detrimental a rule as lines and at the same time have selected so beneficent a one as prohibiting snatching or batting the ball out of another's hands, - a rule which makes the so-called non-interference game. This is designed to prevent injury and rough play, which it does, and it also accomplishes part of the good results claimed for lines-namely, preventing fatigue-for it makes the game one of skill rather than of strength. In the nature of things and by comparison with other games, the person having the ball should in all equity be permitted to play it. As a matter of ethics and sportsmanship this rule should be universally adopted by both men and women. A number of boys' schools have prohibited basketball because of the interference game, for a great part of the rough play and bad feeling engendered is due to it. Officials are confused and lax in their decisions bccause of it. It is not the man who can plan to get the ball first, but the man who can pull it away, who wins. With the adoption of a non-interference rule, we believe Spalding Rules for Men offer the greatest opportunities for both men and women for developing character and the mental, moral and social qualities so essential to good citizenship.

Disadvantages of Rules for Women.-One reason a fair test of both sets of rules has not been made is because the game has not been carefully studied under competent supervision and instruction, and much 
more is claimed for Rules for Women than can be substantiated. For instance, one writer says: "Women's rules make the game one of enjoyment, for the girls are able to play the full time, and there is an increased number anxious to play."

First, there is no proof whatever that the game is really more enjoyable under one set of rules than another. From such testimony as we have gathered from girls who have played under both sets of rules, they favor Rules for Men, and have often refused to play under Rules for Women. On the whole, it is the game itself and not one set of rules or another which attracts them. They are rather indifferent to discussions of rules, for they simply want to play.

Second, "full time" is misleading. It is our observation that players are perfectly willing to play shorter halves with more rests in between, if the total practice time remains the same. It makes not the slightest difference if it is ten or fifteen minutes, so long as they get enough work, and it is equal for all. Rules for Men provide that by agreement the time of the halves may be changed and as short a period as is desired played.

Although the movement for Rules for Women has served to focus attention on the need for uniformity, their adoption has really established a dangerous precedent and complicated the situation. There are not only Spalding Rules for Men, Intercollegiate rules, high school rules and protective association rules, but in addition to Rules for Women there are modified Rules for Women which have been adopted 
by certain schools and called by the school name. There is also "basquette." In other words, any school dissatisfied with the rules feels at liberty to change them, a situation not found in other games.

Where competitive games are played, such variations in rules become a serious matter. The first question asked by teams wishing to compete is "What rules are used?" In many instances the only possible compromise is to play one half of the game by one set of rules and the other half by another set. This makes one half fair to each side, but it makes the game unscientific, perplexing and distressing to an audience. Furthermore, the disagreements due to such an arrangement create bad feeling, and players invariably attribute their defeat to them. It is the worst possible practice for players to be in a position to blame rules for bad feeling and dirty playing.

Is it not possible in conference to agree upon rules which will serve the purpose of both education and recreation and more successfully bring about a uniform game, not necessarily a woman's game, but an educational, sportsmanlike game? When a game is widely played according to standard rules, the rules should be changed only by agreement, based upon wide experience and needs-not only of colleges, but of all institutions of learning and of civic institutions. The present Rules for Women have taken little or no cognizance of the needs of settlements, Y. W. C. A., playgrounds, roof and municipal gymnasia, etc., which are necessarily small and present a different problem. 


\section{METHODS OF TEACHING BASKETBALL}

Many of the following suggestions will seem elementary, and to many doubtless will be superfluous. Each year a considerable group of people, without experience, and oftentimes without much training, undertake to teach this game. Aside from this, many girls play it without instruction and do not know where to obtain suggestions. Every rule has an object and serves a purpose both in the technique of the game and in character building. It is in the hope that these suggestions may be of some value to the groups mentioned and will simplify instruction, that they are given at what may seem to be unnecessary length. They are based upon Spalding's Rules for Men, with the single change of the non-interference rule, and are grouped as follows: Requirements for the game; the green squad; duties and tactics of various positions; rules and team work.

Requirements for the Game.-The physical requirements are a sound body, good heart and lungs and endurance. Anemic girls and working girls with poorly nourished bodies must be played with great care. Basketball almost doubles the demand on the heart, and the dangers of overwork can be diminished if the condition is known. The game is preferably played in loose gymnasium suits or short skirts and in gymnasium shoes. If played in street garb injuries are likely to result. The only paraphernalia needed are a sufficiently large level space, a 
ball and two baskets and some paint or lime to mark off a court.

Basketball cannot be played with less than five on a side, but a second center may be played on a large floor space. There are two forwards, two guards and one center. The two forwards play at one end and try to throw the ball into the basket, which is ten feet from the floor. The guards of the opposite team play at this same end against the forwards and try to get the ball and send it to the opposite end to their forwards, or try to prevent the forwards against whom they play from scoring.

The Green Squad.-A group of small boys can be put on the floor, given a few simple rules and the game started. This is not a successful way of teaching girls. Before rules can be given and positions assigned, they need to learn many things. Preliminary class work is needed to relieve shyness and awkwardness and to stimulate the play spirit. The first thing is to teach them to throw. There are at least five advantageous ways:

The ground floor ball designed to avoid tall, longarmed guards. This should be a long, hard drive to center, or a quick, snappy ball to the other forward or guard, always close to the floor. Avoid having the ball hit the floor at an angle so it will bounce.

Side-arm ball, with unbent elbow and arm swung laterally to the body. Use all the back muscles. The object is to deliver the ball around the body of an opponent when she has her arms up for guarding overhead. 
Overhead balls, with two hands over the head, starting the ball well back. This is effective with short opponents and in throwing goals. By jumping a little in delivering the ball a clean throw may easily be made.

One- or two-hand ball, from shoulder to chest. This is a good goal throw, and may be used over the heads of short opponents.

Ball passed with two hands around back of the thrower's body from right to left. This makes a good short pass, avoiding an opponent very cleverly, and is a good return from out of bounds.

When choosing and making these various throws, teach players to look at their opponents and not where they intend to throw the ball. For instance, when intending to throw a high ball, some players roll their eyes upward, thus giving away their play.

Each instructor should make a special effort to have players make as many different throws as possible. If they know how to throw only one way, there is little variety to the game. The one throw they know is usually an underhand upward ball from the lap, which is slow and easily blocked. A variety of throws develops not only resourcefulness but discrimination and judgment.

They are now ready to practise long and short balls. Long balls are those thrown so as to fall back of a player and prevent the opponent ahead of her from getting them. Short balls fall ahead, so as to prevent an opponent who is standing behind or alongside from running up and getting them. Each 
player should aim to give the advantage to her own team. Throwing long and short balls necessitates good judgment and precision on the part of both thrower and catcher. These throws can be taught to classes in line.

Line up the class and have one person at the other end of the gymnasium. When she throws the ball to the line have the entire line run forward or backward, according to the way the ball is thrown-long or short. Throw swift balls along the floor and have the class line take the position of stopping them. Have it get under way quickly by practising starts and club relay races. Throw balls sharply to the end of the line over the heads of the players into the corner, instructing each one to make the shortest turn in that direction. Some will turn all the way around in place of the correct half-turn before they start. Have them practise running the length of the field on their toes, forward and backward, speed and balance being the objects sought. Throw the balls high and insist upon their jumping for them and running up to meet them. Have them spin about on one foot without making progress, and throw the ball from whatever position they catch it. If there are three or four balls, large classes can be subdivided into short lines. The advantage of this work in class lines is that much more can be accomplished with large classes in a short time. The competitive element leads each line to observe the other and stimulates it to do its best.

In addition to this line work, a necessary exercise 
is throwing and catching balls before beginning to play. One cause of sprains and falls is that green players are put into the excitement of a game without knowing how to run, jump, slide or otherwise use their bodies. Green players have to get used to themselves in action, to the floor, to the ball and to each other before they can begin to play.

We have not emphasized class practice in dribbling or bouncing the ball, because the free, open throwing game is much better for the players, and is much prettier.

One of the most effective ways of teaching guard work is to line the players up in a double line facing each other, with one person back of each line, to throw the balls. Have her throw the ball to a player in the line facing her and require the player to get the ball back to the thrower without the guards blocking it. The guard whose back is to the instructor does not try to block the ball until the forward receives it. This is to teach interference when the forward has the ball. In this way, the proper use of the hands and body, various styles of throwing and of blocking throws can be taught.

An interesting way to teach accurate goal throwing is to line up the players in two rows-one at each goal. At a given signal number one of each team throws for goal. Immediately after throwing she picks up the ball, tosses it to number two and runs back to the end of the line; number two does the same and so on, until all have thrown. The side making the largest number of goals in a given time, or when 
its line is used up, wins. In this practice insist upon use of the various ways of throwing and discourage the lap throw, which is only good on a foul.

There are one or two fouls to which special attention should be called, before the girls begin to play. It is difficult to avoid holding and catching clothing because of the loose, baggy suits, and special training is needed to avoid such plays. It is difficult to detect elbowing-one of the most aggravating fouls. Players should be taught to run with their elbows parallel with their bodies and not out at right angles. Some instructors even permit elbowing as a means of " keeping track of opponents." While not a foul, falling, rolling and sliding are to be discouraged. It is not only poor form, but injurious and prevents good, clean playing. Instruction in jumping, running and throwing will do much toward having one "play up."

While this preliminary work is going on, in the first three or five lessons, depending on the greenness of the material, from five to fifteen minutes may be given to actual play. At the first practice there can hardly be any play at all; at the second ten minutes, without doing more with the rules than to say "Do not run with the ball," or " Do not take it away from another"; at the third increase the play time and give more rules. In the meantime have each player read the rules, and in the third or fourth lesson begin systematic teaching. The first thing is to explain the field-not only the lines but their purpose. Encourage questions and give quizzes, for they help to make 
an intelligent game by having players understand the reasons for various regulations. For instance, if they know the purpose of the two-foot circle, it is easier to observe the rule. From about the fifth lesson on, care must be taken to teach new players their positions. In the beginning some instructors even call fouls to teach forwards not to desert their goals and centers that they are the middle-men. When once players understand this and do it as a result of their own initiative, the result is a really beautiful game. Beginning with the fifth or seventh lesson, fouls should be called strictly. It may take too much time to have each one thrown, but they should be called and explained.

This preliminary work is not a trivial matter. In addition to its educational value, it makes the players familiar with the atmosphere of the game; it arouses the play spirit without burdening the mind too much with rules-a thing that discourages players who have but little interest in games; and it enables the instructor to take a survey of the material and understand her players.

The green squad is now ready to learn something of the science of the game.

Forwards.-Forward is perhaps the most important position. As a rule, she sets the pace. In training, if there are some who need slower work or especial attention or have mental or physical defects, they had better be tried here rather than on the active guard line or in the responsible center's place. This of course applies to preliminary training-the aim 
being to develop all players. There is a belief that team work is not much needed by forwards. Goal throwing should be tried only when there is some chance of scoring, and that chance is often secured by rapid passes which confuse the guards. Completely subjugate the desire of a forward to throw for goal under any and all conditions by explaining that it takes little head work to cage a random throw, but it does takes a great deal to get the ball in position to be caged. This develops unselfishness in the shortest time. A good method of instruction is to train one forward to play up field and the other back; in this way they come quickly to know where to find each other.

A difficult thing to teach forwards is to follow a ball after they throw for goal and judge by its speed and direction where it will fall. Green forwards will stand as if in a trance, waiting to see what happens. Sometimes when a ball bounces back to them they are too dazed to get it.

In free throws emphasize the underhand throw. Its advantages are that the thrower can control the ball and is better able to judge of the necessary amount of force. Have the ball held in the same way, lacing same way, fingers in certain positions on the seams, etc. At least two or three forwards in each class should be trained to throw balls on fouls. When there is the regulation screen, caroming the ball should receive attention.

Teach forwards to make short passes and to play to each other and to their center. Few girls are 
strong enough for accurate long-distance throws. Skill in dodging should be made an especial part of the preliminary training. Give forwards all of the principles of guard work. This is often neglected, as many forwards only throw for goal and do not prevent guards from getting the ball to the other end. Hold forwards responsible for inaccurate throws, thus making it clear that it is not always the fault of a player who fails to catch the ball.

Guards.-Guard work is the least popular, for they have most of the drudgery and little of the credit. A goal scored by any one counts and some encourage guards to throw for goal, which makes the game more complicated and increases the work of the guards. Guard work develops unselfishness and takes out vanity and other " hindering" qualities quicker than does any other position. No matter how many times a guard successfully blocks a ball, every goal scored by her opponent is "laid up against her."

Train a guard to get the ball first; next to block the ball or spoil the aim; and third, to jump quickly. Guards, unlike forwards, must be able to divine a move, and to closely follow the plays. The best position for guards on the toss-up at center is alongside the forwards; not in front, because this may make the forward foul; and not behind, because it is a disadvantage. It is important to keep another player from fouling.

In a non-interference game, where the ball cannot be knocked out of the hands, guards may wave their arms and hands to spoil the aim or block a ball, but 
cannot hit their opponents. Some players wave their hands rapidly in a small radius close to the eyes of an opponent, to prevent her seeing. This and similar tricks are against the spirit of fair play.

Center.-In all-around team work the center has the most responsible position, requires the most endurance, and height counts for more than elsewhere since she may jump and catch the ball with both hands and throw it or bat it. Quickness and ability are necessary to throw goals, but more emphasis should be placed on the ability to do team work than on good throwing. Centers require all of the skill of forwards and all of the tactics of guards. The center is the pivot of team work and requires the finest kind of a combination of qualities, for all members of the team rely most upon her.

Rules.-Basketball rules need simplification. A good classification, which may be posted in the gymnasium or copies distributed, is into those which govern the ball-those which govern players, and general rules. The penalties should be given in each case. An illustration of one which governs the ball is-a ball is out of bounds only when it has completely crossed the line; of one which governs the player-there shall be no shouldering, kicking, etc., or rough play; of a general rule in case of a tie-the referee shall then order the game to continue until each side has made two points. When these rules, and especially the penalties, have been made clear, then officials and their duties and classification of fouls and keeping score may be taken up. 
Another classification based on penalties may be used to advantage: (1) Fouls which give free throws ; (2) violations which give the ball to the other side; (3) violations which give the same side another throw; (4) general rules, as when goals count, disqualifications, etc. Such groups, if explained together, avoid much confusion. Giving rules in sequence and using illustrations are helpful.

Another detailed classification for teaching rules is: Fouls on the ball; fouls on the person; boundary rules; rules for giving ball to the other side; rules for returning ball to the same player; dead balls; scoring; rules relating to officials; and when ball is thrown up between two players.

Team Work.-Nothing is so important in the social education of the individual through games as team work. Its absence means failure to develop the most important moral qualities. When a group of people play or work so well together that there is no friction and their combined activity, with all its variety, results as accurately as though one person, unimpeded, had accomplished it, it is unmistakably the result of real team work. This implies on the part of each player ability to use her body accurately; a knowledge of each other's characteristics and style of play; confidence in each other; and a willingness to adjust herself. Jealousy, rivalry and distrust are fatal to team work. More than anything else team work develops each player and contributes to the beauty of the game from the spectator's point of view. 
There are at least five things for which an instructor should work: Coolness, quickness, accuracy, good judgment and self-control. The essential principle of team work is that each individual must be willing to sacrifice her chance of scoring for what she believes will be a sure throw by some other player. The pivot of success is the captain, who must be able to control herself and others, and who will discourage star-playing and insist upon co-operation at all times.

Quick, continuous, short, unexpected passes and getting rid of the ball quickly are the physical secrets of effective team work. Some believe that twoor three-girl plays constitute all there is of team work. The A. A. U. rules contain this suggestive comment on team play:

"Be sure to remember these points: ' Get out of your head the idea that your first thought should be the basket when you get hold of the ball. Get rid of the ball quickly; when the ball is coming to you have your eye out for getting rid of it at once to another player; don't wait till you get it and then look around; bear in mind that the rules have been formulated by students of the game and that their strictness is necessary to expert playing; don't think that the number of goals you shoot indicates your value to your team. The practice of scoring goals to the credit of individual players ought to be abolished, they should be scored only in total to the credit of the whole team."

A difficult thing to impress upon players is to get the ball on the run and to pass it to a player who is making progress toward her goal. This frequently 
gives a forward the chance to throw for goal before her guard can reach her. Girls are too much inclined to wait for the ball to come to them and then throw it to some one who is standing still.

A principle to be taught first, last and always is: When any opponent has the ball, never get away from your own opponent. Make it impossible for any one on the opposing team to receive or pass the ball. This is more often taught guards than forwards, but it applies to every player equally. There are no exceptions until after the ball is thrown, then of course all make ready to get it.

The reverse of this rule is equally true and equally strong. When your own side has the ball make every effort to get away. One of the difficulties is that instructors do not insist upon these rules, so there is much wild, purposeless playing. Digressions are allowed because occasionally a good play is made by violating the rule, but if every player without exception stuck to this principle, some serious blunders would be avoided. Some players never do any thinking or playing when the ball is at the other end of the field and are, of course, never ready. When the other side has the ball, the main thing is to prevent an opponent from getting it on a pass, rather than to put the whole energy into getting it oneself.

The simplest way to teach team work is to begin in groups of three, using the triangle as the basis. It may be said of the illustrative team plays which follow that they cannot be carried out when the team is playing against opponents. Our repeated experi- 
ments show that they can be carried out eren in interclass contests where both teams have been taught the same plays. In interscholastic contests the opposing team, not knowing the formation or signals, is frequently so confused by the rapidity and peculiarity of the plays, that the complicated five-girl plays are quite successful. But even when they are attempted and fail, the advantages of training remain. It is possible in a limited way to use the triangle for training in "lineball," but the plays can rarely be made in a game. The three forwards do little more than exchange the ball, and cannot carry out a definite plan within the small space allotted to them. They cannot advance far enough to complete a play, and it is not possible to change off forwards with guards.

The following series in the order of their progression has been successfully used. There are many possible variations of these, but the following will illustrate the method. In the diagrams the solid lines indicate the runner, the broken arrows the ball. $A, B, C^{1}$ indicate the first

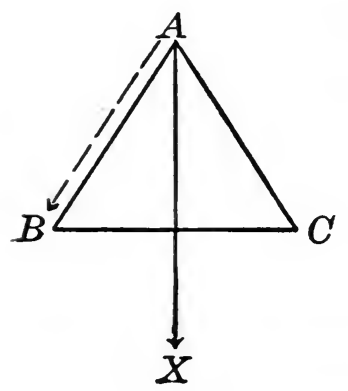
play, and $A, B, C^{2}$ the second.

\section{I}

Three players, $A, B, C$, are lined up about ten or fifteen feet apart in a triangle. $A$ throws the ball to $B$ and immediately runs straight across to $X . \quad B$ throws the ball to $C$, who throws it to $A$ in her new place. $A$ throws it to $B$ and runs back to her former place, and the play is made all 
over again. When this can be done so rapidly that $A$ is kept running constantly in order to get to her place in time to receive the ball again, the play is learned.

\section{II}

Line up players as in I. $A^{1}$ throws the ball to $B^{1}$ and runs as before to $X . B^{1}$ throws the ball to $C^{1}$, but instead of standing still runs across a little to one side of $B^{1}$ 's place. While $B^{1}$ is running towards $C^{1}, C^{1}$ has thrown the ball to $A^{1}$ at $X$ and has started for $B^{1 \text {; s }}$ place. $B^{1}$ and $C^{1}$ pass each other while $A^{2}$ has the ball. $B^{1}$ will arrive in $C^{1}$ 's place in time to receive the ball again from $A$. When each player has changed places once they are

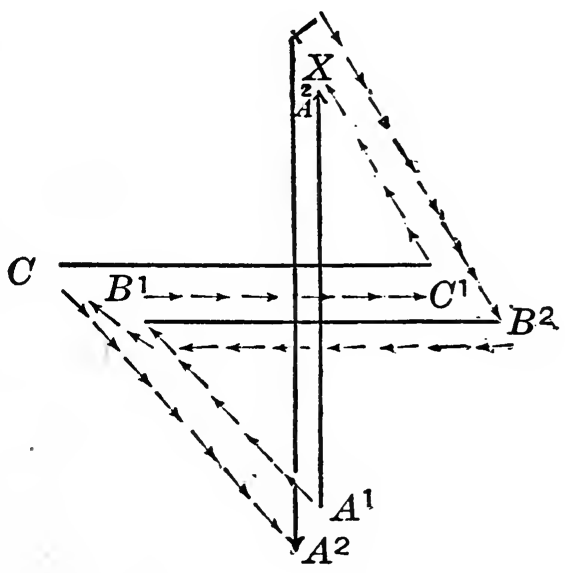
ready for the second play indicated as (2). $A$ throws the ball to $B^{2}$ and runs back again to her first place, $B^{2}$ throws the ball to $C^{2}$ and they again exchange places. $A$ now has the ball and the play begins all over again. Every one should be in the place at which they began to play, if no error has been made. They stop only when they throw the ball, and always throw before starting to run again. When this is played well they are on a continual run except the instant they throw. The ball must 
be thrown high enough to avoid the heads of the runners and accurately, for a dropped ball stops the whole play.

\section{III}

In the preceding play-each player ran opposite to her place. In this one the same throws are made, but the thrower runs to the unoccupied place. The girls call this practice "Pussy wants a corner."

It consists of four series of changes, made consecutively. The ball must be started as indicated or all will run around in a circle. Two things must be remembered: $A$ always throws to $B$ and $B$ to $C$ and $C$ back to $A$. If this order is changed, a mistake has been made. Second, each player immediately after throwing takes the unoccupied space, never going

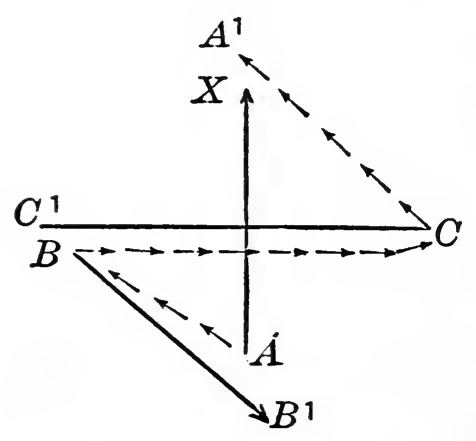
straight to a point where another player stands as in No. II.

(1) $A$ throws to $B$ and runs as before to $X$. B throws to $C$, but now $X$, the unoccupied space, is that vacated by $A$, so $B$ runs there. After $C$ throws to $A$ she sees that $B$ 's first place has now become vacant, and runs there. We are now ready for the second series and the positions are:

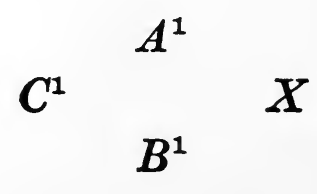


(2) $A$ has the ball and throws as before to $B$, running to $X$; when $B$ gets the ball she throws to $C$ and crosses straight over to the place just vacated by $A$, and $C$ throws to $A$ and goes down to the place vacated by $B$. The positions for the third series now are:

$B^{1}$
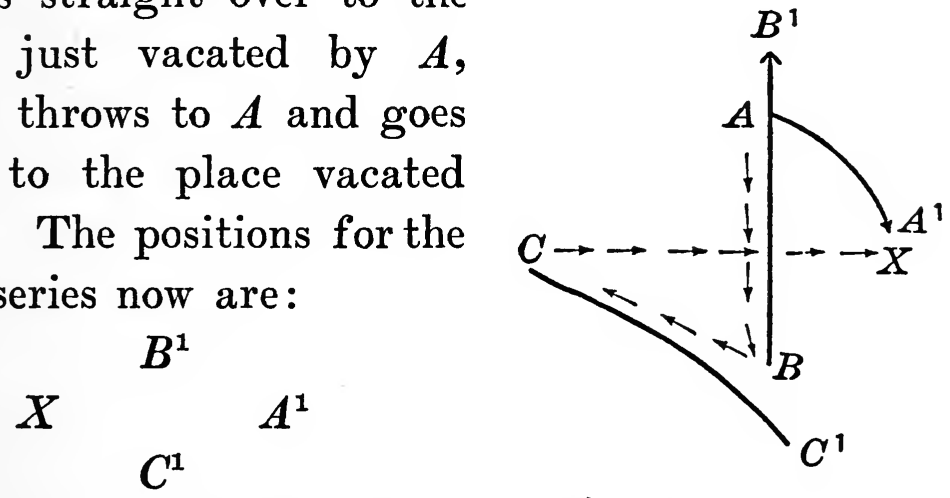

(3) $A$ throws to $B$ and runs across; $B$ throws to $C$ and then runs to the place vacated by $A ; C$ throws

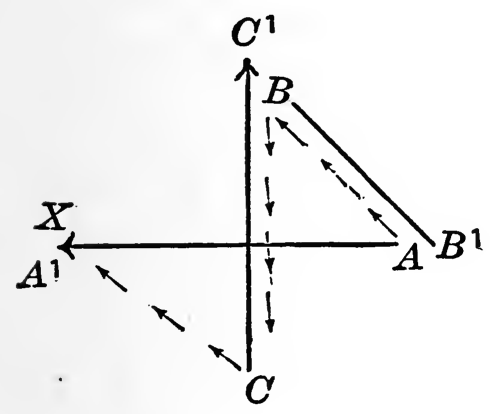
back to $A$ and goes up to the place where $B$ started. The positions for the fourth series now are:

$C^{1}$

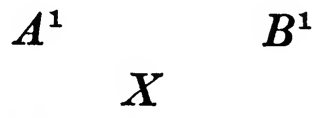

(4) $A$ throws to $B$ and

runs down to $X ; B$ throws to $C$ and goes straight across to the place vacated by $A$, and $C$ throws to $A$ and runs to the place just vacated by $B$. The players are now in the same position as when they first began the series and are ready

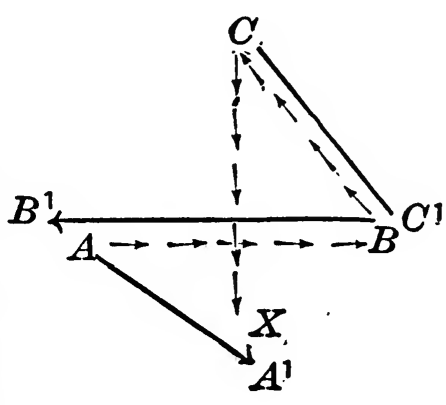
to do the play all over in the same way. This play is not learned until they can 
go through the whole four series at least three times without error or dropping the ball.

I, II and III are the basis of all team work. No play, change or combination will appear in any team play whose principles are not found here, be it three- or five-girl plays. They teach the player to keep her head; to throw the balls without running with them; to catch and throw promptly; to change positions accurately; to throw the balls from the position in which they are caught; to hold the ball away from the body, etc. They offer the best practice for getting the ball out of corners and taking it down the field. They also teach the players to protect a weak or unoccupied part of the field, and to use every opportunity. Players who have done this preliminary team practice well will unconsciously, during the excitement of the game, carry out these very plays,

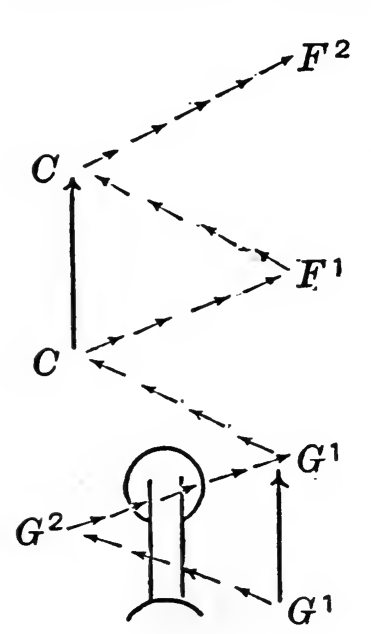

even with opponents against them, much to the delight of the audiences.

\section{IV}

This series possesses the additional advantage of using all of the team and of advancing the ball. Guard ${ }^{1}$ has the ball near the basket, and throws to guard ${ }^{2}$ and runs ahead to receive the ball again. Then she throws to center and gradually leads her forward back, as she is the rear guard. The center throws to forward ${ }^{1}$, and not wishing to draw 
the down field forward away from goal runs down and receives the ball from the forward and then throws to forward ${ }^{2}$, or for goal, depending on the opportunity. The positions may vary, but this is one of the most common and simplest forms of five-team play. In all of the plays where the ball is carried down the field, the number of changes made depends chiefly on the size of the field. Short passes can be. practised by lessening the distances between positions.

\section{V}

This series possesses the advantage of teaching a team as a whole to change positions rapidly, to protect its field and to get away from its opponents. The center gets the ball under the basket, which the instructor has thrown. She then throws it to guard ${ }^{1}$, who throws it to guard $^{2}$. In the meantime the center has run down the field to receive the ball from guard ${ }^{2}$, who after throwing to her runs ahead. Center then throws to

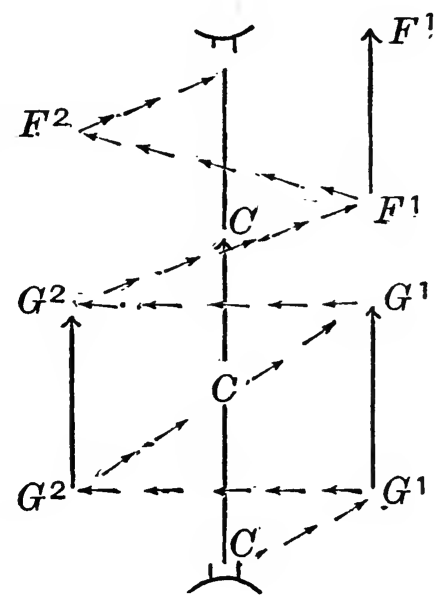
guard $^{1}$, who has advanced the latter, passing the ball on to guard ${ }^{2}$. A little past center the forwards take the ball in the same way, and the center or forward nearest the basket throws for goal and starts the same play back. This should be done the length of the field three times in succession without error or 
fumble before the instructor can be sure the girls know it.

\section{VI}

This is the same play as No. V except that the players cross over, which is No. III applied to five players. While rarely successful in contests where teams are equally matched, it is invaluable in train-

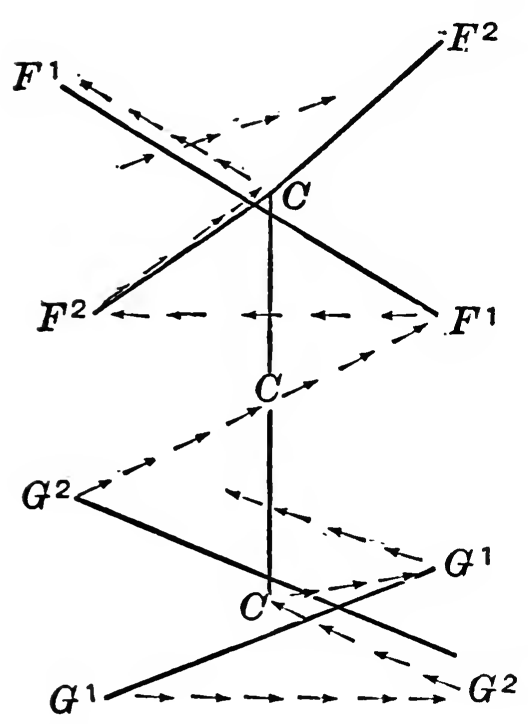
ing players to change to the side of the field that is not protected. Guard ${ }^{1}$ starts the ball to guard ${ }^{2}$, who throws it to center, and then guard $^{1}$ crosses over ahead of guard ${ }^{2}$, and guard $^{2}$ crosses ahead of where guard ${ }^{1}$ first stood, and receives the ball from guard $^{1}$. The forwards make the same play at the other end of the field.

This can be combined with $\mathrm{V}$ and the straight field played at one end and the cross field at the other. Require the players to change off the second time they do it, without being reminded. This play should be carried uninterruptedly through the entire field two or three times, and it has been done without mistake, by a team, six times.

\section{VII}

An interesting variation is the straight line play. In giving this the next one to receive the ball 
must not run to get into line until the girl who is to throw to her receives the ball. Otherwise the formation will be given away and the opponents' will be there, too. Guard ${ }^{2}$ gets the ball, the center who is on the other side runs in behind her to receive it and guard ${ }^{2}$ then crosses over to receive it from center. While the forwards are getting into line the center runs straight toward the basket. When she gets the ball

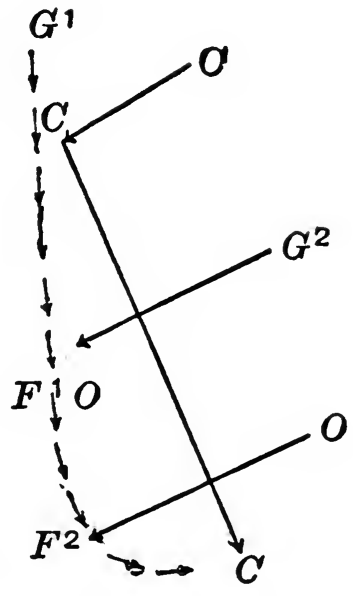
she starts the same play back again, all crossing to the other side.

\section{VIII}

A difficult variation, which can be attempted only after much practice in team work, is to have guards

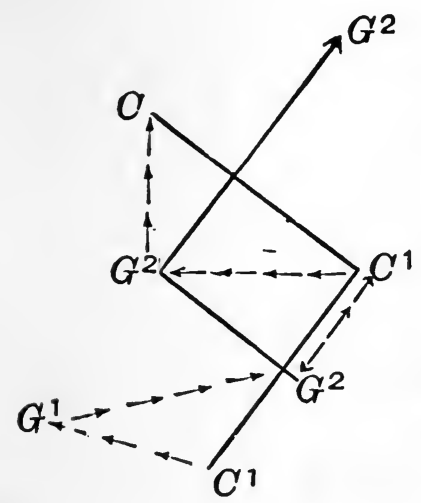
and forwards take the center place and have the center play out. Center ${ }^{1}$ gets the ball, throws it to guard $^{1}$; then instead of keeping in the center field she runs out to the side. Guard $^{1}$ then throws the ball ahead to guard ${ }^{2}$, who throws it to center in her new position. Then guard $^{2}$ takes the center position, etc. When it comes to the forward end, they make the same changes with the center that the guards did. If the players are not very quick 
guard $^{1}$ will have to follow down the field so as to be ready in case the others do not get into position in time.

These illustrative plays by no means represent all of the possible combinations. They simply indicate some of the possibilities and show the splendid mental training, the superb physical control and the admirable group education which team work gives. It is the training which is most valuable, whether the plays are used in contests or not. Dancing and other esthetic exercises are not more beautiful and graceful than the precision, form and skill with which these team plays may be made.

Basketball gives girls another opportunity for team practice which few other games provide, namely the use of signals. These have to be comparatively simple. The various team plays may be indicated by numerals or letters or names. These may also be used to indicate a player's change of position when one of her side gets the ball. For instance, if a forward sees that her center will get the ball she can say sevenand her center knows that an odd number means that she intends to run quickly to the right side of the field. The opposing guard, not knowing what seven means, has to wait until she starts to run before she knows the direction. It is a great advantage to know where to throw a ball without turning to see. Simple visual signals like throwing the head back for a long ball, or holding the right hand out horizontally for a ball to be thrown in that direction, etc., are effective. Throwing the hand up may be taken as a signal for 
a high ball and gives the player a chance to make the distance. Bending forward is a good signal for a floor ball. Successful use of team plays and signals depends upon a strong center, and players should avoid giving signals when they have a poor chance. Some girls think signals are only valuable to attract attention of other players and audience and do it when they are in poor position. It has become such a habit that calling players by their first name, which means " throw me the ball," is done by girls who are replacing side-combs or fastening suits, with no idea that they will get the ball. This is not team work.

Unfortunately these team plays and signals are not used a great deal by girls. Instructors only think them worth while to win games and not for individual training. Clapping hands, yells, whistles, etc., are more popular though not pleasing or successful, for if all the players want the ball, they all do these things at once.

In the use of these team plays and signals care should be taken that the habit of running with the ball is not formed; that the game does not become a series of passes with no try at goal; and that the ball always goes forward and is not played back into the opponents' territory. 


\section{CHAPTER X}

\section{INDOOR BASEBALL}

\section{VALUE OF THE GAME}

Baseball is not widely played by women, but possesses the greatest educational possibilities, for it is the most highly organized of all games. There have been four causes of the lack of interest: the hard ball, the heavy bat, the long-distance throws and the complexity of the rules. While retaining all of the fun and value of the outdoor game, indoor baseball has solved all of these problems but one, and is admirably suited to women. It was invented in Chicago in 1887, but was not popular at first, owing to the great difficulty of devising rules enabling a base-runner to get from base to base after a pitched ball. The indoor game may be played outdoors by using a larger diamond and the smallest ball allowed by the regulations.

Advantages.-The ball used is soft; the bats are short and light; curves are not much used; the pitching is the straight arm, which is especially easy for girls, as it is the way they ordinarily throw; gloves and masks are not required, as the element of injury is greatly minimized; sliding bases is but little practised, owing to the rule that the base-runner cannot 
leave the base until after the ball has passed the batsman or while the pitcher holds it; bunting is much used, so strength does not count for a great deal; and the distances are short, so the throws need cause no strain. A high degree of exertion is required only at intervals and then is not prolonged. Above all it is a pretty game with much fun in it. The only remaining difficulty is the complexity of the rules.

Baseball has some advantages over basketball. It can be played by girls not strong enough to endure the constant strain of basketball. The order of team work is higher, for every player has to learn to field, bat and run bases, and she has to adapt herself to more players and learn more varied plays than in basketball. It also accommodates more players at one time.

Baseball like basketball requires a good body and good lungs, but there is so little strain that almost any girl can play. It develops to the highest degree, concentration, observation, memory, judgment, quickness, accuracy and the moral qualities. An illustration of unselfishness through team work is the "sacrifice hit," where the batsman deliberately puts herself out in order that another, who has a better chance, may score. No game offers better opportunities for corrections_in bad standing postures and general carriage. The following suggestions for teaching indoor baseball to girls are made at length, in the hope that the game will be more widely used for both education and recreation, as it so richly deserves. More 
information is available for those who wish to play baseball than basketball, but it is also more technical. Spalding's many books on outdoor baseball and how to play the various positions and bat contain many valuable suggestions.

\section{METHODS OF INSTRUUCTION}

As in basketball, there should be much preliminary class work in the use of the bat, throwing, catching and base-running. We have found baseball most intelligible and easily taught by dividing the instruction into the following groups: Duties of various positions; definition of terms; rules applicable to the various positions. The following suggestions are made according to this classification:

Pitcher.-It is well to make clear to the pitcher from the start that she has other responsibilities than merely throwing the ball to the batsman; that playing the bases is important, and that she is responsible for fielding batted balls in her territory. There are second season pitchers who never go out of the box because they have been instructed "only to pitch." Teaching the pitcher to play second base when the baseman goes after balls should be begun early. Strive to develop, first, accuracy, then head work, and lastly speed.

The pitcher should practise getting control of her ball for a little longer distance; then in a game her control remains good with shorter distances. Have her observe the style of the batsman. For instance, if she stands close to the plate and grasps the bat 
near the handle, throw the balls toward the inner side of the plate, for these are difficult to hit. If she stands well back, a ball on the outer side may be hard to hit.

Establish the feeling of co-operation between pitcher and catcher. In order to get balls over the plate, the pitcher needs something to aim at, and the catcher's hands in a good position help her a great deal. From the beginning, have her throw careful balls, and have the ball held in the same way before delivery. Although only one base can be taken on a passed or muffed ball, it is most important to remember in training, and the catcher should return the ball to the pitcher as soon as possible.

The pitcher in indoor baseball need not be taught to watch the bases while she holds the ball, for no bases can be stolen, but she should always know how many base-runners are on bases, their location and the number of outs, and should make up her mind before she pitches where she will play the ball if she gets it. Teach her to put out the one farthest around, and when there is a runner on third, to pitch accurately so the catcher will not miss the ball.

When there is not the full number of shortstops, the pitcher plays this position and leads up toward home immediately after delivering the ball, so as to be ready for a bunt or pop-up.

Catcher.-The catcher needs to be observant and cool and to have a good steady hand and be capable of good head-work. Size and weight are of some importance, speed is desirable, and she must be fear- 
less. A timid person rarely plays well behind the bat at first, but it is a good place to develop physical courage, as well as desirable mental qualities.

The catcher stands directly behind the bat. The first thing is to teach her to stand up close and nct to be afraid of the bat or ball. Practice in catching hard-thrown balls will help this. The second thing is to insist that she "clutch" the ball when once it reaches her. The large soft ball is likely to get away unless much care is used in teaching players how to use their fingers in catching. The third thing is for her to throw the ball accurately as soon as she catches it. The fourth thing is to teach her to anticipate the ball. For instance, if it is going high, jump; if wide, run to one side. Insist upon her making an effort to get the ball instantly and never to take it for granted that a run will be made. She must be taught to watch bases and throw to the right one instantly. She should always make careful note of the position of each base-runner, number of outs, etc., before each pitched ball.

She is the home baseman and as such has to learn its tactics. This double position needs much attention, as it is very difficult to teach girls this combination.

By putting hands in position the catcher can signal if she wants a high or a low ball. The pitcher need not throw it, but if they work together the catcher's instructions are usually followed.

She always makes an effort to catch all foulsfor a foul tip caught counts as a strike and a foul 
hit caught is out. She has a view of the entire field and knows all that is going on, and is therefore most responsible for the field. She plans plays to catch the runners and keeps the pitcher moving. When two are out a run on a passed ball is almost always tried, so the catcher must watch closely. She must always know where the ball is. Sometimes when the ball is in the outfield her attention is diverted by a girl stealing in, and she loses track of it. Then when it is thrown to her it often hits her because she is not paying attention. The natural attitude of most players is that there is nothing to do when they do not have the ball.

Avoid throwing too high or too hard balls into the field, as girls are not expert catchers. When catching a ball always give with it. Players have a tendency to hold the body rigid and arm stiff and thus receive more jar and strain.

Batsmen.-When one team goes to field, every girl on the opposing team becomes a batsman and all scoring is done while they are at bat. This is where baseball excels every other game in its educational value, for a new kind of physical control, mental activity and group combination is required. The girl who a minute before was using all her faculties to outwit the base-runner, now endeavors to outwit the very position she just played.

Coolness, a good eye for distances and good judgment are the first essentials. While no two people bat alike, it is difficult for a girl to assume an easy, natural attitude and use all of her muscles. She should 
stand so the bat will swing over the plate and a little back so she can judge where the ball will pass. Ungraceful positions can well be avoided. At first she bats only with her arms, hugs her elbows to her sides, or keeps the arms stiff. Much preliminary work has to be done in teaching the free use of the body in batting. Girls bunt exceedingly well, and it is worth while spending considerable time on this.

When players are used to handling the bat and are not afraid to use it, they are ready to discriminate as to when to strike and when not to. Over the plate and between knee and shoulder seems a simple instruction, but at first they hit at a sky-scraper or stoop down to dust the plate, so anxious are they to " hit something." A great deal of time must be spent in teaching them to judge when a ball is a ball and when a strike. The absence of curves renders this less difficult than in outdoor ball. They are careless about remembering how many "balls" and strikes they have and "forget to run." For this reason they need to be urged to get under way quickly after every hit. If it is a foul, they can come back anyway, and no harm is done. They have such a natural aversion to starting unless they are sure, that the matter of quick starts has to be overdone at first.

The lack of initiative is exposed pitilessly in baseball. The batsman always waits to be told to run, she sticks to her base until forced off ; she hesitates to take a risk; and waits to see if the third strike is caught. Instead of running and hearing the decision afterward, she wants the decision first, and is slow to learn 
to take risks. Another thing, girls are inclined to start slowly and gradually increase speed. The reverse is needed. After a hit speed must be greatest at the start, because the distance is short and it counts for most at the beginning.

The girl can now handle her bat, she knows strikes from balls and how to get away after a hit. She is then ready to learn something of placing hits. She looks up the outs and position of her base-runners and decides what kind of hit will help most, and then tries to make it. For instance, if there is a girl on first, it is a good thing to bunt, as a fly may mean a double out. A bunt is also a good play when there are runners on first and second with no one out. As a rule she hits high-pitched balls, and bunts low ones. To bunt a ball successfully, slide the hand quickly down the bat after the ball has started from the pitcher, and let the bat give with the ball when it is hit, holding the bat well in front of the body.

For a fake bunt before the ball is pitched, slide the hand down the bat and get into a position as for a bunt. The shortstop will begin to draw up to the batsman; then suddenly slide the hand up, swing the bat back and hit hard.

With basemen and fielders who cannot hold hardhit balls well, a hard swing is not as effective as a long sweeping swing or short quick chop, which gives a hit that may land a base. Left-handed batsmen should be encouraged, as the swing throws them in direct line for first base.

Base-Runners.-It is difficult at first to make clear 
to a girl just when she ceases to be a batsman and becomes a base-runner, with a new set of rules to regulate her actions and a new set of tactics. She becomes a base-runner under the following conditions: (1) Immediately after four balls. (2) Immediately after three strikes. (3) Immediately after she makes a fair hit. (4) If pitcher does not give her time to return, after she starts on a foul hit, etc. (5) When a fair hit ball strikes the umpire. When she is stopped or obstructed by an adversary. (7) On an illegal pitch.

The business of the base-runner seems simple-to get from base to base without being put out-but it is a perilous journey to the beginner, and she needs considerable encouragement. In the first place she has erroneous ideas about being put out. The average girl thinks it means she is out of the game, and not infrequently goes home. She also thinks it a humiliation if she fails to catch a ball. If she is put out often she gets discouraged.

Getting around all the bases and home without being put out is an art. This depends upon the ability - first to hit balls at all, and second to place them; third to run; and fourth upon head-work-such as judging distances, seizing opportunities, etc. Baserunning means getting the most out of every situation with the least possible effort. In outdoor baseball, she can steal a base at any time; in indoor ball only after the ball has passed the batsman and then only one base; or when a ball is hit, then, as many as she can get. 
The distance between bases is so short that bursts of speed are required. Practising starts in dashes is good training for this. Sometimes when a ball is caught it is dropped, and unless it is a fly, the baserunner should keep on going. Her business is to get to the base and not to stop every instant and see what is going on back of her. She should always know where the ball is and must remember that first is the only base that may be overrun.

When the pitcher has not the ball the runner may bluff by getting off a base in order to have the ball thrown there, and then run on to the next. Judgment of time and distances plus speed make safe baserunning.

A runner should not get the idea that the next batsman will always help her out after she gets to first. 'Many outs are due to timidity. "I knew I was all right there, but not sure of the next," said one player. When the rule of two on a base is explained they think it the fault of the batsman who runs them off, not realizing their responsibility in making way for her. When team work is dwelt upon, signals between batsman and runner, as to the kind of play they will make together, are helpful. There is the danger of being too self-satisfied. When a runner makes one base she is of ten so pleased that she forgets all other players or that there is anything more to be done to score.

Sliding bases is not much used in indoor ball and is not advocated for girls, as effective slides are usually head first. The game can be successfully 
played without them. Sliding even for small girls is always to be discouraged, owing to the liability to injury on the hard floor. As a rule they do not do it gracefully, and they have quite enough to learn to do well, without undertaking unnecessary tactics. Where it is practised out of doors, it is best to take a long slide usually, on the inside of bag, and catch hold of bag in passing. This depends upon the position of the baseman and sometimes it is better to go on the outside of the bag. Once started on a slide it is best not to look back, lest she change her mind. She can usually judge by a baseman's action where the ball is. If the throw is high, slide on the inside; if the baseman is in front of the base, slide on the outside.

Stealing bases adds to the excitement and interest. A good time to steal is: (1) When there is a girl on first and the batsman is getting strikes or is a weak batsman. (2) When a weak batsman is up and two are out and the base-runner is on third. (3) When the bases are full and a bunter comes to the bat. Stealing third is not so of ten attempted. It is mostly on second and home, for a hit counts for as much at second as at third.

In order to become good base-runners, the following should be practised constantly: getting a quick start from the plate; getting down to first with the utmost diligence; cutting the bags from the inside when running for more than one base; getting under way quickly; avoiding changing the mind when starting to run; avoiding crowding the runner ahead 
off her base; getting away from first as soon as possible, for that is the only place for the batsman if she makes a hit; and dodging flies, for if they hit the base-runner she is out.

Basemen.-With the exception of first, the business of the baseman is to catch the ball and tag the base-runner with it, either between bases or on the base. Each baseman is responsible for putting baserunners out at the base she is holding down. The mistakes most commonly made are: Basemen think base-runners are out: if they throw the ball at them and hit them before they reach the base; if they hold the ball in one hand and touch them with the other or their feet; if they catch the ball and touch base before the runner gets there, and then throw the ball again, before the runner arrives. This last holds good only at first.

Basemen must be good catchers, able to pick up grounders and to use the underhand throw so much despised in basketball. A good practice for second and third basemen is to throw left-handed balls. It is quicker and decreases the likelihood of colliding with or hitting base-runners. Remember to tag every runner and field every ball that comes near, and not hug the base as though it might get away. When fielding a ball, allow time to return to the base before it can be reached by the base-runner. Some basemen have to be urged to get balls in their territory. On one occasion the first baseman missed a high, hard ball from third. She jumped up and down on the bag squealing for help until all her team began 
yelling that it was her business. The three baserunners in the meantime started for home. Then she started on a dead run, picked it up and instead of throwing it ran with all her might toward home, hugging the ball and calling to the runners, "Wait a minute, wait a minute." This tendency to carry the ball instead of throwing it is a hard one to overcome.

The fact that a baseman has not only the ball to watch but the pitcher or catcher and base-runner as well, develops in her a high degree of co-operation. Double plays are unusual and triple plays rarely occur. The head-work and quickness required for these come with long practice, and girls have not played games enough to reach this high degree of team work. It is, however, worth striving for in team practice.

To be able to play the various bases well requires much versatility, for the same tactics are not employed at all bases. At first, the main thing is to get the ball and touch the base. At second and third a baseman may have to play fielder if a ball comes her way while the pitcher or shortstop takes her place. When the bases are full she has to put out the runner who is on her way to the base she is guarding, and to put out another who may be on her way to the next. At third, there are a few things worth remembering constantly. Never block a runner unless you have the ball. Avoid mix-ups. When a runner gets on third the excitement is intense, as a score is likely and too many people try to get the ball. This 
is especially true of flies. With bases clear the third baseman may field wherever she thinks the ball may be hit. When the bases are empty a good position while waiting for a ball is inside between second and third bases. In fielding grounders, keep knees together and body low, so as to block the ball if the hands miss it. The third baseman should make a special effort to catch foul hits in her direction.

Shortstop.-Shortstops play inside the diamond and give attention to foul hits, bunts, short flies or "pop-ups" and grounders. Practice should emphasize: Learning quickly to catch "pop-ups," to field grounders and to make quick underhand throws to basemen. Shortstops may have to play basemen if the basemen turn fielder; and so need to know the tactics of this position. Close team work is required among the shortstops, catcher, pitcher and baseman.

Outfielders.-They need to be able to catch flies and to practise hanging on to the ball. When they miss it they need to get under way rapidly so as to return it with the least delay. Learn to run up on the grounders and to pick up and throw balls quickly. Fielders need good eyes to be able to judge distances. They are required to make the longest throws and need good strong arms.

Never take the eyes off the ball from the time the batter is ready to hit. It is not enough to see it when it comes your way.

An outfielder must back up the bases. Whenever there is a throw to bases try to get in line to stop it 
if the baseman misses. If the hit is over the head too high to catch, turn instantly and run back so as to be on the spot where the ball drops.

Stand squarely facing the batter so a run can be made in any direction. Never give up trying to get a ball and do not forget to jump for balls over the head.

When catching, keep the thumbs out of the way. A low ball, which is anything below the waist-line, should be caught with the thumb line toward the ball.

The following suggestions from Spalding rules are applicable to the indoor game for girls:

"Always keep in front of the ball; always go in to meet the ball; when running to the right pick up the ball with the left hand; unless there is plenty of time, always throw on the run; return a throw to the catcher underhanded, to stop a double steal; never throw the ball unless your chance of catching the runner is good; have the catcher or others who throw to you aim to reach you about shoulder high-you are then in a better position to return a throw; where time is scarce, scoop the ball to the player covering the bag with the same motion that you field it."

Coaching is not used to any degree in indoor ball, as the small area of the diamond makes it little needed. The coacher is usually a player who goes to first or third base, watches the plays and position of ball, and encourages or advises the base-runner when to steal a base and when to run. It is helpful at third base, for the runner cannot very well turn around to see what is going on in the field.

If the main part of the game-as pitching-is 
played by the instructor while the girls are green players, good results are obtained in understanding the game and in speed.

Baseball Rules.-Because of its high organization and complicated and badly arranged rules, baseball must be taught in a very elementary way by persons who understand and love the game sufficiently to be patient with the slowness and many faults and misplays of new players. It is not a game the rudiments of which can be taught in a half-dozen lessons, as is basketball.

In basketball a girl can play, if she learns the tactics of but one position, and the maximum is three. In baseball, she cannot play until she has learned the tactics of at least three-batsman, base-runner and a field position, and she may try seven positions, all requiring variation-pitcher, catcher, baseman, shortstop, fielder, batsman and base-runner. Not only this, but she is compelled to change positions rapidly, resulting sometimes in ludicrous confusion. On one occasion a hit was made, letting in three baserunners. After the excitement was over it was found that the third baseman was standing among the victorious group of base-runners on the other side. "What are you doing with the opposing team, helping them score?" asked a fellow baseman.

"Helping them score!" said the bewildered girl. "Why, I saw everybody running and I thought I ought to run, too, so I came along with Miss J-_."

On another occasion after changing sides, one team was found to be a player short. One of the 
basemen volunteered to go and look her up, thinking she might have been hurt. She was found dressing and saying unkind things about baseball. "Are you going to stop playing?" asked the baseman. "We are short a player without you." "Stop playing!" retorted the girl. "Didn't the umpire put me out? Baseball is the worst game I've ever tried to play. Can't play ten minutes without being put out of the game!"

There are so many things to learn in the early stages of the game that dire confusion often prevails. We have seen seven players all on second base-the baseman who belonged there and the two shortstops, the pitcher and one fielder-all trying to shut out the base-runner coming from first and another baserunner who had started to third, but changed her mind and was coming back. The tendency is for all players to gravitate in the direction of the ball.

The following definitions and classification may serve as a ready guide for instructors, and if given to the players in this way are readily learned and remembered.

Definition of Terms.-Number of players is usually nine, as follows: pitcher and catcher, constituting the battery; two shortstops; three basemenfirst, second and third; and two fielders-right and left. By tossing up a bat or a cent the sides choose whether they will go to bat or play in the field.

Going to bat means that all the members of one side take their turn in regular order one after the other at batting, while all the members of the other 
side play in the field, on bases and pitch and catch. The team in the field tries to put out the team at bat.

Innings.-Baseball is scored by innings. There are two halves in each inning-one for each team. A half lasts until three members of one team are put out; an inning lasts until three members of both teams are put out. There are nine innings in a game unless it is a tie, or otherwise changed by agreement of both teams.

Runs.-Baseball is scored by runs. A run is when a batsman succeeds in going around all three bases and home and is not put out before the third out is called.

Overrunning base.-Overrunning a base is when a base-runner goes beyond the bag and no part of her body touches it.

Foul line.-The foul line is back of the base line from home to first and from home to third-all the space on the other side is the field.

A fair ball is one which is over any portion of the home plate between the knee and shoulder of the batsman. Such a ball is called a "strike," whether hit by the batsman or not.

A " ball" is called by the umpire when a pitched ball does not go over any part of the plate or is below the knee or higher than the shoulder, and is not struck at by the batsman. When the batsman bats at such a ball, no matter how badly thrown, it counts as a strike. When four balls have been thrown before three strikes are called, the batsman is given a 
base, that is, allowed to go to first without being put out.

A strike is (1) when any ball is batted at; (2) when it is a fair ball and not batted at; (3) a foul tip caught; and (4) a good ball interfered with by the batsman.

A foul tip occurs when a ball is hit and the bat knocks it back of the foul line, no higher than the batsman's head. Such a ball, if caught, counts as a "strike."

A foul ball is one striking back of the foul line, higher than the head and not caught. Where a ball hits first and not where it rolls is the test of a foul.

A foul strike occurs when a ball is hit, and any part of the person of the batsman is outside her box.

A fair hit is one which goes into the field.

A bunt is a ball struck soft, so as to fall near the home plate.

A fly is a ball batted high enough in the air to be caught before touching the ground. A grounder is one which skims along close to the ground.

An illegal ball is one pitched when any part of the pitcher's body is out of her box; or when she fails to heel the line; or when she takes more than one step forward. Any one of these mistakes entitles the batsman or base-runner to a base.

A balk occurs when the pitcher makes a motion to deliver the ball and does not do it; or holds the ball too long and delays the game.

A dead ball is caused by a pitched ball hitting the 
batsman, but does not entitle the batsman to a base. If it is the third strike, the batsman is out.

A one-base hit is one which enables the batsman to get to first; two-base hit, or " two bagger," one which enables her to get second; and three-base hit, to third without stopping. A home run is made when the runner goes all the way round without stopping. An umpire calls "out" when the batsman is to retire; and "safe" if she has reached the base before the ball or has not been tagged, or slides with the bag and clings to it.

A double out occurs when the ball reaches first base before the batsman and then is thrown to second base before the base-runner from first gets there. In this way two are put out. This may occur on any base.

A forced run is where a base-runner holds a base and is forced on to the next base to make room for another base-runner or batsman.

A sacrifice hit occurs when the batsman hits the ball so that she will be put out, thus enabling a baserunner who is on third or second to score. While she is being put out at first, it may be quite easy for a runner to get home.

The ball is not in play, $i$. $e$, no one can run or score, (1) when there is a foul strike; (2) when there is a foul hit ball not legally caught; (3) when there is a dead ball; and (4) when the base-runner is put out by being hit by the ball. In these cases the ball is in play again only when it is held by the pitcher in the box.' 
Rules for Batsmen.-The batsman is out: (1) If a third strike is caught by the catcher. (2) If there is a base-runner on first, the batsman is out on a third strike whether it is caught or not; except when two are already out. (3) If the ball is not caught by the catcher, but is thrown to first base and is held by the first baseman while some part of her body touches the base-before the batsman gets there. (4) If, as a base-runner, she is touched with the ball in the hands of a fielder before she reaches a base. (5) If she bats out of her turn and makes a fair hit before it is discovered. The order of batting is made up before the game begins, and must then be adhered to. (6) If she fails to take her position within one minute when it is her turn to bat. (7) If a foul hit or a fair hit is caught. (8) If she makes a foul strike, $i$. e., bats while any part of her body is outside the batsman's box. (9) If she interferes with the catcher or intentionally fouls the ball. (10) If she intentionally gets in the way of a pitched ball. (11) If she is hit by the ball on the third strike, i. e., intentionally fouls the ball and it hits her.

Rules for Base-Runners.-A base-runner can leave her base only when the ball has left the pitcher's hand and reached or missed the catcher. If she leaves at any other time she may be put out or called back. A base-runner who, at any time after she overruns first, is off base, may be put out if she is touched with the ball in the hands of a player. Only one base may be taken when a ball passes the batsman or is fum- 
bled, except when it is the third strike or four balls, then she takes all she can get.

A base-runner may take one base under the following conditions: (1) Immediately when the umpire calls four balls she goes to first. (2) If the pitcher does not give her time to return. (3) When a fair hit ball strikes the umpire. (4) If she is stopped or obstructed by an adversary.

When a fair or foul ball is caught the baserunner can only advance from the base after the ball is caught. If she starts before she must go back and touch base, or if touched with the ball before returning to the base, she is out. On a fair hit ball a baserunner runs all the bases she can get. A base-runner must be on base when the pitcher is ready to deliver the ball.

The base-runner must return to her base under the following conditions : (1) When there is a foul hit not legally caught. (When it is caught it is a strike and the base-runner can advance.) (2) When there is a foul strike. (3) When a dead ball is called. When the umpire is struck by a ball thrown to the baseman. (5) When she leaves her base too soon.

The base-runner may be put out under the following conditions: (1) If a foul hit or fair hit is caught. (2) If third strike is caught. (3) If she interferes with ball, as kicking it. (4) If after three strikes or fair hits she is touched with the ball in hands of a player, or the ball reaches the first base before she does. (5) If she runs more than three feet either side of the base line.

(6) If she fails to avoid 
a fielder trying to field a batted ball, or obstructs a fielder. (7) If at any time, except when she overruns first, she is touched with the ball in the hands of a fielder when no part of her body touches the base, except when she goes back on a foul, or is ordered back by the umpire or given a base. If a baserunner overruns first and goes on to second, then she is not entitled to exemption for overrunning.

When a foul hit or fair hit is caught, not only is the batsman out, but the base-runner also if the ball reaches the baseman before she returns to the base and touches it after the ball was caught. (9) When a hit ball strikes a base-runner, who is running between the bases. (10) If she fails to touch bases as she runs and the ball is returned first to the base that she did not touch.

A baseman on first need not touch the batsman running to first; on a double play where a fair hit or foul hit is caught, the ball need only be held by the baseman. At all other times she must be tagged.

Illustrative Hypothetical Questions.-The only way to make baseball popular and interesting for girls is to have them thoroughly understand it. A series of hypothetical questions helps them in this. The following are some illustrations:

If there is a base-runner on first and on second and a grounder is hit to third, what will the third baseman do with the ball?

If there is a base-runner on second and the shortstop gets the ball, where will she throw it? 
If there are base-runners on first and on second and the right fielder catches a fly, where will she throw it?

If there is a base-runner on third and the ball is hit to second baseman, what does she do with it?

If there is a base-runner on third and the ball is bunted, and the catcher gets it, what will she do with it?

If all the bases are full and the ball is batted to the pitcher, what does she do with it?

If a hit grounder misses the pitcher and goes three feet one side of second base, what should the second baseman and pitcher do?

If there is a base-runner on third and the umpire calls four balls, where should the catcher throw the ball?

If all the bases are full and the umpire calls three strikes and the ball is caught, where should the catcher throw it?

If a pitched ball is missed by the catcher and she runs for it, what does the shortstop do?

When a base-runner has started from second and the ball gets to third before she does, who plays and where?

If there are base-runners on first and on second and the third strike is caught, where is the ball to be thrown?

If there is a base-runner on first and a hot grounder comes to the second baseman, where will she throw it?

If there is one out and base-runners on first and 
third and the third strike goes over the catcher's head, to whom is the ball thrown?

If there is a base-runner on each base and a grounder goes to the third baseman, what does she do with it? If it is a fly caught by her, what does she do?

When no base-runner is on bases and a hard single grounder goes out to the left field, where should the ball be returned?

When there is a base-runner on third and a single goes to the right fielder uncaught, where should it be returned?

When there is a base-runner on first and a grounder gets to first before the batsman, what should the baseman do with the ball? 


\section{CHAP'TER XI}

\section{FIELD HOCKEY}

\section{VALUE OF THE GAME}

Field hockey was first introduced into this country by Miss Constance Appleby in 1901. The game is of English origin, and played to a large extent by women's clubs in England and Ireland, where the bright greens and reds of the club costumes add much to the picturesqueness of the game. Ordinary street clothes, however, with a skirt at least six inches from the ground, are suitable, and make hockey especially adaptable to schools where only an unenclosed field is available, and where outdoor work is desired till late in the fall, or in the early spring.

The game can be played on any large, fairly level lot. The more evenly graded the turf, of course, the more accurate passing is possible and the better game results. The regulation field is fifty or sixty. by one hundred yards, though smaller dimensions can well be used. The only paraphernalia necessary are the regulation ball and a hockey stick for each player. A great deal depends on the kind of stick used. If it is too light, a hard stroke will jar the hands and may, with repetition, cause injury. A good average weight is 22 ounces. The weight depends somewhat 
on positions, forwards generally using lighter sticks, halfbacks the medium weight and fullbacks the heaviest sticks.

Hockey has an especial advantage because of the chance it gives to so many different types of girls to play, the forward, halfback, fullback and goal positions each calling for special qualifications. With eleven players on a side, the offense and defense so finely differentiated, the need of team work as an absolute necessity to scoring, the many chances of clever. strokes and of outwitting opponents-with all of these-the educational possibilities are manifold. Speed, accuracy, good judgment, fearlessness, determination, discrimination, precision, all must be developed to make good hockey players.

It is surprising that hockey is so little played among girls in this country. In a short while even comparatively poor players become very fond of the game. Wholly apart from the instructor, the game itself seems to awaken a spirit of play and fun which brings a glow and healthy excitement to even the most sluggish natures. A squad of girls from the classroom who, before practice, have been lifeless and dull, never fail to return full of spirit, every one chattering as hard as she can.

\section{METHODS OF INSTRUCTION}

From the point of view of the instructor, hockey is a difficult game to teach for two reasons-the size of the field and number of players. There are eleven players on a side, five forwards, three halfbacks, two 
fullbacks and a goal. To watch each one of these twenty-two players on such a large playing space, with the ball traveling so quickly back and forth, is almost a physical impossibility'. Before the instructor can reach a girl who has made a bad play, the ball may be down at the other end, and the instructor have missed two or three plays. Individual coaching must be done while the game is in progress. Girls who are at fault must be corrected while the ball is in other territory. The usual plan of stopping the practice for criticism is not generally desirable, for that would mean constant interruption and loss of the spirit of the game. There are, of course, rules for forwards and backs as a whole which must be taught in this manner, but all fine points of coaching must be individual while the ball is in play.

Rules.-In contrast to basketball and baseball, the rules are simple, and by the following classification easy to learn:

Fouls.-1. Rough play. 2. Carrying ball. 3. Kicking ball (except goal). 4. Using back of stick. 5. Sticks. 6. Crosschecking. \%. Off side.

Penalties.-I. For fouls: 1. Committed outside striking circle. 2. Committed within striking circle: $a$, by attacking; $b$, by defending. II. For sending ball out of field of play: 1. Over side lines. 2. Over goal lines. $a$, by attacking; $b$, by defending; $x$, intentional; $y$, unintentional.

Preliminary Work with the Green Squad.-The preliminary work of teaching girls to hold the stick correctly, to hit accurately, stop the ball by foot or 
stick, execute the dribble, to stop and hit immediately, use the back-handed and never the left-handed play, to execute well the short hit to right and rum around left of an opponent, to hook sticks, is slow and uninteresting with a large squad of girls where many are unoccupied much of the time. It is well in such a case to warm the girls up by putting them into a game right away, and giving the necessary practice in passing "between halves."

One way of giving practice in passing, and also of developing team play, is to line up only one side, as at the beginning of a game, start the ball at the goal and tell the girls to advance it as rapidly and accurately as possible towards and through the opposite goal. This sort of practice develops quicker reaction than the ordinary class practice in double line passing.

Another manner of teaching accurate hitting is to divide a large class in half, each half forming a circle, the girls to stand from fifteen to twenty-five feet apart; start one ball in each circle, and have it passed as quickly as possible from one girl to another, the circle first finishing one or more rounds being the winner. This element of competition adds interest to otherwise rather tiresome but very necessary work.

Before the green squad is put on the field to play, two things are necessary. The girls must be shown how to hold the stick and make the wrist stroke, and must have a short talk on the principal rules. It is just as well not to have two full teams at first. Five forwards, three halfbacks and a flying goal can be 
played, or three forwards, two halves, a fullback and a goal. When the rules are violated, immediately stop play, explain and penalize the offender. "Sticks" and using the back of the stick should seldom occur after the first three or four practices.

In these beginning hockey periods, all girls will be so anxious to play the ball that what will seem hopeless confusion will at first result. Four or five or even six girls will be on the ball at the same time. Girls will make hits to right or left and follow up the ball, or repeatedly straight ahead into the hands of opponents; will stand stock-still after playing the ball; right wings will play on the left side of the field; center halves outside of right or left halves. Slowly the principles of correlating offense and defense and of playing their own positions must be taught.

Offense and Defense.-The offensive work is done largely by the forward line and to some extent by the halfbacks. It is the forwards who score points by sending the ball between their opponents' goal-posts. The defense is taken care of by the halves, fullbacks and goal. The halves must attack the opposing forward line, recover the ball and feed it to their own forwards. If the halves allow the ball to get past them, it is the fullbacks who must keep the ball out of the striking circle and must return it quickly to their halves. The goal-keeper is sole guardian of the twelve feet of goal line between the posts. Hers must be the foresight, agility, determination and courage which prevent the actual scoring of a point. Between the twenty-five-yard lines defensive work 
falls somewhat to the hands of the forwards. At the twenty-five-yard line, however, defending forwards stop. Beyond that, it is entirely up to the backs to break up the team work of the attacking forwards, to regain the ball and send it to their waiting forward line on the twenty-five-yard mark. The tendency is for beginners in the forward line to do too much defensive work, to play on top of their halfback line instead of ahead of it. It is expedient to give general rules to green players which, later on, even with increased efficiency, are occasionally broken. In defense, require players to stay back of the ball, namely between the ball and the goal they are defending, whether the ball is in their territory or not, at the same time watching closely the particular girl opposed to them, to prevent her receiving a pass. In offense, require forwards to play on a line with each other or only slightly ahead of the girl with the ball (cautioning against off side), halves between fullbacks and forwards, fullbacks between halves and goal. It is remarkable how often these very obvious and simple rules must be repeated.

Forwards.-Because the forwards do all of the aggressive playing and cover practically the whole field, they must have above all things sound lungs and great endurance. Speed, alertness, agility, quick reaction are essentials. These qualities must find their highest development in the center forward, about whom the whole line swings, who is the pivot for team work and the very life of the attack. She should be a sure, accurate hitter, able to make passes to left 
or right with equal ease, and to receive from either direction. She must not be too fond of the ball, attempting to carry it down the field alone, but must know just when to pass it and in what direction most advantageously. "The inside forwards act as pivots between center and wings. They also want to be accurate hitters and should be able to pass the ball as easily to one side as to the other, ever on the alert for chances, watching the half and fullback lines for passes, and prompt to pass the ball on to the wings or center."

Wing Position.-This, like the guard in basketball, is probably the least appreciated, for the tendency is to pass toward the center of the field. The wise player, however, uses her wing to good advantage, as that position is the most open and unprotected on the field. The wing of all forward positions, because of the great distance to travel, needs girls with a high amount of endurance. The left wing is especially hard to play, because of the skill needed for receiving passes from the right and returning in the same direction.

Halfbacks.-These do not need quite such endurance or speed as the forwards. Nevertheless, they must have good lungs. They must be heavier girls, for they must be, above all, hard, accurate hitters. They must never fail in energy or resource, for theirs is the duty of first defense, of attacking the onrushing opponents in the forward line. If these succeed in passing them, they must be quick to turn and resume defense once more with tireless insistence. 
Center Halfback.-This player is probably the busiest girl on the team. She must watch the opposing center forward and halfback, back up her own center and know always the best forward to send the ball to. She must be cool and very sure and have absolute grasp of the new situations as they develop.

Right and Left Halfbacks.-These must watch the opposing inside forwards and wings, must be quick to receive passes from their fullbacks, and take them away from opposing forwards. They must be able to send long, hard balls, for at times diagonal passes across the field are necessary.

The most reliable girls at stopping the ball and hitting should be the fullbacks. A firm, quick, hard, sure stroke from the fullback exactly to the right gir] of ten prevents a score and saves the day. Here speed is not an essential. A girl of slow temperament, upon whom her team-mates can always depend, is the desirable fullback. Her stability gives a sense of security to the whole team. When she rescues a ball from the striking circle and passes it accurately on to her waiting halves or forwards, new spirit enters the attack, and half the game is won. The fullback, though slow of temperament, must be an adept at stopping the ball with the foot and instantly shooting it away from the danger line. She must be quick of eye and indefatigable in defense of the goal line.

Goal-tender.-The goal-tender must be a girl of absolute fearlessness and instant reaction. Her chances do not come often, but when they do, they bring the most critical tests of nerve, eye, body and 
brain on the field. No timid, shrinking girl will do for a goal-tender, unless she is put there to overcome these qualities.

Team Work.-The final great task in hockey is to develop team work, without which the game seems crude, aimless and uninteresting to spectators and players alike. It is only after constant repetition of "stick to your own position," "follow your position, not the ball," that bunching is done away with and girls are taught the meaning of team work. Stop the game in order to make a right wing who may be left of her center play her own side of the field; or to call back a center-half who may be rushing toward the side lines after the ball. There is nothing more exasperating than not having a girl in her proper relative position when some one wants to pass her the ball. In learning to play her own position, she will learn her neighbor's and not to interfere with it. When finally each girl realizes that she is one of eleven players, each one of whom has a special part to play, all of whom have one end in view, and without any of whom that end cannot be accomplished, a really beautiful game results which is a pleasure to all spectators and players alike. 



\section{APPENDIX I}

PRINTED FORM OF INQUIRY USED FOR SECONDARY SCHOOLS AND COLLEGES

1. Name of School or College.

2. How much physical work is required?

3. How many instructors in Athletics? Men or Women?

4. Give name of each sport played:

For what length of time during the year is each played?

Name exact title of the rules used for each game and state reasons for preference.

5. What are the requirements for playing each sport?

6. What preliminary measurements or examinations are invariably made?

7. State average age or range of ages of girls playing under your supervision.

What regulations exist in regard to dress?

Times when a girl should play, especially the menstrual period?

Baths?

Length of practice period?

8. What percentage is athletic work and what gymnastic of the required work?

Of elective work?

9. May a girl play games without taking gymnastic work? 
10. In how many sports can she play in a quarter or term?

11. What is the maximum amount of practice allowed?

12. Is it necessary to stimulate interest in athletics?

13. Give all the various means, contests, prizes, organizations, etc., by which interest is stimulated.

How are prizes supplied?

14. What is your system of coaching, student, professional?

15. Give in detail the arrangement of your work.

16. Do you have a field?

17. What is the object of coaches, to develop teams or individuals?

18. What has been the previous training of your coach or instructor?

19. What do you consider to be the qualifications of a coach?

20. Do you select teams and play match games?

21. Do you play outside teams?

22. Do you play for prizes?

23. If you play only in your own school or college, who are the opposing teams?

24. Who arranges for these contests and under what organization?

25. State the average number of contests per season for each sport.

26. Are all players permitted to take part in contests or only first and second teams?

27. Are the officials men or women?

28. Are the contests public?

29. On what conditions are men permitted to attend?

30. Is admission by purchase of ticket or invitation? 
31. When teams travel about the city or from city to city, under what supervision are they?

32. Is eligibility to play in contest based on standing in academic work?

33. Have you any kind of athletic organization or association?

34. If so, please enclose constitution, regulation, and other details.

35. What is their object?

36. How are they maintained?

37. In what way do they influence school or college life as a whole?

38. In what way is the social side of athletics emphasized?

39. Suggestions and experiences. 


\section{APPENDIX II}

SOME ILLUSTRATIVE CONSTITUTIONS OF COLLEGE AND HIGH SCHOOL ATHLETIC ASSOCIATIONS

1. The name of this Association shall be "The Athletic Association of College."

2. All members of the Undergraduate Association shall be members of this Association.

3. The officers of the Association shall be President, Vice President with the duties of Treasurer, and Secretary. The duties of the President shall be to call and preside at meetings. The duties of the Vice President shall be to assume the duties of the President whenever necessary, and to act as Treasurer. The duties of the Secretary shall be to keep the minutes of the Association and a list of the members, to post notices of the meetings and to attend to the correspondence of the Association.

4. There shall be two managers, one for indoor, and one for outdoor athletics, who together with the officers of the Association shall constitute an Executive Board of which the President shall be chairman.

5. The constitution and a report of the proceedings of the previous year shall annually be read by the Secretary of the Association at a meeting held within the first week of the first semester.

6 . A meeting may be called at any time by the Presi- 
dent on her own motion and must be called on the application of five members. When the President is unable to call a meeting on application it shall be called by the Vice President or some member of the Executive Board. It shall be the duty of the Secretary, twentyfour hours previous to any meeting of the Association, to post on the bulletin board in each hall a notice stating the time of said meeting and the subject to be discussed.

7. The Executive Board shall be annually elected by ballot during the first week of May, and shall enter upon their duties immediately.

8. To defray the expenses of the Association every member shall pay an annual due to be fixed by the Executive Board. To defray expenses of intercollegiate athletics every member shall pay a due to be fixed by the Executive Board subject to the approval of the Association. If any member find herself unable to pay the whole or part of the assessment she shall make known her case to the Treasurer and, if she fail to do so, shall be held responsible for the whole.

9. One-fourth of the members of this Association shall constitute a quorum.

10. To amend this constitution a majority of threefourths of the members of the Association shall be required.

\section{II}

ARTICLE I-NAME

This club shall be known as the Athletic Association.

\section{ARTICLE II-OBJECT}

The object of this Association shall be to promote an interest in gymnastics and athletic sports among the 
students of College, and to hasten the preparation of a playground.

\section{ARTICLE III-MEMBERSHIP}

$\S 1$. Only students of College who are regular attendants of the gymnasium, shall be eligible for membership.

$\S 2$. Members shall register and pay dues before November first; no new members shall be admitted into the Association after the second week preceding the second meet.

\section{ARTICLE IV-DUES}

The annual dues shall be fifty cents. This does not include the additional fees for outdoor sports.

\section{ARTICLE V-OFFICERS}

$\S 1$. The officers shall be President, Vice President, Secretary, and Treasurer.

§2. Duties of Officers.

1. The President shall call all meetings of the Association and preside at the same.

2. In the absence of the President, the Vice President shall fulfil the duties of that officer.

3. The Secretary shall take charge of all the correspondence of the Association, keep the records of meetings, give due notice of same, and prepare a report to be read at the annual meeting.

4. The Treasurer shall be in charge of the finances of the Association, and shall prepare a report to be read at the annual meeting.

§3. Election. The officers shall be elected by double ballot at the annual meeting for the term of one year. A majority of the members present shall be suf- 
ficient for election, but for re-election a vote of twothirds shall be necessary. The quorum shall be fifteen to carry on this business.

ARTICLE VI

$\S 1$. The Executive Committee shall consist of the officers of the Association, the Physical Director, and a representative from each of the three lower classes.

§ 2. Duties. 1. The Executive Committee shall be in charge of the four regular meetings of the Association, and shall be empowered to determine and meet the incidental expenses of the Association and to appoint all other committees.

2. Meetings of the Executive Committee shall be called at the discretion of the President, who shall act as Chairman.

\section{ARTICLE VII-MEETINGS}

$\S 1$. There shall be four regular meetings.

1. The first gymnasium meet to be held the second Saturday in January.

2. The open meet to be held on the second Saturday before the spring vacation.

All members of the Athletic Association will be eligible to compete in these meets. The members of the four college classes shall compete for their respective classes. Specials will compete for the four college classes according as they are first, second, third, or fourth year students. No student who has been at college more than four years shall be eligible to the meets.

3. The Reception to the Freshmen to be held during the last two weeks of November.

4. The Annual Business Meeting to be held during the last week in May. 
$\S 2$. All other meetings shall be called at the discretion of the President.

$\S 3$. A quorum consisting of eleven members shall be necessary for the transaction of business with the exception of that of the election of the officers.

\section{ARTICLE VIII-AMENDMENTS}

Amendments to this Constitution shall be passed by two-thirds of the members present.

\section{ARTICLE IX-SPORTS}

$\S 1$. Basketball. 1. All candidates for class and college teams and the Business Managers shall be members of the Athletic Association.

2. Captains shall be chosen by the members of the teams for a term of one year.

3. The College Team shall be selected by the Captain, the Physical Director and the Physical Instructor.

4. The expenses of the College Team shall be met by the Athletic Association.

5. Regulations for competitive class games shall be left in charge of the Physical Director.

§2. Tennis. 1. A Chairman of the Tennis Section shall be elected at the Annual Business Meeting of the Athletic Association, who shall be in charge of the Tennis interests of the Association; and she shall be empowered to collect the annual dues of the Tennis Section, and to appoint committees.

2. The outdoor courts which belong to the Association may be used by members of the — Athletic Association who have paid their Tennis Section dues, and by any college girl who does not belong to the Athletic Association, on payment of her tennis dues. The latter 
persons will have no voice in the management of the Tennis Section.

§3. Hockey. 1. A Chairman of the Hockey Section shall be elected at the Annual Business Meeting of the Athletic Association; and she shall be empowered to collect the annual dues of the Hockey Section and appoint committees.

2. The outdoor grounds which belong to the Association may be used by members of the Athletic Association who have paid their Hockey Section dues, and by any - student who does not belong to the Athletic Association, on payment of her hockey dues. The latter persons will have no voice in the management of the Hockey Section.

\section{III}

\section{ARTICLE I-NAME}

The name of this organization shall be the Woman's Athletic Association of the University of - .

ARTICLE II-PURPOSE

The purpose shall be co-operation with the Woman's Department of Physical Culture for the promotion of the physical and social activity of university women.

ARTICLE III-OFFICERS

The officers shall consist of a President, Vice President, and Secretary and Treasurer.

\section{President}

The President, and in her absence, the Vice President, shall call, and preside at all meetings of the Association, Executive Committee and Advisory Board, and shall per- 
form such other duties as the Association may assign her.

\section{Secretary-Treasurer}

The Secretary-Treasurer shall conduct all correspondence, keep the minutes of the meetings, and all athletic records, and shall have charge of all funds of the Association. She shall have all disbursements authorized by the Executive Committee, and shall notify persons of their election to membership.

\section{Executive Committee}

The Executive Committee shall consist of the President, Secretary-Treasurer and Director of the Woman's Department of Physical Culture or some one appointed by her. They shall have charge of all funds and properties of the Association, and decide such matters as the Advisory Board may refer to them.

\section{Advisory Board}

The Advisory Board shall include the Executive Committee, and the chairmen in charge of the various sports and branches of organized work. They shall supervise all movements for the promotion of athletic spirit and interests, including all features of public games (except as provided in Rule II of the By-Laws), mass-meetings and social functions. They shall control all matters not otherwise provided for.

\section{ARTICLE IV-MEETINGS}

A meeting of the Association may be called at any time by the President, or upon the written request of any twenty-five members of the Association.

There shall be an annual meeting held the second 
Tuesday in December for purposes of election and other routine business.

\section{ARTICLE V-ELECTION}

$\S 1$. All nominations for officers shall be made by a nominating committee selected by the Advisory Board. There shall be at least three nominations for each office.

$\S 2$. The remainder of the Advisory Board shall be elected as follows: Each branch of organized work shall nominate and elect from the floor a committee of five, whose duty shall be to supervise and represent the sport so electing it; and to have charge of the matters designated to it by the body electing it. The chairmen of these committees constitute, with the officers designated, the Advisory Board.

§3. All nominations shall be posted one week prior to the meeting, all voting shall be by ballot, and a majority vote shall be required to elect. For all meetings of the Association seventy-five persons shall be deemed a quorum.

\section{ARTICLE VI-TERM OF OFFICE}

$\S 1$. All officers and members of the Board shall hold office for the period of one year. Committees shall serve for the same length of time.

§ 2. All vacancies for President, Vice President and Secretary-Treasurer shall be filled by the Advisory Board appointing one of its own members. All other vacancies shall be filled as provided in Article $V$, Section 2.

\section{ARTICLE VII-MEMBERS}

The Association shall be open to all women in the University under the following: 
§ 1. Active. All women registered in all organized sports, track athletics and indoor competitive work, conducted by the Women's Department of Physical Culture.

$\S 2$. Associate. All women registered for gymnasium work, but not included in Section' 1 .

§3. Honor: All women who make the University and College teams, who win points and make records in athletic and gymnastic contests and tournaments. These members must be without university conditions.

$\S 4$. Honorary. University faculty and alumnæ.

$\S 5$. All applications for membership, other than honorary, shall be made to the Secretary, who shall refer them to the Director of the Woman's Department of Physical Culture, who shall decide upon eligibility and membership.

Recommendations for honorary membership shall be sent in writing to the Secretary and referred to the Advisory Board, who shall pass upon and refer them to an Association vote.

$\S 6$. Active and associate members shall not have voting powers or right to hold office.

\section{ARTICLE VIII-FEES}

There shall be no regular membership fee or tax, but contributions may be solicited by a committee appointed by the Advisory Board, for purposes designated by them.

\section{ARTICLE IX-AMENDMENTS}

This Constitution may be amended by a two-thirds vote of the members required to be present at the meeting. These amendments shall be posted in the gymnasium at least ten days prior to such a meeting. 


\section{IV}

\section{HIGH SCHOOL CONSTITUTION}

ARTICLE I-NAME

The name of this Association shall be the High School Girls Athletic Association.

\section{ARTICLE II-OBJECT}

The object of this Association shall be to encourage gymnasium work and such sports as girls may properly enter into.

\section{ARTICLE III-MEMBERSHIP}

All girls and lady teachers of the - High School shall be eligible to active membership. Grade teachers may also be elected.

\section{ARTICLE IV-MEETINGS}

$\S 1$. The annual meeting of this Association for the election of officers shall be held on the third Tuesday of September.

§2. Special meetings shall be held at the call of the President or upon the written request of five members.

\section{ARTICLE V}

Quorum. A quorum shall consist of three-fifths of the active members.

\section{ARTICLE VI}

$\S 1$. The officers of this Association shall be a President, Vice President, Treasurer and Secretary.

§2. The Executive Committee shall consist of the President, Vice President, Secretary and Treasurer, and one member of the faculty elected from those holding a preliminary certificate. 
ARTICLE VII

$\S 1$. Duties of the officers. The President shall preside at all meetings of the Association and Executive Committee.

She shall appoint all sub-committees, not otherwise provided for, whenever duly requested or when in her judgment she may deem it necessary.

$\S 2$. The Vice President shall, during the absence of the President, perform all the duties of the President as specified in $\S 1$.

$\S 3$. The Secretary shall keep the minutes of all the meetings of the Association and Executive Committee. She shall conduct all correspondence except such as may be in the hands of the managers and shall be responsible for all the books and papers of the Association except those belonging to the Treasurer.

$\S 4$. The Treasurer shall have charge of all money belonging to the Association. She shall pay all bills on order signed by the President and Secretary, and shall submit a written report of her transactions at the annual meeting of the Association or whenever called upon to do so by one of the Executive Committee.

$\S 5$. It shall be the duty of the managers of the several teams to prepare a schedule of games.

$\S 6$. All schedules of games and expenditures of money shall be submitted to the Executive Committee for ratification. They shall also have supervision of all matters relating to the Association, not otherwise provided for in the Constitution, and shall have power to remove captains and managers by four-fifths vote.

§7. The Executive Committee shall hold at least one meeting each month during the school year. 
$\S 8$. The Executive Committee shall hold a special meeting at the request of three members.

$\S 9$. Three, one of whom shall be a teacher, shall constitute a quorum of the Executive Committee.

\section{ARTICLE VIII-ELECTIONS}

$\S 1$. The President, Vice President, Secretary and Treasurer shall be elected by ballot at the annual September meeting.

$\S 2$. Team officers shall be elected when necessary.

$\S 3$. The elections of captains shall be confirmed by the Executive Committee.

$\S 4$. All vacancies occurring among the officers of the Association shall be filled by the Executive Committee.

\section{ARTICLE IX-FEES}

$\S 1$. The membership dues of this Association shall be tein cents a month, payable monthly.

§2. The dues for honorary members shall be the same as for active members.

$\S 3$. Any member failing to pay her dues shall cease to be a member of the organization.

\section{ARTICLE $X$-RESIGNATIONS}

All resignations shall be made in writing to the Secretary of the Association and shall be acted upon at the next meeting.

\section{ARTICLE XI-SUSPENSION AND EXPULSION}

$\S 1$. The Association shall have power to punish any member by suspension or expulsion for any failure to comply with the articles of the Constitution or By-Laws 
or for any conduct that will bring discredit on the Association.

§ 2. The rote for suspension or expulsion shall be by ballot. A three-fourths rote of the members present at a meeting shall be necessary to expel or suspend.

ARTICLE XII-REINSTATEMENT

Members, after suspension, may be reinstated by a three-fourths rote of the members present at a meeting.

\section{ARTICLE XIII-AMENDMENT}

$\S 1$. This Constitution may be amended by a threefourths rote of the members of the Association present and roting.

§ 2. Notice of such proposed amendment shall be made at a previous meeting.

\section{BY-LAWS}

1. The business mectings of this Association shall be carried on according to parliamentary law.

2. Admittance to membership. Names may be proposed to the Membership Committee, who with the Executive Committee shall discuss and vote upon such names, after which the name or names may be brought before the Association with the recommendation of these two committees. Two-thirds of membership vote shall be necessary for election.

3. No member of this Association shall play or practise basketball with any boy or boys from the High School or town. The least penalty for this offense shall be suspension from the privileges of this Association. 
4. No public games shall be held to which men may be admitted.

5. All questions of policy must be submitted to and passed upon by the Executive Committee before being put to vote by the Association.

If not passed upon favorably by this committee they shall be rejected. 


\section{INDEX}

Anatomy, courses in schools, 59

Associations, high $\mathrm{school}$ leagues, 72; athletic, in colleges, 103; in private schools, 93; functions of, 106; in settlements, 125, 128; social and educational value of, 128; influence upon contests, 157

Audiences, social value of games to, 40; and contests, 152 ; influence of on players, 156

Battle-ball, value of, 166

Baseball, see Indoor baseball

Basketball, in private schools, 88,90 ; in colleges, 100 ; in settlements, 123, 127; in high schools, 70; in school gardens, 119; in welfare work, 138; rules for men and women, 179 ; lineball, 181; non-interference rule, 186; physical requirements for, 189; training green players, 190; training forwards, 195; training guards, 197; training center, 198; teaching rules, 198; team work, 199; use of signals, 210

Boarding schools, athletics in, 82

Board of Education, and N. Y. athletic leagues, 75; and conferences, 81

Camps, athletics in, 128

Captain-ball, value of, 27; in colleges, 102, 166
Captains, qualifications and duties of, 173

Center-ball, value of, 166

Citizenship, athletics and, 24; training for, 36 ; in country and village, 80

Clubs, women's, 12; whist, 13

Colleges, as schools for instructors in athletics, $\overline{6} 2$; athletics in, 96 ; athletics for graduates of, 98 ; instructors in, 98 ; contests, 99 ; systems of work, 100 ; athletic associations in, 103; field days, 108

Confidence and teachers, 50

Contests, high-school, 72 ; intercollegiate, 99; in parks, 115; in settlements, 124; class, 149; interscholastic, 150 ; effect on schoolgirls, 151 ; and the audience, 152; prizes, 153; essentials of, 153, 155 ; and audience, 156; and athletic organizations, $15 \tau$; instructor's attitude toward, 171 ; field etiquette, $1 \%$; dangers in, from conflicting basketball rules, 188

Co-operation, training for, 31

Country school athletic leagues, 79

Courage, training for, 34

Dance halls, as recreation centers, 110

Discipline, value of, 36 ; and instructors, 49 ; emphasis on, in reformatories, 141

Drive ball, 27 
Elocution and oratory, schools of, 61

Esthetics, and athletics, 38; form, 41 ; atmosphere as a part of, 42

Etiquette, field, 177

Fair play, training for, 32

Field days, in colleges, 108; contests and, 155; programs for, 159 ; regulations, 160 ; field etiquette, 177

Fieids, municipal, 116

Games, mental $\mathrm{tr}$ a in in $\mathrm{g}$ through, $2 S$; esthetic value of, 38 ; atmosphere of, 41 ; education by minor, $16 j$

Gymnastics, instruction in, 53; in private schools, 91 ; in colleges, 102

Health, and athletics, 23; influence of athletics on, 24; and high school games, 73

High schools, training of teachers, 63; responsibility for selecting good teachers, 64; conditions in, $\% 0$; instructors in, 71, leagues, 72 ; responsibility of parents and school authorities, $\boldsymbol{7 4}$; athletic leagues in, 75 ; remedies for conditions, 80 ; contests in, 149

Hockey, value of training, ' 27 ; value of game, in colleges, 101, 23\%; instruction, 238; green squads, 239; offense and defense, 241; forwards, 242; wings, 243; halfbacks, 243; goal tenders, 244 ; team work, 245

Imagination, training of, 30

Immigrants, need of athletics for, 13t; and Y. W. C. A., 137
Immorality, increase of among women, 11

Indoor baseball, value of training, 27,88 ; advantages of game, 212; physical requirements, 213; pitchers, 214; catchers, 215; batsmen, 217 ; base runners, 219; basemen, 923; shortstops, 225; outfielders, 225; coaching, 226; rules, $22 \tau$; definitions of rules, 228

Instruction, courses of, 53; combinations of courses in high schools, 89 ; need of in special schools, 147; use of prescription cards in, 169

Instructors, special qualifications of, 46 ; play spirit, $4 \tau$; proficiency of, 48; general qualifications of, 51 ; relation to players, 52; men, 52; and schools of physical education, 53; dishonesty of, 65 ; in high schools, 71 ; interference with, 90 ; in colleges, 98 ; in private schools, 8\%; in settlements, 124, 127; methods of teaching, 166; as officials, 171

Investigation of conditions in athletics, 81

Lacrosse, place and value, 166 Leagues, athletic, public school, 75 ; country school, 79 ; defects of, 78

Legislation, and social ethics, 16

Long-ball, value of, 166

Loyalty, training in, 33

Managers, duties and qualifications of, 173

Measurements, in private schools, 91

Men, as instructors, 52

Men's basketball rules, 180

Normal schools, instruction in athletics, 62; and athletic leagues, 79 
Officials, deficient training of, 59 ; responsibility for good game, 155, 157; women as, 155 ; and audiences, 157 ; instructors as, 171 ; qualifications and duties of, 174; scorers, 175; timers, 176; linesmen, 179

Organizations, non-ethical, 12; athletics in private schools, 93

Parents, and athletics, 43; attitude toward play in country, 80; responsibility of, 87

Parks, Chicago system and work, 114

Pass-ball, value of, 166

Pedagogy, and athletics, 22

Personal morality, women and, 10

Physical education, schools of, 53; summer schools of, 57; defects of, 58

Physician, excuses, 87, 101

Physiology, courses in, 59

Playgrounds, 112; associations, 113; play festivals, 121; need of in N. Y. City, 121; and settlements, 123

Polo, value of, 166

Private schools, responsibility for teachers, 64; conditions in, 83; attitude toward, 84; gymnastics in, 85, 91; instructors and parents, 87; chaperon coach, 89; methods of instruction, 91 ; measurements, 92; organizations, 93; remedies for present conditions, 94

Prizes, too much emphasis upon, 153

Probation work, use of athletics in, 142

Psychology, courses in, 59

Public opinion, by women, 7

Public school athletic league,
75 ; and instructors, $7 \tilde{7}$; defects of, 78

Push-ball, value of, 27

Reason, training of, 30

Recreation centers, 117

Reformatories, need of athletics in, 141; conditions in, 143; athletics in, 143

Responsibility, training in sense of, 35

Roofs, use of for games, 128, 138

Rules of the game, women's part in, 9 ; training in, in private schools, 89; general suggestions for teaching, 169

Rules, basketball, 198; baseball, 227; hockey, 239; methods of teaching, 172

School gardens, 112, 118

Schools of philanthropy, need of courses of instruction in athletics, 147

Schools, physical education, 53; summer, 57; defects, 58 ; and social education, 60 ; of elocution and oratory, 61 ; normal, 62; university and college, 62; use of for games, 122

Self-control, training in, 30

Settlements, 122; facilities for games, 123; and instructors, 124; contests in, 124, 127; need of athletic associations, 125,128 ; systems of work, 125

Social control, by women, 7

Social education, 3; need of, 19; influence of athletics on, 20 ; special kind for women, 24; by means of athletics, 26, 116; and schools of physical training, 60; and athletic leagues, 78; and Y. W. C. A., 137; need of in reformatories, 141

Social ethics, women and, 10; 
non-ethical acts and attitude, 13; benevolence and, 15; legislation and, 16; and athletics, 29

Social morality, women's influence upon, $\mathrm{S}$; and athletics, 29 ; in reformatories, 146

Sociology, courses in, 59

Teams, appearance of, 153; and spirit of playing, 154

Team work, and social ethics, 15; hocker, 245; limitations by women's rules in basketball, 1S4; basketball, 199; use of signals, 210

Trades unions, value of athletics in organization training, 140 ; classes for in settlements, 141

Training, athletic, neglect of, 21 ; advantages, $26-38$

Universities, training in physical education, 62

Vacant lots, use of for games, 120,128

Vacation homes, athletics in, 128

Vacation schools, need of social education in, 19 ; athletics in, 117
Villages, athletics in, 80

Volley-ball, value, $2 \tau, 166$; in colleges, 10?

Welfare work, athletics as a part of, 138; in laundries, 138; use of roofs, 139; fields for workers, 139

Women, social responsibility of, 3 ; as property holders, 4 ; in politics, 4 ; in industry, 5 ; in society, 6 ; working and athletics, 130, 189; as officials, 155

Women's basketball rules, 179; disadvantages of, 181, 186

Young Men's Christian Association, training schools, 56, 13\%, $14 \tau$

Young Women's Christian Association, course of instruction, 55; opportunities for social education, 129; need of work in, 130; facilities and methods, 131; fees, 133; limitations, 134; remedies, 135; instructors in, 136, 137; use of Sundays, 136; immigrants and, 13\%; need of training schools, 137 



\section{Fitz's Physiology and Hygiene}

By George W. Fi'z, M.D., former Assistant Professor of Physiology and Hygiene in Harvard University, and sometime Teacher of Science in Cook County Normal School, I11. xiii + 357 pp. I2mo. \$I.I2.

The book is suitable for use in the first year of the high school. Special emphasis is laid upon hygiene and sanitation, and experimental work is fully outlined in connection with each chapter.

Dr. G. L. Meylan of Columbia University in the "Educational Review" :-This volume marks a distinct advance in the effort to produce a satisfactory text-book of physiology and hygiene for high schools. . . . It includes chapters on physiology, personal hygiene, community hygiene, and first aid to the injured. . . An abundance of exceptionally good illustrations and the addition at the end of each chapter of simple experiments constitute valuable aids in understanding the structure and functions of the various organs.

Martin's The Human Body Briefer Course.

By H. Newell Martin, F.R.S., sometime Professor in the Johns Hopkins University. Fifth Edition, Revised, with Practical Exercises, by George W. FiTz, former Assistant Professor in Harvard University. xiv $+408 \mathrm{pp}$. I2mo. (American Science Series.) \$1.25.

\section{Peabody's Laboratory Exercises in Anatomy and Physiology}

By James E Peabody, Instructor in the Morris High School, New York. $x+79$ pp. I2mo. Interleaved. 60 cents.

\section{Martin's The Human Body Advanced Course.}

By H. Newell Martin, sometime Professor in the Johns Hopkins University. New Edition. xvi+685 pp. 8vo. (American Science Series.) \$2.50. Copies without the Chapter on Reproduction will be supplied when specially ordered.

\section{HENRY HOLT AND COMPANY NEW YORK




\section{Second Printings of Two Books That Are Interesting as Well as Useful. \\ PROBLEMS OF BABYHOOD}

By Rachel Kent Fitz, A.M., and George Wells Fitz,

M.D. With twenty illustrations by EDWARD A.

Bell. II8 pp., I6mo. \$1.25 net, by mail \$r:33.

A scientific study of the controllable features of child development toward building a constitution and forming a character, intended to give frank and practical guidance to all who are confronted with the problems of parenthood.

"Every parent . . . will welcome the expert aid offered. The gospel of common sense as applied to the training of the child by a thinking, intelligent father and mother. It is theory reduced to practice."-The New York Herald.

"Of decided value and needed by thousands of parents who ought already to have mastered many of its teachings. Worth its weight in gold." -St. Louis GlubeDemocrat.

"Much valuable advice and information in regard to the rearing of children."-Chicago Record-Herald.

\section{NATURE A N D HEAL T H}

By Edivard Curtis, M.A., M.D. 313 pp., I2mo. \$1.25 net, by mail $\$ 1.37$.

Sensible advice on the care of the person and the home.

"One can dip into it here and there, and be certain always of finding something worth while, told succinctly with a dry wit that, like the claws of the burr, makes it stick. . . . His book will make its readers think."

- New York Times Review.

"Writes from long experience and with simplicity of language and robust directness. . . May be heartily commended to the lay reader desirous of leading a sane, clean, wholesome life."'-Literary Digest.

"I have a pile of these health books, and I am inclined to think that this is the best one that I have ever seen. It does not go wild over some hobby, and it is wonderfully sweet and clean. . . I I can recommend this book to every reader as one of those that will help him to live better, nobler and truer, as well as healthier.'

-E. P. Powell in Unity.

Henry Holt and Company

Publishers

(xI'06)

New York 


\section{THE AMERICAN NATURE SERIES}

In the hope of doing something toward furnishing a series where the nature-lover can surely find a readable book of high authority, the publishers of the American Science Series have begun the publication of the American Nature Series. It is the intention that in its own way, the new series shall stand on a par with its famous predecessor.

The primary object of the new series is to answer questions which the contemplation of Nature is constantly arousing in the mind of the unscientific intelligent person. But a collateral object will be to give some intelligent nction of the "causes of things."

While the coöperation of foreign scholars will not be declined, the books will be under the guarantee of American experts, and generally from the American point of view; and where material crowds space, preference will be given to American facts over others of not more than equal interest.

The series will be in six divisions:

\section{NATURAL HISTORY}

This division will consist of two sections.

Section A. A large popular Natural History in several volumes, with the topics treated in due proportion, by authors of unquestioned authority. 8vo. $7 \frac{1}{2} \times 10 \frac{1}{4}$ in.

The books so fur publisht in this section are:

Fishes, by David Starr Jordax, President of the Leland Stanford Junior University. $\$ 6.00$ net; carriage extra.

AMERICAN INSECTS, by Verixon L. Kellogg, Professor in the Leland Stanford Junior University. $\$ 5.00$ net; carriage extra.

$$
\text { Arranged for are: }
$$

SEedLeSS PLANTS, by George T. Moore, Head of Department of Botany, Marine Biological Laboratory, assisted by other specialists.

WILD MAMMALS OF NORTH AMERICA, by C. Hart MerRIAM, Chief of the United States Biological Survey.

BIRDS OF THE WORLD. A popular account by FraNk $H$. Krowltos, M.S., Ph.D., Member American Ornithologists Union, President Biological Society of Washington, etc., etc. 
A M ERICA N N T U R SERIES (Continued) with Chapter on Anatomy of Birds by Frederic A. Lucas, Chief Curator Brooklyn Museum of Arts and Sciences, and edited by Robert Ringway, Curator of Birds, U.S. National Museum.

REPTILES AND BATRACHIANS, by Leonhard Stejneger, Curator of Reptiles, U. S. National Museum.

Section B. A Shorter Natural History, mainly by the Authors of Section A, preserving its popular character, its proportional treatment, and its authority so far as that can be preserved without its fullness. Size not yet determined.

\section{CLASSIFICATION OF NATURE}

1. Library Series, very full descriptions. 8 vo. $7 \frac{1}{2} \times 10 \frac{1}{4}$ in.

Already publisht:

NORTH AMERICAN TREES, by N. L. BRITTON, Director of the New York Botanical Garden. \$i.00 net; carriage extra.

FERNS, by Campbeli E. Waters, of Johns Hopkins University Sro, pp. xi+362. \$3.00 net; by mail, \$3.30.

2. Pocket Series, Identification Books-"How to Know," brief and in portable shape.

\section{FUNCTIONS OF NATURE}

These books will treat of the relation of facts to causes and effects - of heredity and the relations of organism to environment. 8 vo. $6 \frac{5}{8} \times 8 \frac{7}{8}$ in.

\section{Already publisht:}

THE BIRD: ITS FORM AND FUNCTION, by C. W. BEEBE, Curator of Birds in the New York Zoological Park. 8vo, 496 pp. $\$ 3.50$ net; by mail, $\$ 3.80$.

\section{Arranged for:}

THE INSECT: ITS FORM AND FUNCTION, by Vernon L. Kellogg, Professor in the Leland Stanford Junior University.

THE FISH : ITS FORM AND FUNCTION, by H. M. Sмrth, of the U. S. Bureau of Fisheries. 


\section{A M E R I A N N A T U R E S RIES (Continued)}

\section{WORKING WITH NATURE}

How to propagate, develop, care for and depict the plants and animals. The volumes in this group cover such a range of subjects that it is impracticable to make them of uniform size.

\section{Already publisht:}

NATURE AND HEALTH, by EDWARD Curtis, Professor Emeritus in the College of Physicians and Surgeons. 12mo. \$1.25 net; by mail, $\$ 1.37$.

THE FRESHWATER AQUARIUM AND ITS INHABITANTS. A Guide for the Amateur Aquarist, by Otro Eggeling and Fredertck Ehrenberg. Large 12mo. \$2.00 net; by mail, \$2.19. THE Life of a FOSSIL HUNTER, by Charles H. Sternierg. Arranged for:

PHOTOGRAPHING NATURE, by E. R. SANBors, Photographer of the New York Zoological Park.

THE SHELLFISH INDUSTRIES, by James L. Keliogg, Professor in Williams College.

CHEMISTRY OF DAILY LIFE, by Henry P. Talbot, Professor of Chemistry in the Massachusetts Institute of Technology.

DOMESTIC ANIMALS, by Wimimam H. Brewer, Professor Emeritus in Yale University.

THE CARE OF TREES IN LAWN, STREET AND PARK, by B. E. Frrnow, Professor of Forestry, University of Toronto.

\section{DIVERSIONS FROM NATURE}

This division will include a wide range of writings not rigidly systematic or formal, but written only by authorities of standing. Large $12 \mathrm{mo} .5 \frac{1}{4} \times 8 \frac{1}{8}$ in.

Already publisht:

INSECT STORIES, by VerNoN L. KeLLOG G. \$1.50net; by mail,\$1.62. Fish STORIES, by Charles F. Holder and David Starr Jorday.

HORSE TALK, by Willian H. Branged for:

BIRD NOTES, bY C. W. BEEBE.

\section{THE PHILOSOPHY OF NÂTURE}

A Series of volumes by President Jordan, of Stanford University, and Professors Brooks of Johns Hopkins, Lulr of Yale, Thомson of Aberdeen, Przibrani of Austria, zur Strassen of Germany, and others. Edited by Professor Kellog of Leland Stanford. $12 \mathrm{mo}$. $5 \frac{1}{8} \times 7 \frac{1}{2}$ in.

\section{HENRY HOLT AND COMPANY, NEW YoRK} JANUARY, '09. 


\section{Two Masterpieces on Edducation}

\section{JAMES'S TALKS ON PSYCHOLOGY}

TALKS TO TEACHERS ON PSYCHOLOGY AND TO STUDENTS ON SOME OF LIFE'S IDEALS. By WILLiam James, Professor in Harvard University, Author of "The Principles of Psychology," etc. xi + 30I pp., I2mo, giit top. \$r.5o, net.

Contents: Psychology and the Teaching Art ; The Stream of Consciousness ; The Child as a Behaving Organism : Education and Behavior; The Necessity of Reactions; Native and Acquired Reactions; What the Native Reactions Are ; The Laws of Habit ; The Association of Ideas ; Interest ; Attention; Memory ; The Acquisition of Ideas ; Apperception; The Will; The Gospel of Relaxation; On a Certain Blindness in Human Beings; What Makes Life Significant.

In writing these "Talks" out, the author has gradually weeded out as much 2s possible of the analytical technicalities of the science. In their present form they contain a minimum of what is deemed "scientific" in psychology and are practical and popular in the extreme.

The Nation: "His style has the quality of a communicable fervor, a clear, grave passion of sincerity and conviction, from which some vibration detaches itself and passes into the reader, and forms him into the writer's mood."

The Critic: "When pedagogical libraries can show a preponderance of such books, they may well begin to rival the fiction departments in popularity."

\section{WALKER'S DISCUSSIONS IN EDUCATION}

By the late Francis A. WALkER, President of the Massachusetts Institute of Technology. Edited by James Phinney Munroe. $34^{2}$ pp., 8vo. \$3.co, net.

The author had hoped himself to collect these papers in a volume.

The Dial: "A fitting memorial to its author. . . The breadth of his experience, as well as the natural range of his mind, are here reflected. The subjects dealt with are all live and practical. . . He never deals with them in a narrow or so-called "practical 'way."

Literature: "The distinguishing traits of these papers are open-mindedness, breadth, and sanity. ... No capable student of education will overlook General Walker's book; no serious collection of books on education will be without it. The distinguished author's honesty, sagacity, and courage shine on every page."

The Boston Transcript: "Two of his conspicuous merits characterize these papers, the peculiar power he possessed of enlisting and retaining the attention for what are commonly supposed to be dry and difficult subjects, and the capacity he had for controversy, sharp and incisive, but so candid and generous that it left no festering wound."

\section{HENRY HOLT \& CO. $\checkmark$ 'o}



I.

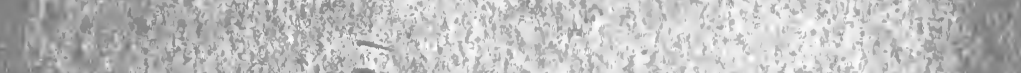

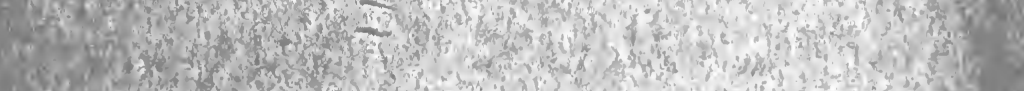

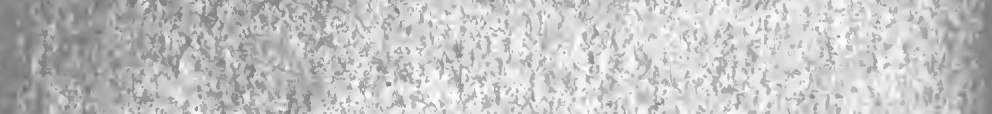

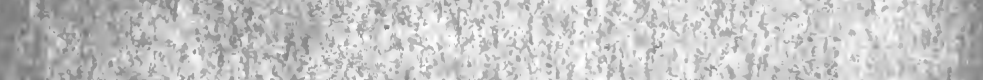

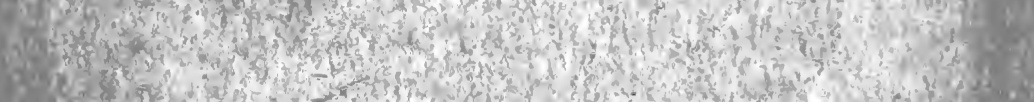

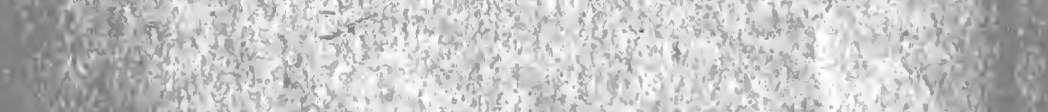

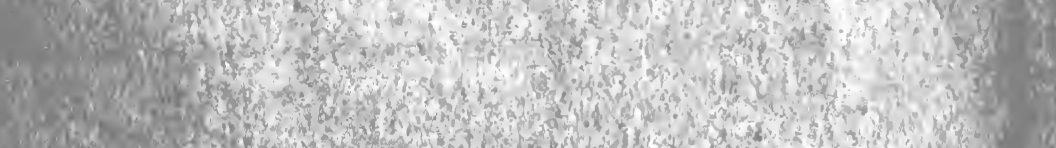

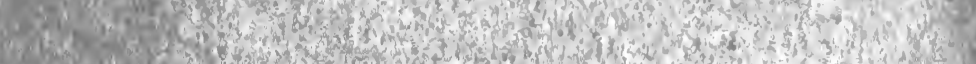

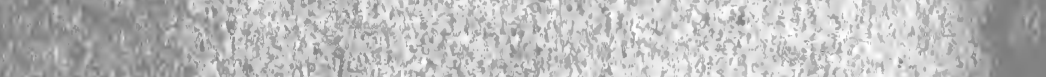

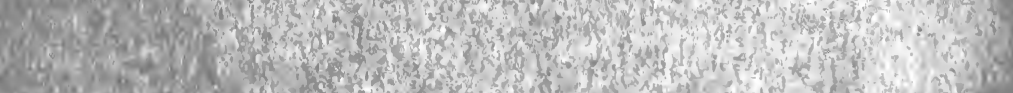

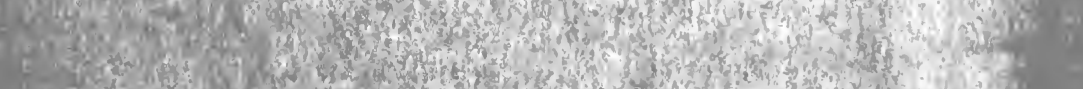

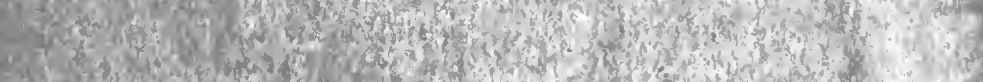
2013)

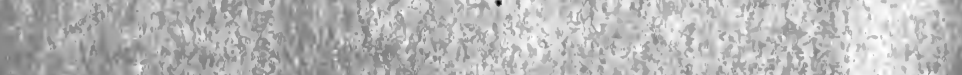

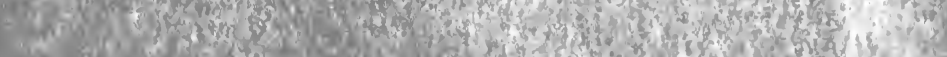

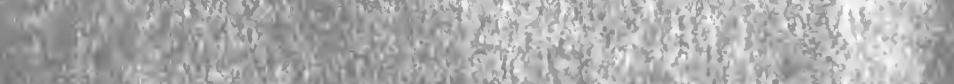

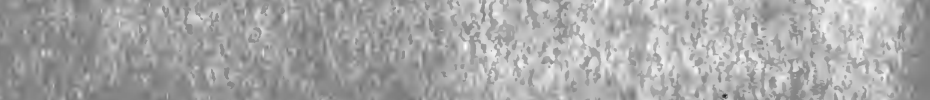

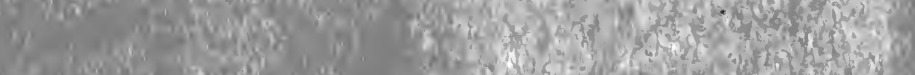

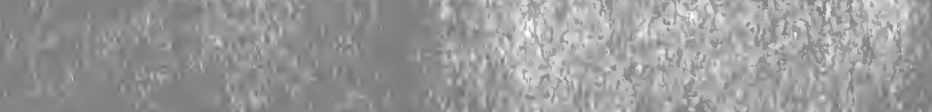

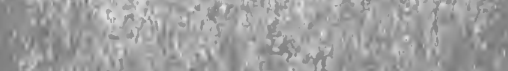


FEB $5 \quad 190 \%$ 

LIBRARY OF CONGRESS

|||||||||||||||||||||||||||||||||||||||||||||||||||||||||||

00199536114 